\title{
Desenvolvimento de algoritmos genéticos para consultas por similaridade em domínios métricos
}

\author{
Renato Bueno
}


Aluno: Renato Bueno

A Comissão Julgadora:

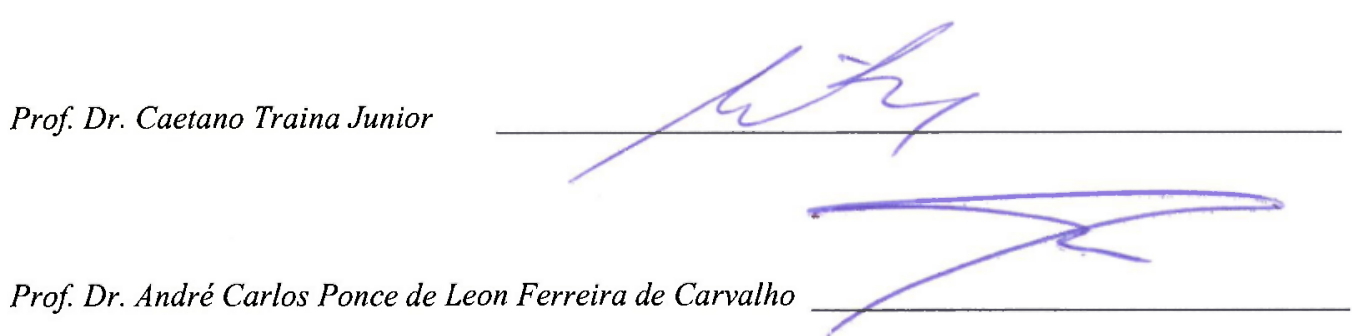

Profa. Dra. Karin Becker 
Aos meus pais Milton e Elizabete. À minha namoradia Márcia 


\section{Agradecimentos}

A Deus, por tudo.

À rninha família n minha namorada, por sempre estarem ao men lado.

Ao meu orientador Prof. Dr. Caetano Traina Júnior, polo apoio, confiança e arnizacle.

À Profa. Dra. Agma J. Machado Traina, à Profa. Dra. Josiane M. Bueno e a todos os membros do GBDI, pelo incentivo e apoio oferecidos nestes anos de trabalho.

A bockos os professores e funcionários do ICMC sempre dispostos a ajudar.

Aos meus amiges a a todos aqueles que de alguna forma contribuíram para a realização deste trabalho.

A FAPESP, pelo apoio financiro. 


\section{Sumário}

Lista de Figuras

Lista de Tabelas

Lista de Abreviaturas viii

Lista de Símbolos $\quad x$

Resumo

Abstract $\quad$ xii

1 Introdução 1

1.1 Motivasio . . . . . . . . . . . . . . . . . . . . 2

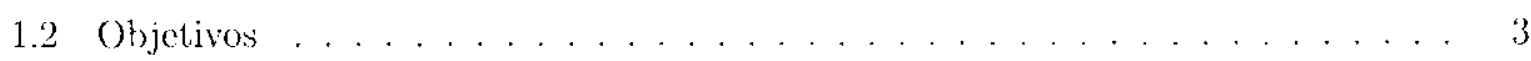

1.3 Organização do Trabalho . . . . . . . . . . . .

2 Consultas por similaridade 5

2.1 Consideracónes Iniciais . . . . . . . . . . . . . . . . . . . . . 5

2.2 Domínios Vétricos . . . . . . . . . . . . . . . . . . . 6

2.3 Seleçāo por similaridade . . . . . . . . . . . . . . . . 7

2.3 .1 Consulta por abrangencia . . . . . . . . . . . . . 7

2.3 .2 Consulta ans vizinhos mais próximos . . . . . . . . . . 8

2.3 .3 Variacoss . . . . . . . . . . . . . . . . . . . 9

2.4 Junçäo por similaridade . . . . . . . . . . . . . . 9

2.5 Consideraçöes Finais . . . . . . . . . . . . . . . . . 9

3 Estruturas de Indexação 11

3.1 Considenayós Iniciatis . . . . . . . . . . . . . . . . . . . . 11

3.2 Estruturas de Indexaçăo . . . . . . . . . . . . . . . . . . . . 11

3.3 Slim-tree. . . . . . . . . . . . . . . . . . . 14

3.3 .1 Organizaşăo da Slim-tree. . . . . . . . . . . . . . 14

3.3 .2 Construção de uma Slim-tree . . . . . . . . . . . . . . . 15

3.3 .3 Consultas por similaridade na Slim-lree . . . . . . . . . 17

3.1 Consideragoes Finais . . . . . . . . . . . . . . . . . 18 
4 Busca Inexata 20

4.1 Considerações Iniciais . . . . . . . . . . . . . . . . . . . . . . 20

4.2 Domínios com Relação de Ordem Total . . . . . . . . . . . . . . . . . . 20

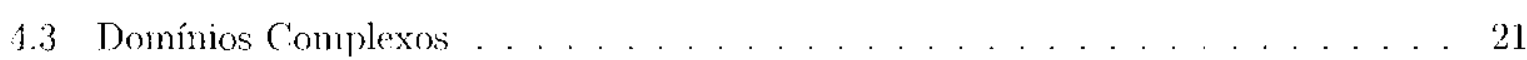

4.4 Consideraçõos Finais . . . . . . . . . . . . . . . . . . . . . . . 24

5 Algoritmos Genéticos $\quad 25$

5.1 Consideraçoes Iniciais . . . . . . . . . . . . . . . . . . . . . . . . . . 25

5.2 Algoritmos Genticos . . . . . . . . . . . . . . . . . . . . 25

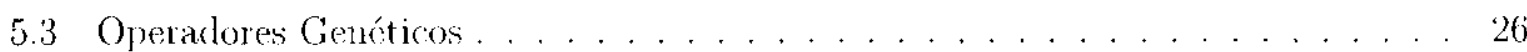

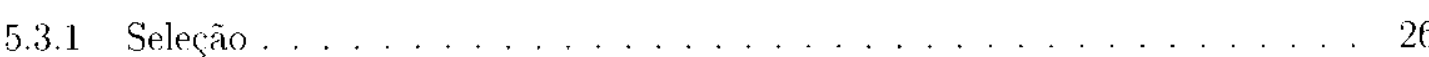

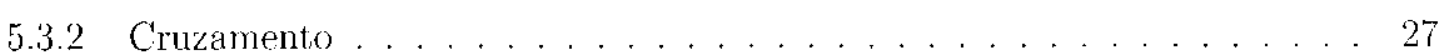

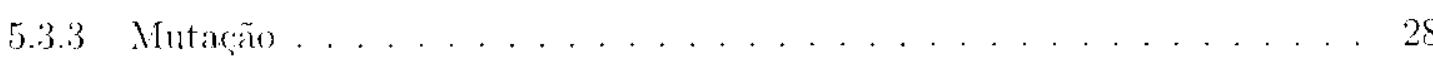

5.3 .1 Elitismo . . . . . . . . . . . . . . . . . . . . . . . 28

5.4 Convergência dos Algoritmos Genéticos . . . . . . . . . . . . . . . . . 29

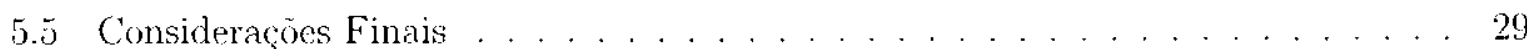

6 Algoritmos Genéticos para Consultas Aproximadas por Similaridade 30

6.1 Consideracoes Iniciais . . . . . . . . . . . . . . . . . . . . . . . 30

6.2 o) Algoritmo Genético . . . . . . . . . . . . . . . . . . . . . . . . . . 31

6.3 Estrutura de controle . . . . . . . . . . . . . . . . . 33

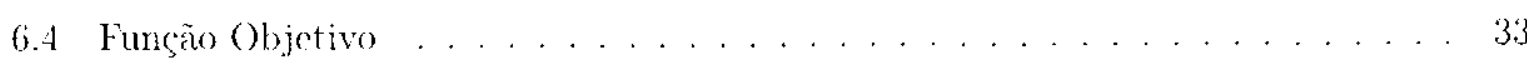

6.5 Tratanche de indivíduos infactiveis . . . . . . . . . . . . . . . . . . . . . . .

6.5.1 Correção dos caminhos que podem ser podados . . . . . . . . . . . 36

6.5 .2 Funçào objetivo com aplicação de penalidades . . . . . . . . . . . 36

6.6 Algoritmos desenvolvidos . . . . . . . . . . . . . . . . . . . 37

6.7 Modificacóes para redução de acessos a disco . . . . . . . . . . . . . . . . 39

6.7 .1 Método 1: Organização da Populaçăo . . . . . . . . . . . . . 41

6.7 .2 Método 2: Cachés por nível .................. 41

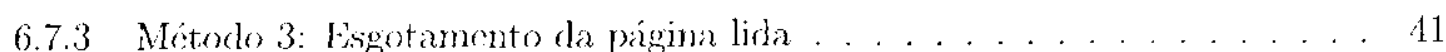

6.8 Estratégia Elitistal . . . . . . . . . . . . . . . . . . . . . 42

6.9 Consideraçoes finais . . . . . . . . . . . . . . . . . . . . . 43

7 Experimentos Realizados

7.1 Matcriais e métodos . . . . . . . . . . . . . . . . . . . . . 44

7.2 Resularlos e discussão . . . . . . . . . . . . . . . 46

7.2 .1 Avaliação dos Algoritmos Iniciais . . . . . . . . . . . . . 47

7.2 .2 Avaliaçào dos Algoritmos definitivos . . . . . . . . . . . . . 50

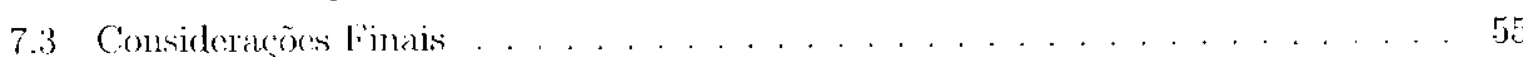

8 Conclusões $\quad 56$

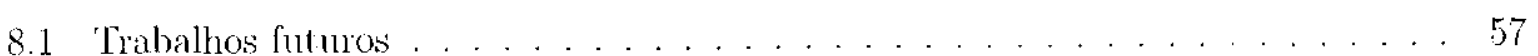




\section{Lista de Figuras}

2.1 Áreas de cobertura de algumas funıçoes de clistância da família das nomas $L_{p}$. . 7

2.2 Consulta por abrangência. . . . . . . . . . . . . . . . 8

2.3 Consulta pelos vizinhos nais próxinnos . . . . . . . . . . . . 8

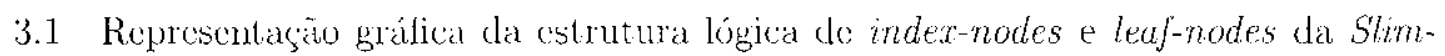
tree. [Traina et al., 2002a] . . . . . . . . . . . . . . . . 15

3.2 Exemplo de indexação de sete paliavras a função de distância LEdit. . . . . . . 15

3.3 Representação do uma Slim-lree em (a) o sua estrutura lógica cm (b). . . . . 16

3.4 Descarte de objetos con o uso da desigualdade triangular. . . . . . . . . 18

5.1 Representagão gráfica da roleta relativa a Tabola $5.1 \ldots \ldots \ldots . \ldots 27$

5.2 Crizamento de 1 ponto. . . . . . . . . . . . . . . . . 28

6.1 Representacão Cromossomica. . . . . . . . . . . . . . . . . 31

6.2 Algoritmo genćtico para Consultas por similaridade. . . . . . . . . . . 32

6.3 a)Cromossomo infactível; b)cromossomo corrigido . . . . . . . . . . 35

6.4 Algoritmo genético para Consultas por similaridade com aplicaçäo da estratégia

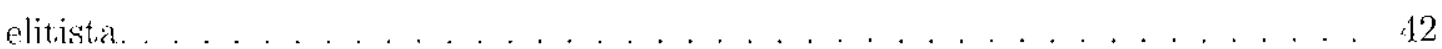

7.1 Visualização da distribuição dos conjuntos de dados utilizados nos experimentos. 46

7.2 Conjunts) IIistograma256 e conjunto Random128: Alternativas para (ualificação) de um nó da árvore. . . . . . . . . . . . . . . . . . . 47

7.3 Preciscio us. Cálculos de distancis, Precisáo us. Acessos a disco e Precisáno us.

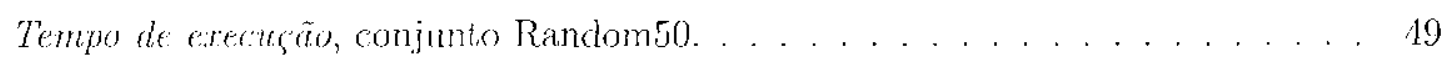

7.4 Precisão vis. Cálculos de distâncis, Precisão vs. Acessos a disco e Precisäo vs. Tempo de execučăo, conjunto P'alavras em Inglès. . . . . . . . . . . . . . 49

7.5 Conjunto Histograma256, aplicasçõo cla estratógin elitista. a) Algorit mos de reparação; b) Funcão com penalidados . . . . . . . . . . . . . . . . 50

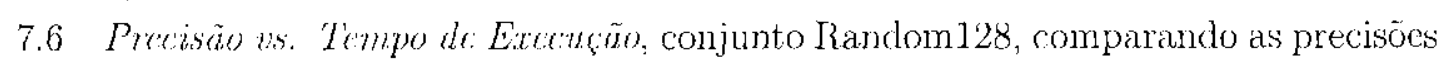
das respostas obtidas polos algoritnos, variando o número de geraçós do algoritmo genético. . . . . . . . . . . . . . . . . . . . . . . . 51 51

7.7 Precisăo vs. Porcentagem de cálculos de distancias da consulta exata, Precisäo vs. Porcentagem do acessos a disco da consulta exuta e Precisüo ts. Potcentagem do tempo de taceusio da consulta cxata, conjunto Palavras on Ingles. 
Lista de Figuras

7.8 Precisa us, Poresnlagem do tempo de execucăo da consulta exata, conjunto Cluster128. . . . . . . . . . . . . . . . . . 52

7.9 Precisio os. Porcentagem do tempo de execuça da consulla exala, conjunto MRTIistograndis. . . . . . . . . . . . . . . . . . . . 5is

7.10 Média de cúlculos de distancia us. \% de dados recuperados pela consulta $k-N N$ e Tempo de execuçâo vs. \% de dados recuperados pela consulta $k-N N$, conjunto Palavras em Ingles, comparando o algoritmo de k-NNQ exato com os algoritmos para consultas aproximadas sem limite de tempo para execusăo

7.11 Média de cálculos de distancia vs. \% de dados recuperados pela consulta $h$ NN, conjunto Random128, comparando o algoritmo de k-NNQ exalo com os algoritmos para consultas aproximadas sem limitar o tempo de execusão . . . . 


\section{Lista de Tabelas}

5.1 Exemplo da técnica da rolela om uma populacão do 6 indivíduos. . . . . . . . 27

7.1 Descricano dos conjuntos de dados ntilizados nos experinentos. . . . . . . . . . 40

7.2 Identificação dos algoritmos segundo o método utilizado para redução de acessos a clisco e o tipo de tratamento dado aos individuos infactiveis. 


\section{Lista de Abreviaturas}

CSP

DBM-tree

$D F$-tree

$E R Q$

GBDI-ICMC-USP

GH-tree

GNAT

$k-F N Q$

$k-N N J$

$k-C N J$

$k-N N Q$

k-RFNQ

$k-R N N Q$

LRU

$M A E S$

MAMS

$M S T$

$O L A{ }^{\prime}$

$P A C-N N$

$P Q$

P-Sphere tree

R.J

$R Q$

$S G B D$

$S Q L$

VP-tree

Constraint Salisfaction Problem - Problema de sallisfação do restriçoes.

Density-Based Motric tree

Distance Ficlds tree.

External Range Query - Consulta por exclusão.

Grupo de Bases de Dados e Imagens, Institulo de Ciencias Matemáticas e de Computação, Universidade de São Paulo. Generalized Hyperplane Deromposition tree.

Geometric Near-neighbor Access Tree.

ki- Firthest Neighbor Querics - Consulta aos k-vizinhos mais distantics.

k-Nearest Neighbors Join - Junção por vizinhança.

k-Closest Neighbors Join - Junção por proximidade.

$k$-Nearest Neighbors Query - Consulta aos k-vizinhos mais príximos.

$k$-Reverse Farthest Neighbor Queries - Consulta aos $k$-vizinhos matis distantes reversos.

k-Reverse Nearest Neighbors Qucry - Consulta aos k-vizinhos mais próximos reversos.

(Least Recenlly Used - Menos recentemente usadas.

Métodos de Acesso Espacial.

Wétodos de $\Lambda$ cesso Mítrico.

Minimal Spanning Tree - Árvore de caminho mínimo.

On-Line Analytical Processing - processamento analítico de infornação on-line.

Probably Approximalely Correct Nearest Neighbor

Point Query - Consulta pontinal.

Probabilistic sphere tree.

Range Join .. Junção por al rangencial.

Range Query - Consulta por abrangència.

Sistema de Gerenciamento de Bases de Dados.

Structured Query Language.

Vantage. Point tree. 


\section{Lista de Símbolos}

\begin{tabular}{|c|c|}
\hline $\mathcal{M}$ & Domínio métrico definido como $\mathcal{M}=(\mathcal{D}, d())$. \\
\hline D & $\begin{array}{l}\text { Conjunto de todos os elementos que atendam às propricdades do } \\
\text { domínio. }\end{array}$ \\
\hline$S$ & Subconjunto de dados onde as consultas são feitas. $S \subseteq \mathcal{D}$ \\
\hline$s_{i}$ & Elemento de $S$. \\
\hline$d\left(s_{i}, s_{j}\right)$ & Função de distância métrica ou função de dissimilaridade. \\
\hline$s_{q}$ & Objeto de referência, objeto de busca on objeto central da consult ta. \\
\hline$s_{r c p}$ & Objecto representativo de un nó, \\
\hline & Raio de uma consulta por abrangência. \\
\hline$R Q Q(s$ & Preelicado de uma consulta por abrangencia. \\
\hline$k-N N\left(s_{q}, k\right)$ & Predicado de 1 m consulta aos $k$-vizinhos mais próxirross. \\
\hline$k$ & $\begin{array}{l}\text { Número de vizinhos mais próximos a serem recuperddos por uma } \\
\text { consulta } k-N N\left(s_{q}, k\right) \text {. }\end{array}$ \\
\hline$L_{\text {Edit }}$ & Função de distäncia métrica Levenshtein. \\
\hline$L_{y}$ & Função de distância métrica Minkouski. \\
\hline \#. Ent & $\begin{array}{l}\text { Número de objetos contidos na subárvore apontada pela entrada } i \text { de } \\
\text { um nó. }\end{array}$ \\
\hline$P t r_{i}$ & $\begin{array}{l}\text { Tontciro para o nó raiz da subárvore apontada pela entrada } i \text { de um } \\
\text { nó. }\end{array}$ \\
\hline$O I d_{i}$ & Identificador do objeto $s_{i}$. \\
\hline$P_{(o p}$ & População de um algoritmo genćtico. \\
\hline$f()$ & Função objetivo do algoritmo genético. \\
\hline
\end{tabular}




\section{Resumo}

custo do acesso exato a dados complexos tencle a ser muito alto, do ponto de vista da carga de processanento computacional. Além disso, a operação de busca cm dados multimídia não é efetuada realmente sobre os dados originais, mas sobre características extraidas desses dados, as quais os descrevem. Por excmplo, na busca por imagens similares utilizando-se histogramas de cor, realizando uma consulta exata, o que se obtém são as imagens cujos histogramas são exatamente os mais sinilares aos da imagen referenciada na consulta. mas isso não implica necessariamente que se obtenha as imagens que atendam exalamente a consulta efetuada, pois as imagens recuperadas poden ser muito diferentes quanto a forma, por exemplo. Portanto. cm muitas aplicaçöes que auessam dados complexos, a recuperação exata deixa de $u$ requisito fundamental. podendo a cxatidão das respostas ser trocada por um melhor desempenho

Nest re trabalho foram desemvolvidos algorit mos para rocuperacão aproximada do conjumloresposta de consult as por similaridade em domínios métricos utilizando algorilmos genćticos.

Neste traballo, com a udilizacio de algoritmos genéticos, foram desenvolvidas técnicas de recuperacäo aproximada de dados cun domínio métrico, cujo refinamonto das respostas obtidas é dependente do tempo de processamento disponível, definido pelo usuário.

Os algorimos desenvolvidos foram implementados utilizando a Shm-lree mas outros métudos de acesso podern ser extendidos para utilizá-los também. Os algoritmos contemplam consultas por abrangencial e vizinhos mais próximos, além de algumas variaçoes.

Os algoritmos desenvolvidos foram testados e validados com conjuntos de dados sintéticos e reais, e mostraram-se capazes de obter respostas aproximadas com boa precisão utilizando apenas uma fraça do tempo exigido pela consulta exata.

Os resultados obtidos nos experimentos mostram que é possível obter respostas com precisäo superior a $90 \%$ utilizando apenas metade do tempo da consulta exata com o algoritmo convencional, e até $65 \%$ de precisão com apenas un quinto do tempo da consulta exata. 


\section{Abstract}

scarch process on complex domains for exact answer to a similarity query is an expensive process considering computational resources, such as memory and processing time requirements. However, when comparing multinedia data, the comparison operations usually consider some properties of each datum olement, so exact queries involving this daia return results that are exact regarding the properties compared, but not necessarily exact regarding the multimedia data itself. For cxample, searching for similar images regarding their colors return images whose color histogram are the most similar, but the retrieved images can be very clifferent regarding for example the form of the objects pictured. Therefore, for applications dealing with complex data types, trading exact answering with query time response can be a worth exchange.

In this work we developed techniques hased on gonelic algorithms to allow retrieving approximate data indexed in a Metric Acress Methods (MAMs) within a limited, user-defined. amount of time.

For evaluation purposes, the algorithens were developed regarding the Sthm-tren, but the approximate query techniques developed in this work can be straighterwardly implemented on other MAMs. The algorithms can be used to perform nearest neighbor quories, range querics and some other variations.

Synthetic and real world datasets were used to evaluate the approximato algorithms, achieving good results in a fraction of the time required to obtain the exact answer. The experimental results show that, allowing the algorithm fo run during $50 \%$ of the exact query time, the precision of the approximate results is about $90 \%$, and precision of $65 \%$ can be obtained consuming just $20 \%$ of the sane exact cuery time. 


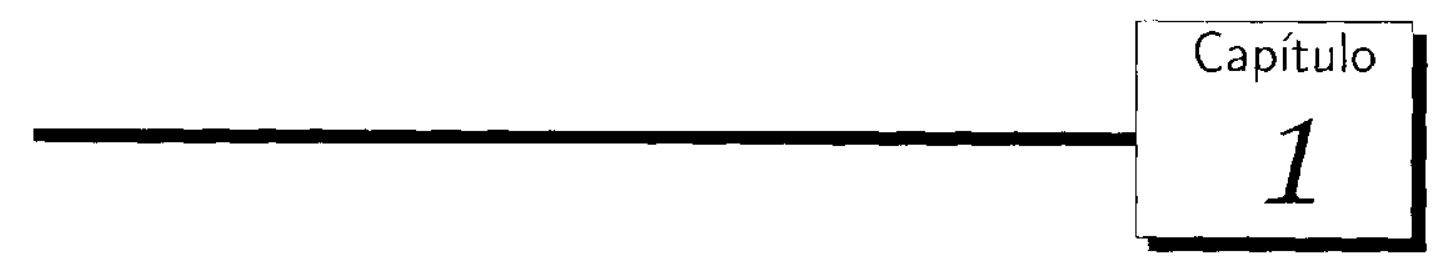

Introdução

$O$ s sistemas gerenciadores de basses de dados (SGBDs) foran desenvolvidos deste o início com o objetivo de facilitax e agilizan a recuperação exata do dados cm grandes arquivos de dados. A recuperaçäo exata é um requilisito das aplicacócs que os $\mathrm{SGB}$. originalmente deveriam suportar. as quais inclucm por exemplo infomaços sobre cmpregados das empresas para elaboraçäo de folha de paganento, controle de estovue para indústrias e estabelecimentos comerciais, controle de correntistas e contas em bancos, censos populacionais, otc. Com o passar do tempo, outras aplicaçoes foran sendo incluádas no rol daquelas que os gerenciadores deveriam suportar, como por exemplo ammaenagem de dados coletados por instrumentos científicos, darlos de projetos do congenharia e de software culminando atualmente no esforço para amazenar e recuperar adequadamente dados muito mais complexos que os atributos numéricos ou textuais tratados no injecio, tais como imagens, vídcos, audio, mapas geográficos, estruturas genćticas, ete, para aplicações que vão desde sistemas de apoio a decisão. a prontuários cletrônicos de pacientes en ambientes hospitalares, passando por sistemas de mineração de dados o antomarãa de processos dos mais diversos.

Dentro desse rol de aplicaroos muito mais abrangente às quais os SCFDs atualmente devem atender, o requisito de recuperaçän exata, originalmente omni-presente, cm muitas aplicaçoes deixa de ser necessário. Em aplicaçóes tais como sistemas de apoio à decisão, devido a sua natureza geralmente exploratória, a resposta cxata pode não ser necessária, sendo (1ue o nswário

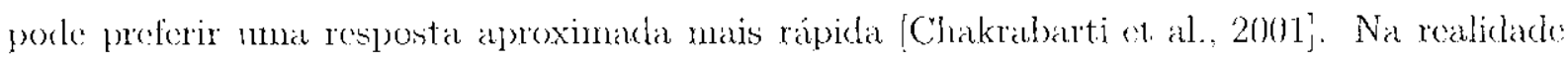
praticamente todo acesso feito a dados complexos deixa de ter a recuperasião exata como um requisito fundamental, uma vez que numa comparação custo/benefício, a "cxatidão até a últinna. casa" pode, de bom grado, sor trocada por um melhor desempenho [Podgorelec ot al, 1999]. Essa troca já vem ocorrendo cm ambientes de suporte à decisão, principalmente naqueles apoiados em técricas de data uarehousing e processamento analítico de informação on-line (OLAP), por exemplo através de utilizaçio de técricas de anostragem (sampling) do banco de clactos [Lee et al., 1998] [Palner \& Faloutsos, 2000]. Nessas aplicaçós faz muito sentido ter uma idéia aproximada de valores estatísticos sobre grande volumes de dados com tempos de resposta significativamente menores [Kollios et al., 2001].

Neste trabalho, o principal objetivo foi ficxibilizar o requisito de acesso exato a dados 
nultimídia, mais particularmente no acesso a inagens, utilizando algoritmos genéticos para obtenção de conjuntos de respostas aproximados.

\subsection{Motivação}

Recentemente, cada vez mais pesquisas vêm senclo realizadas sobre consullas por similaridade aproximadas, devido à vários fatores. () custo do acesso exato a dados multimídia tende a ser muito grande, do ponto de vista da carga de processamento computacional. Alóm disso, as operaçós de busca em clados multimídia năo são cfotuadas realnente sobro os darlos originais, mas sobre caractoristicas extraíclas desses daclos, as quais os descrevem [Faloutsos. 1996] [Smeulders et al., 2000]. Essa situaçāo decorre da maneira como a tecnologia atual vem sendo desenvolvida para prover suporte à recuperação de dados multimídia nos SGBDs. Considerenos sem perda de generalidade o suporte à armazenagem e recuperação de imagens. O que se faz é cxtrair alguns conjuntos de características das imagens a serem armazenatas, como por exemplo seus histogramas do cores, transfomacous baseadas om wavelcts, etc. 'Vailaya et al., 2001! I'Zrimec, 2001] Albuz el, al., 2001] IStehling et al., 2000] [Marques et al., 2000]. e utilizar essas características para serem indexadas por estruturas de indexação espaciais ou métricas [Petrakis \& Faloutsos, 1997j PPetrakis et al., 2002j. A seguir, quando alguma consulta deve ser cxecutada sobre os dados indexados, as imagens de relerência indicardas na consulta tôn sua características extrádas, as quais são a seguir utilizadas para realizar-se a busca, exata, nas imagens indexadas. O ponto a ser ressaltado aqui é que cmbora a busca seja exata, o que se obtém são as imagcns cujas caractcrísticas extraídas atendem exatamente às caracteristicas das imagens referenciadas na consulta, o que não necossariamente significa que sc obtôn as imagens que atendem exatamente à consulta - existe um processo de transformação intermediário correspondente a extração das caractcrísticas, sobre o qual vão se porle garantir exatidão. Note-se que a representação de una imagem por um conjunto de características corresponde a um processo de reduçào de dimensionalidade o cual necessariamente implica em perda de detalhes, e portanto leva à introduçâo de um fator de erro em qualquer processo que utilize o conjunto de características no lugar da imagem em si. Outro fator importante é o fato de a própria definição de como comparar duas imagens, na busca das mais semellantes, é um fator subjetivo 'Tversky, 1977].

Por exemplo, considere-so a consulta "selecione as 10 imagens mais somelhantes à cesta imagem $x$ dada". Admitindo que exista uma estrutura indexando os histogramas da coleça do imagens a ser pesquisada, o histograma da imagen $x$ é extraído e nsado na busca. Com isso obtêm-se as 10 imagens cujos histogramas são exatamente os 10 mais semelhantes ao histograma da imagem $x$. Isso não significa que o usuário, nurna inspeção visual sobre o conjunto de imagens, näo considere que outras imagens cujos histogramas são menos semclhantes aos da imagem dada possam ser escolhas melhores. Além disso, dois usuários poderiam até escolher diferentes conjuntos como os que contêm imagens que parecem ser as mais semelhantes para cada um.

Dados complexos. como dados multimídia, geralmente não possuen und relação de orden 
total, sendo representados como dados em domínio métrico, que como as estruturas de indexação desenvolvidas para dados nesses domínios. dispōem apenas dos objetos de dados e do uma funçāo de distância (ou dissimilaridade) entre eles. Assim, as consultas realizadas sobre esses darkes assumern (plase sempre ajonas dulis formas: consull as por vizinhanca (nearest neighbors queries) e consultas por abrangencia (range queries). Fm ambas as cousultas é dado um objeto de referencia $s_{q}$. Uma função de distancia (métrica) deve atender às propriedades de năonegatividade, simetria e desigualdade triangular. Essa última propriedade permite realizar as operaçies de "poda" nas estruturas de inclexação, diminuindo a quantidade de comparações necessárias ì resposta de unna consulta. Por exemplo, cm estruturas bascadas em árvores, uma subárvore somente é percorrida se seus objetos de controle (rejuresentativos) e o objeto central da consulta atenderem à propriedade de desigualdade triangular da maneira determinada pelo algoritmo de busca de cada estrutira em particular [Traina et al., 2002b]. Mas ao contrário das estruturas construídas para operar em dominios que apresentem a propriedade de ordem total entre seus elementos, as estrut uras mét ricas (bem como as espaciais), na maioria das vezes, não podem evitar a ocomencia de sobreposiçẽes entre nús das subárvores, o que là com cue nuitos nós devam ser pesquisados numa busca determinística por respostas cxatas.

Dentro desse contexto, o trabalho de mestrado estudou maneiras de agilizar a busca de dados por similaridade indexados em estruturas métricas, desenvolvenelo técricas de lunsca nầo exatas que aproximann as respostas dentro de algum parámetro de controle cono por exemploo tempo de processamento permitido. Em particular, foram exploradas lócnicas de busca bascadas em algoritmos genéticos, linitadas pelo tempo de execução da consult a fornecido pelo usuário.

\subsection{Objetivos}

Este trabalho tem por objetivo desenvolver mótodos para executar operações de busca por similaridade que aceitem respostas aproximadas, cmpregando algorilmos genéticos. A grosso modo: pode-se descrever o conceito básico de tais métodos como centrado em um algoritmo que opera da seguinte matreira. Considerando-se que uma estrutura de indexaçăo métrica

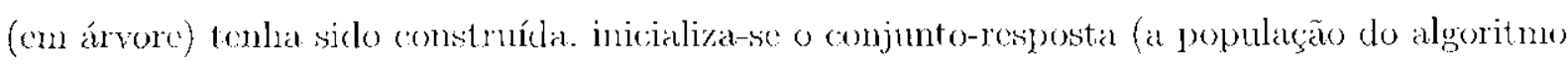
genétiro) com caminhos que levem desde a raiz até objetos que atendam à propriedade do desigualdade triangular da maneira determinada pelo algoritmo de busca da respectiva estrutura de indexação. sem se preocupar cine esses objetos sejam a resposta exata da consulta. A seguir. através dos processos de cvolução, busca-se caninhos melhores, levando à obtenção de objetos que respondem melhor à consulta. O processo é deixado para evoluir até que scja atingido uni tempo pré-deteminado para se obter a resposta. Os algoritmos gencticos visam, nesse caso, otiunizar os caminhos cncontrados, o não diretamente o conjunto resposta da consulta Portanto, foran utilizados algoritmos genćticos para desenvolver métodos de busca para acelerar a execução de operações de seleção por similaridade que aceitem respostas aproximadas, sobro un conjunto de dadios complexos, indexados por uma estrutura de indexaçào métrica. 


\subsection{Organização do Trabalho}

Neste capítulo estáa apresontados o contexto do trabalho, a motivarào para o descrnvolvimento da pesquisa e os objetivos a sercm alcançados.

No Capítulo 2 são apresentados os operadores por similaridade, dasse do operadores adequada para manipulasăo rle dados om domínios métricos, como clarlos multimúdia.

No Capítulo 3 ćapresentado um histórico da evolução das estruturas de inclexação para os diversos domínios de dados, com ênfase em dominios métricos. É apresentada também a estrutura de indexação métrica Slim-lree, que foi a estrutura utilizada para innplementação dos algoritmos propostos

Consultas por sindilariade an domúnios complexos tendem a ter un alto custo computacional. No Capítulo 4 säo discutidas algumas técnicas de busca inexata utilizadas para agilizar as operaçôes de busca lesses domínios.

No Capítulo 5 são descritos os Algoritmos Genéticos, modelos computacionais inspirados na seleção natural e genética, que foram utilizados para o descnvolvimento dos algoritmos para recuperação aproximada do conjunto-resposta de consultas por similaridade.

Os Capítulos 2 a 5 efotuam un fundamento bibliográfico a apresentam os conceitos fundamentais envolvidos neste trabalho. As contribuiçoes inéditas deste trabalho estão descritas no Capítulo 6. () Capítulo 7 apresenta resultados de experimentos realizados para validação e avaliação dos algoritmos desenvolvidos. Finalmente, o Capítulo 8 apresenta as conclusiese sugestöes para traballos finturos. 


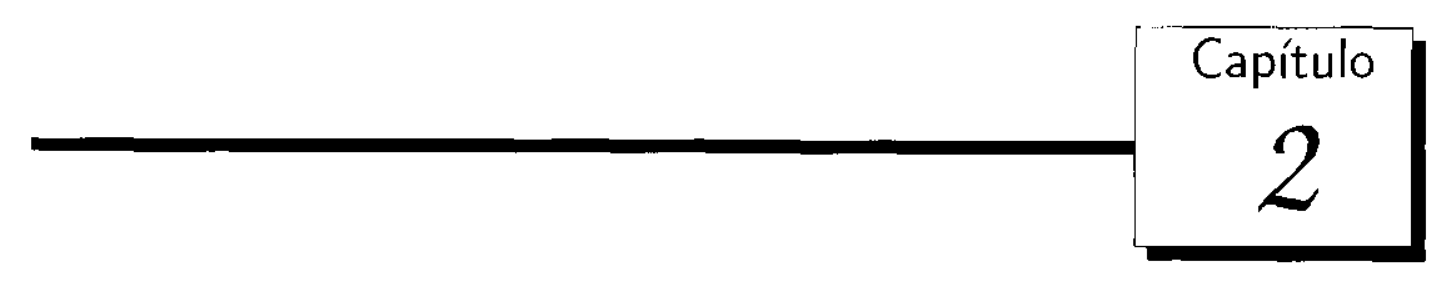

\section{Consultas por similaridade}

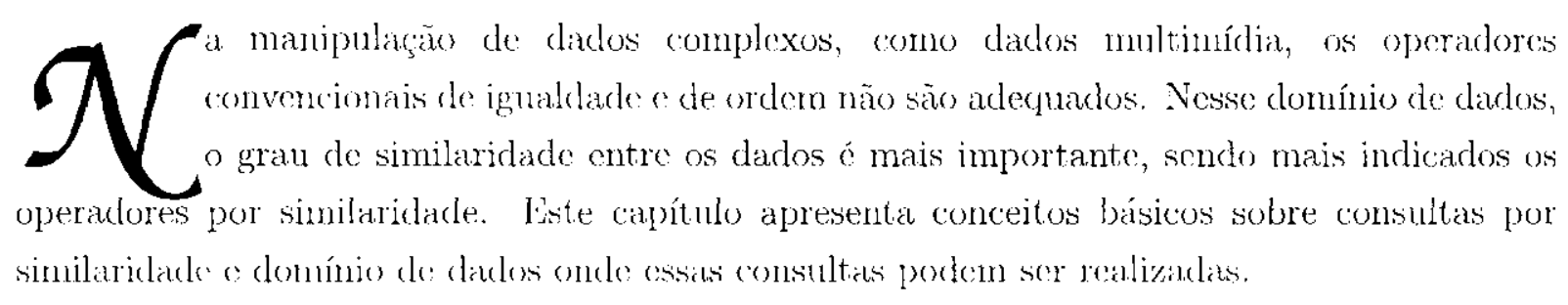

\subsection{Considerações Iniciais}

Duante todo o desenvelvinento dos sistemas relacionais e objeto-relacionais até hoje, os dados suportados sĩo majoritariamente on de tipo numérico ou textual curto, aproveitando at relação de ordem total que existe entre os elementos desses domínios de dados para executar as operaçes de consulta e atıalizaçăo dos dados. Tesses domínios, mesmo quando una operação

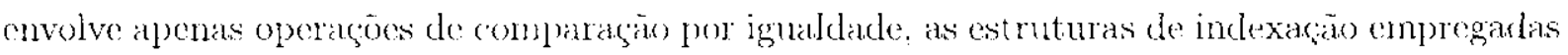
para agilizur a consulta dependem das relasoes de ordem existentes nos domínios do dados envolvidos. No entanto, dados mais complexos em geral não possinem uma relacia do ordem total - genericamente, não é possível dizer que uma imagem ó "monor" ou "maior" do que outra. Mesmo operaçôs de comparação por igualdade têm pouca utilidade nas operaçöes envolvendo esses daclos, uma voz que a existência de dois elementos exatamente iguais é rara [Falontsos, 1996]. Nesses casos, o grau de similaridade entre os dados é o fator mais importante.

Una classe de operadores mais adequada para manipular esses dados são os operadores por similaridade [Faloutsos, 1997]. Para que possam ser cmpregados, o domínio do dados em questão deve dispor de uma função de dissimilaridade, também chanlada função de distância, que deve alcuder as propriedades de não-megatividade, simetria e desigualdade triangular. Domínios de daklos que apresentan una funçäo do distância mótrica säo chamados domínios (ou espaços) métricos.

Na Soção 2.2 são aprescutados o conceito de dominio métrico e alguns exemplos de funçöes do distância. Na Seçä 2.3 sãu descritos os principais operadores de seleção por similaridade: consulta por abrangencia e consulta aos $k$ vizinhos mais próximos; alón de algumas variaçóes. Na Seção 2.4 são citados brevemonte os operadores de junção por similaridade, e finalnente, na Seção 2.5 são feitas as consider dyoes finais desse capítulo. 


\subsection{Domínios Métricos}

Um domínio mótries ó definido como $\mathcal{M}=(\mathcal{D}, d())$, onde $\mathcal{D}$ ́s o conjunto de todos os objetos que atendem às proprictades do domínio e $d()$ ó uma função de distância, ou métrica, entre esses objetos. A função de distancia é dependente do tipo dos objetos e da aplicação, e quanto menor o valor resultanto da aplicação da função de distância entre dois objetos, mais semclhantes são os objetos.

Dados $x, y$ e $z \in D$; una função de distância (métrica) deve satisfazer as seguintes propriedades:

1. Simetria: $d(x, y)=d(y, x)$ :

2. Nao Negatividade: $0 \leq d(x, y) \leq \infty, d(x, x)=0$;

3. Desigualdade Triangular: $d(x, y) \leq d(x, z)+d(z, y)$;

Dados em espaços vetoriais podem ser considerados como estando em um domínio nnétrico se for definida unra função de distância (métrica). Mas, en dados vetoriais, além da função de distancia cntre os objotes, pedem ser exploradas informaçoes geométriens duante o processo do consulta, o que nāo ocorre com dados em comínios puramente métricos, onde apenas o objeto de referència e a função de distância estão presentes.

Para dados vetoriais, as funçoes de distancia mais comms são as da família das normas $L_{p}$ (on Minkowski), definiclas en 2.1 por:

$$
L_{p}(x, y)=\sqrt[7]{\sum_{i=0}^{d-1} x_{i}-y_{i}}
$$

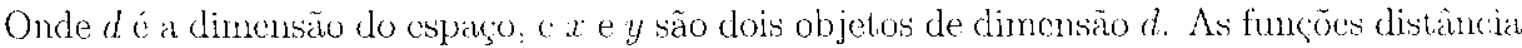
mais ntilizarlas da familia $L_{p}$, são:

- $L_{0}$ - conhecida como Infinity ou Chebychen;

- Ll - conhecida como City block ou Manhatan:

- $L_{2}$ - conlecida como Euclidiana;

A Figura 2.1 mostráa diferentes regiöes de cobertura relativas is funçoes de distancia citadas acima, para um darlo objeto representativo e un dado raio $r$.

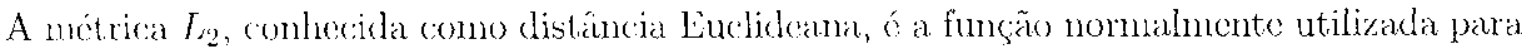
calcular a distância entre objetos no espaço cm que vivemos.

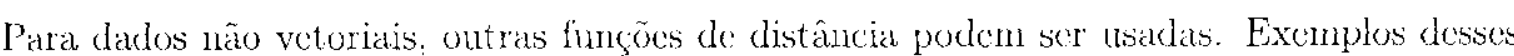
domínios são os conjuntos de palavras de ma linguagem ou conjuntos de impressões digitais representadas por seqü̂encias de minutaes. Em conjuntos de seqüèncias de caracteres (como palavras), a função de distância Levenshtein, conhecida como $L_{\text {edit }}(x, y)$, indica a quantidado mínina de simbolos que devenn ser substitúclos. inseridos ou removidos para transformar uma 


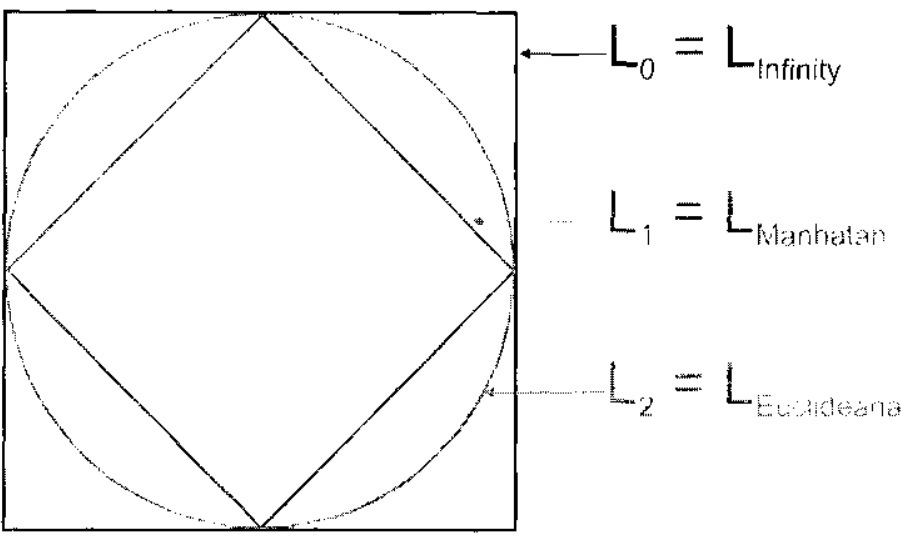

Figura 2.1: Áreas de cobertura de algumas funções de distância da familia das normas $L_{p}$.

palava $x$ em outra $y$. Por exemplo, $L_{\text {Edit }}($ "Head", "Hobby") $=4$, três substituicócs e uma inserção.

Desde que garantidas as propriedarles de uma função de distância mótrica, a funçăo de dissimilaridade pode ser considerada como uma "caixa preta", geralmente definida por um especialista na aplicacão.

\subsection{Seleção por similaridade}

Em domínios métrices, existem basicamente dois operalores de consulta por similaridade: a consulta por abrangência ("range queries", $R Q$ ), que considera os objetos que cstejam até uma distância limite do objeto de referencia; e a consulta aos vizinhos mais próxinnos ("k-nearest. neighbor queries". $k-N N Q$ ) (Yianilos, 1993] [Korn of al., 1996] [Btaunmüller et. al., 20000], que limita os objetos do conjunto resposta a $1 \mathrm{~m}$ número máximo: além de algumas variações

Considerando um conjunto de objetos $S=\left\{s_{1}, s_{2}, \ldots, s_{n}\right\}$ de um domínio $D$, uma função de distância (métrica) do) entre esses objetos, temos a scguir os principais opcradores de seleçãa por similaritlade.

\subsubsection{Consulta por abrangência}

Uma consulta por abrangencia recele como parametros um demento do domínio de dados $s_{q} \in S$ (chamado objeto de referência) e um grau de dissimilaridade $r_{q} \geq 0$, c obtém todos os elementos da base de dados que diferem do objeto da consulta por no máximo a dissimilaridade indicada.

Formalmente temos:

$$
\operatorname{range}\left(s_{q}, r_{q}\right)=\left\{s_{i} \mid s_{i} \in S, d\left(s_{i}, s_{q}\right) \leq r_{q}\right\}
$$

Um exemplo de consulta por abrangencia em una base com dados gcográficos seria "selecione as cidades que distem até 100 quilometros da cidade apresentade como referência". Na Figura 2.2 podemos ver a ilustração desse exemplo. 


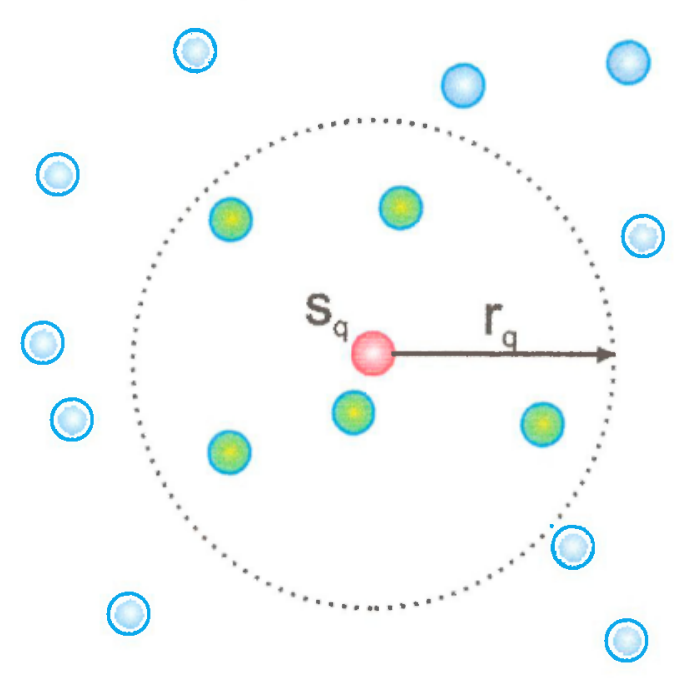

Figura 2.2: Consulta por abrangência.

\subsubsection{Consulta aos vizinhos mais próximos}

Uma consulta aos vizinhos mais próximos recebe como parâmetros um elemento do domínio de dados $s_{q} \in S$ (o objeto de referência) e uma quantidade $k>0$, e obtém os k-elementos da base de dados que estejam mais próximos do objeto da consulta.

Formalmente,temos:

$$
k-N N\left(s_{q}, k\right)=\left\{a_{i}\left|a_{i} \in A, A \subseteq S,\right| A \mid=k, \forall a_{i} \in A, s_{i} \in S-A, d\left(s_{q}, a_{i}\right) \leq d\left(s_{q}, s_{i}\right)\right\}
$$

Um exemplo de consulta de vizinhos mais próximos em uma base de dados com imagens seria "selecione as 4 imagens mais similares à imagem apresentada como referência para a consulta", como pode ser visto na Figura 2.3

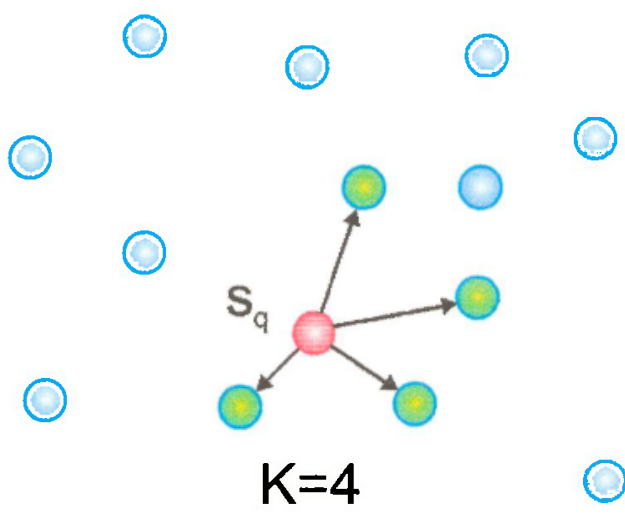

Figura 2.3: Consulta pelos vizinhos mais próximos 


\subsubsection{Variações}

Fxistem diversas variascoes sobre esses operadores, algumas levando a algoritmos significativamente diferentes dos empregados para os operadores básicos. Por exemplo, ao invés de fazer a busca procurando por maior proximidade, pode-se buscar por menor proximidade. Os operadores resultantes são os operadores do consulta aos vizinhos mais distantes ("k-farthest neighbor queries", $k-F N Q$ ) e consulta por cxclusão ("external range queries", ERQ). ()s algoritmos para exceutar essias variaçocs são essencialmente os mesmos cmpregados para os opcrarlores básicos. Uma outra variagão simples, que leva a algoritmos bastante simplificados dos algoritmos básicos são a consulta ao (único) vizinho mais próximo("nearest neighbor query": $N N Q$ ) ou mais distantc ("farthest ncighbor query", $F N Q$ ), e a consulta pont ual ("point query"; $R 0 Q$ ou $P Q$ ), equivalente à consulta por abrangència com raio de abrangència nulo, que retorna opróprio objete ceutral da cousulta se ale estiver presente no conjunto de darlos; on nulo, caso) contrário.

Por fim, variações que levam a algoritmos bem mais sofisticados (e custosos) são is consultas aos vizinhos mais próximos (e) mais distantes) reversos ("reverse nearest neighbor quertes" e "reverse farthest neighbor queries", k- RFNQ e RFNQ) [Yang \& Lin, 2001]. Cada uma dessas consultas retorna quais são os objetos do conjunto de dados que tim o objeto central da consulta como o vizinho mais próximo (ou mais distante), com as correspondentes variaçoes que permitem retornar os objetos que tèm o objeto central da consulta como um dos seus atć $k$ objetos mais próximos (ou distantes). Embora carla uma dessas consultas scja unária (o portanto seja efetivamente uma operação de seleção), as consultas por similaridade roversas têm complexidade de execucão quadrática, semelhante aos operadores de junção por similaridade.

\subsection{Junção por similaridade}

É possivel também executar operaçoes de junção por similaridade. Quanto aos operadores de jungão por similaridade, existem basicamente três. Dados dois conjuntos de objetos cm um mesmo domínio métrico: os operadores do junção comparam as distâncias entre pares de objelos: tomados um de cada conjunto, e retomam como resultado um conjunto de pares de objotos que atendam a determinada propriedade [Koudas \& Sevcik, 2000] [Böhm \& Kriegel, 2001] [Shim et al., 2002] [Yang \& Lin, 2002|. O operador de junção por abrangencia ("range join", RJ) retorna os pares de objetos cuja distanncia é inferior a um limite dado. O operador de junção por vizinhança ("nearest, neighbors join", $k-N N J$ ), que não é comutativo, retorna para. cada objeto do primeiro conjunto um subconjunto con os $k$ objetos mais próximos do segundo conjunto. () operador de junçüo por proxinnidade ("closest netghbors join", $k-C N J$ ) retornd os $h$ pares de objetos mais próximos entre si.

\subsection{Considerações Finais}

Dados em domínios métricos não possuem uma relaçâo de ordem total, só dispondo do uma funça de distancia (mctrica), que calcula a distancia entre quaisquer dois objotos do domínio. 
Os operadores por similaridade são mais adequados na manipulação de dados multimídia.

Os principais operadores de sckçào por similaridade são: consulta por abrangência, que seleciona todos os objetos que estejam dentro de uma distancia limite do objeto de referencia; e consulta aos $k-v i z i n h o s$ mais priximos, pue soleciona os $k$ objotos mais próximos do olojoto de referencia. Nlćm de algumas variações desses operadores de seleção, existem também os operadores de junçăo por similaridade, que năo foram focados neste trabalho.

Para indexar dados em espacos métricos e ulilizar os operadores por similaridade, sâo necessárias estruturas de indexação mais complexas, que serão discutidas no Capítulo 3. 


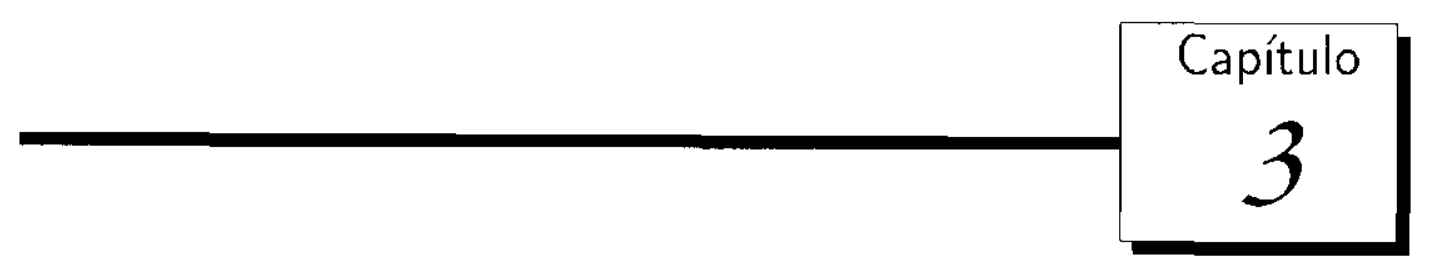

\section{Estruturas de Indexação}

$\mathcal{A}$

sestruturas de inclexação são dependentes dos domínios dos dados que pretendese manipular. Para consultas por similaridade, nas quais os dackos genoricamente estão em dominios métricos, são necessárias estruturas de indexação mais complexas, chamadas de Métodos de Acesso Métrico.

\subsection{Considerações Iniciais}

As cestruturas de indexaçăo devem acompanhar a evolncão dos tipos de dados a serem armazenados e manipulados pelos SGBDs

Desde os métodos de acesso tradicionais aplicáveis em domínios de dados que possnem relaça de ordem total, muitos trabalhos foran realizados até o desenvolvimento dos Métodos de Acesso Métricos, para domínios de dados que só dispõem dos objetos e de uma função de distancia mitre cles. Esses são os métodos mais adequados para consultas por similaridade em rlarlos multimidia.

Na Seção 3.2 ó mostrada a evolução das estruturas de indexação para os diversos dominios de dados. Na Seção 3.3, ó apresentada com mais detathes a cstrutura de indexação métrica Slim-tree, a qual será utilizada para o desenvolvimento dos algoritmos gensticos para consulta

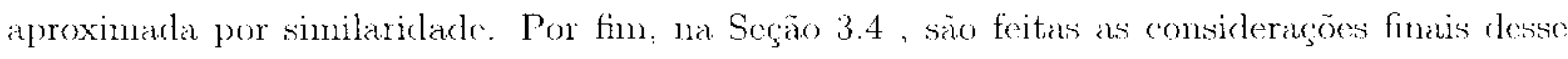
carpítulo.

\subsection{Estruturas de Indexação}

Para dados que possuem uma relação de ordem total foram desenvolvidos operadores de selegăo que permitem cxecutar operaçots do busca com complexidade sub-linear para o numero de elementos da base de dados, ou seja, existem algoritmos de busca com complexidade $O(N)$ on menos, onde $N$ é o número de clementos na base de clados. Esses algoritmos recacm sobre o uso de métodos de aresso tradicionais, tais como a amplanente utilizada B-troe [Johnson \& Shasha, 1993] e suas variantes $B^{*}$-tree e Bt-trec [Zisman, 1993]. Por cxemplo, a seleção de múmeros ou textos curtos ntilizando árvores de indexaçăo pode ser executada com algoritmos que exiben complexidade $\log (N)$. Invariavelmente esses algoritmos utilizan 
a possibilidade de comparar os elementos dois a dois c decidir pela vordade on falsidade de determinada relaçāo de ordem (menor que, igual, maior ou ignal, etc.) entre cada par de clementos; o que permite evitar (podar) a comparacão com ramos iuteiros cla árvore.

Una outra classe de domínios interessantes säio os chamarlos domínios espariais, também chamados domínios em espaços dimensionais. Fxemplos comuns desses domínios são: dardos que represcnutan informaçós geográticas [Güting, 1991; a disposição espacial de estrelas e galáxias

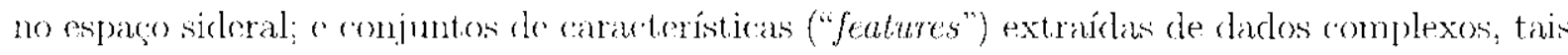
como imagens e dados de sensoreamento científico, que são utilizados para a realização de busca por conteúdo bascada nessas características [Faloutsos, 1996;. Domínios espaciais podem ser vistos como um subconjunto dos domínios métricos. onde alérn da função de distancia (em geral funçoes de distância do tipo $L_{p}$, tacl como Euclidiana - $L_{2}$ : "Manhaltan" - $L_{1}$ ou Infintity - $\left.L_{0}\right)$, são definiclas rolaçós clo clireção, permitindo a definição de ângulo entro triplas de clementos do conjunto, e a representação de hiper-volumes [Papadias et al., 1995]. A projeção de elementos en climensões menores também ó possivel em domínios espaciais.

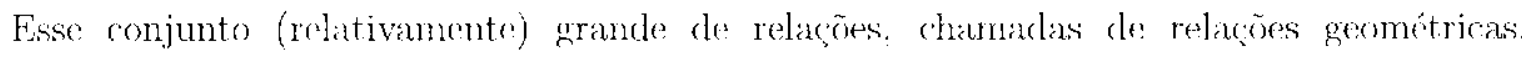
permitem a construção de algoritmos elaborados e eficientes para a indexação e suportc à execugão de consultas em espaços dimensionais. Para esses domínios de dados foram desenvolviclas diversas estruturas de indexação, conhecidas como "Métodos de Acesso Espacial - MAEs" (on Spalial Access Methods - SAMs) a partir do trabalho pioneiro sobre as R-trees [Guttman, 1984] e suas derivadas $R^{*}$-tree [Beckmann et al., 1990] e $R+$-tree [Sellis et al., 1987]. Om excelente tutorial mostrando a evolução dos M $A$ Fs pode ser cncontrado cm [Gacde \& Günther, 1998], o um ontro tutorial mostrando sen uso cun ambientes de altas dimensões é apresentado en [Böhm et a]., 2001].

Para conjuntos de dados que não apresentam relações geométricas, mas nos quais somente existem os objetos e as distàncias entre eles, diversas pescuisas têm sido eletuadas, levando-se ao desenvolvimento das estruturas de indexação chamadas genericamente de "Mćtodos do Acesso Métrico - MAMs". Os métodlos propostos por Burkhard and Kcller [Burkhard \& Keller, 1973] foram o ponto de partida, apresentando as técnicas de particionamentos recursivos que pernitem a construção de NAMs. A primeira téenica particiona um conjunto de daxios escolhendo $1 \mathrm{~m}$ representativo dentro do conjunto e agrupando os demais elementos de acorlo com as distâncias de cada elemento com o representativo. A segunda técnica particiona o conjunto original en uma quantidade pré-determinada de subconjuntos, selecionando a seguir $u m$ representativo para carla conjunto. Cada representativo e a maior distância dele para um elemento do subconjunto são mantidos na estrutura, para permitir consultas por vizinhos mais próximos.

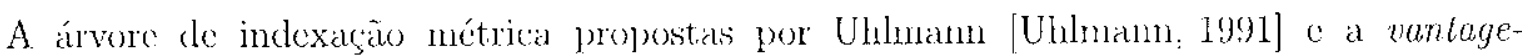
point lrec (vp-lree) proposta por Yianilos [Yianilos, 1993] são desenvolvimentos que partem da primeira técnica, onde os "vantage poinls" são os representativos propostos $\mathrm{cm}$ [Burkhard \& Keller, 1973]. A "árvore por hiper-planos generalizados" (Generalized Hyperplune Decomposition tree - gh-tres) [Uhlmann, 1991] é um ontro método, que recursivamento 
particiona o conjunto de dados em dois, selecionando dois representativos e associando os objetos restantes com o representativo mais próximo. Já a "árvore de acesso geométricamente próxino" (Geomelric Near-neighbor Access Tree - GNAT Irce) [Brin, 1995] pode ser vista como um refinamento da segunda técnica apresentada $\mathrm{cm}$ [Burkhard \& Keller, 1973]. Fla armazena a distância entre pares de representativos, alóm da maior distância a urn elomento associado a cada representativo. Fssa estrutura pode usar essas distâncias para podar cálculos de distâncias no espaço de busca, usando a propriedade da desigualdade triangular.

Os MAMs discuticlos anteriormente constroem a estrutura de indexaçäo utilizando todo o conjunto de dados clisponível numa única operação, e não permitem operaçós posteriores de inscrção e remoção de elementos, sendo por isso denominados métodos estáticos. A $M$ tree, desenvolvida por Ciaccia, Patclla and Zozula [Ciaccia et al., 1997], foram os primeiros MAMs dinâmicos propostos na literatura. A Slim-tree [Traina et al., 2000] aperfeicoou a $M$ tree, propondo a primeira (e até agora úmica) técnica de redução de sobreposição de nós de regióes que pode operar en espaços métricos. A sobrcposição do nós é um efeito indesejável, pois obriga a busca em profundidade em diversas subárvores para a localização dos clomentos solicitidos pelas consultas [Traina et al., 2002a].

Os MAMs Slim-lree serão atilizados nesse projeto para o descnvolvimento dos algoritmos genéticos para buseas por similaridade, e portanto teräo sua estrulura mais detalhada na Secão 3.3 .

Também foi proposto utilizaren-se núltiplos representativos chamados "omni-focos" (usados para medir a distancia em qualduer região do espayo ocupado por un conjunto de dados) para atuar como geradores de coordenadas para todos os elementos de um conjunto [Santos et al., 2001]. Essas coordenadas porlem ser indexadas utilizando-se quaisquer MAMs ou MALs, gerando toda uma nova fannília de métodos do acesso métrico, denominada "famíliaOrni1", baseada em ommi-focos.

O conceito fundamental da família-Omni é utilizar os omni-focos para caleular um conjunto de coordenadas que são indexadas no lıgar dos objetos propriamente ditos, ou seja, calculamse as coordenadas e depois clas são usadas na estrutura de indexarajo. Una outra abordagem utilizando o nesmo conceito de omni-focos ó uttilizá-los durante a construçäo de uma estrutura de indexação métrica, como $1 \mathrm{~m}$ mecanismo de refinamento das operações de poda, durante a navegaça da estrutura nas operacooses de consulta. Essa abordagem foi a base para a criaçäo de MA.Ms recentes, chamados de DF-tree [Traina et al., 2002b]

Mais recentemente, em [Vicira de al., 2004] ó proposta a DBM-trec, ondo é possível diminuir a sobreposição entre os nós através da flexibilização do balanceamento da estrutura.

Un tutorial que mostra as técnicas fundamentais de trabalho om estruturas de dados para espaços métricos, bem como uma descrição das prineiras estruturas desenvolvidas, é apresentado em Chávez of al.: 2001]. Em 'Hjaltason \& Samet, 2003] é apresentada uma extensa revisäo bibliográfica dos mótodos de acesso métricos. 


\subsection{Slim-tree}

A Slim-tree [Traina et al, 2000] [Traina et al., 2002a] é uma estrutura balanceada e dinâmica, que tem crescimentio botton-up, das folhas para a raiz. e permite inserçöes de dados de un domínio métrico.

Na Slim-lree pode ocorrer sobreposição das árcas do cobertura de nós no mesno nível da árvore. Portanto, a divisão do espaço métrico não gera regiões necessariamente disjuntas. A Shm-tree dispõe de um algoritmo chamado Slim-Doun. utilizado posteriormente a construção da árvore para minimizar o problema da sobreposição entre os nós. $\Lambda$ estrutura também tem a capacidade de avaliar o grau de sobreposição do seus nós (Fal-Factor).

\subsubsection{Organização da Slim-tree}

Os objetos são agrupados no disco en páginas de tamanho fixo, cada página correspondendo a $u m$ nó da árvore. Os objetos são armazenados nas folhas, organizados numa estrutura hicrárquica que utiliza um objeto representativo como centro de uma regiäo de cobcrtura dos objetos en uma subárvore, delimitada por um raio.

Existem dois tipos de nós na Slim-lree os dala-nodes (leaf-nodes) e os index-nodes. Cada página armazena un número máxinno de objetos que, para simplificação, é o mesmo para leaf-nodes e index-nodes

A estrutura de um leaf-node, onde são armazenados todos os objetos da Stim-lree. é a seguinte:

$$
\text { leaf-node i vetor de } \left.<O I d_{i}, d\left(s_{i}, s_{\text {rep }}\right), s_{i}>\right]
$$

onde $O I d_{i}$ ó o identificador do objeto $s_{i}$ e $d\left(s_{i}, s_{r e p}\right)$ ć a distancia entre o objeto $s_{i}$ e $s_{\text {repa }}$ qué o representativo desse leaf-node.

A estrutura de un index node ć:

$$
\text { index-node [ vetor do } \left.<s_{i}, r_{i}, d\left(s_{i}, s_{r c p}\right), \operatorname{Plr}\left(T s_{i}\right), \# \operatorname{En} l\left(\operatorname{Ptr}\left(T s_{i}\right)\right)>\right] \text {, }
$$

onde $s_{i}$ armazena o objeto representativo da subárvore apontada por $\operatorname{Ptr}\left(T s_{i}\right), r_{i}$ é o raio de cobertura da região, $d\left(s_{i}, s_{r e p}\right)$ é a distância entre $s_{i}$ e o representativo deste nó, c \#Enl( $\left.\operatorname{Ptr}\left(T s_{i}\right)\right)$ armazena o número de entradas na subárvore apontado por $\operatorname{Plr}\left(T s_{i}\right)$.

Na Figura 3.1. Lemos una representaçäo gráfica da estrutura lógica de una Slim-tree, con a distinção cntre index-nodes e leaf-nodes, o na Figura 3.2 um cxemplo de sua utilização para a indexação de um conjunto de sete palavras, utilizando a função de distância $L E$ dit.

A Figura $3.3(a)$ apresenta a disposiça de 17 objelos $\left(s_{1}, \ldots, s_{17}\right)$ indexados por uma Stimtree com capacidade máxima de 3 oljetos por nó.

Os círculos brancos da 3.3 (b) representam nós folha, e o de cor cinza os nós índice. Os objetos representativos de ada nó são mostrados en preto, a os demais objetos indexados são representados por pontos cinzas. Podemos ver na figura várias sobreposiçócs entre os nós. indicadas pelas interseções entre as áreas de cobertura. Neste cxcmplo: o objeto $s_{13}$ está localizado na região de interseção de dois nós-folha, con representativos $s_{6}$ e s $s_{8}$. Porlanto, o objeto $s_{13}$ poderia estar inserido om qualquer urn dos dois nós-folla 


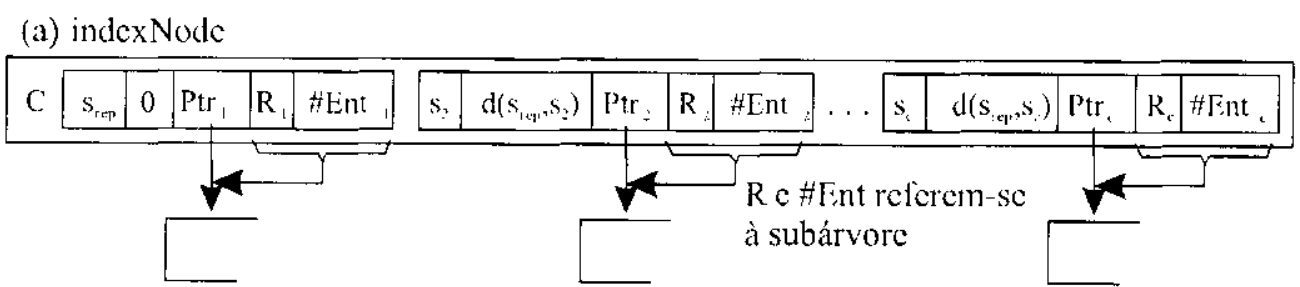

(b) lcafNode

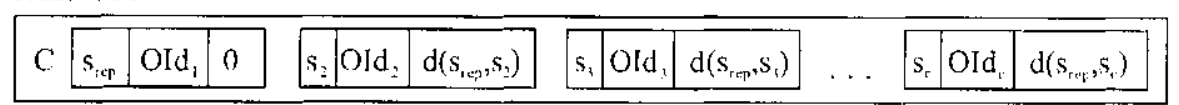

Figura 3.1: Representacão gráfica da estrutura lógina de index-nodes e leaf-nodes da Slim-tree. [Traina et al., 2002al]

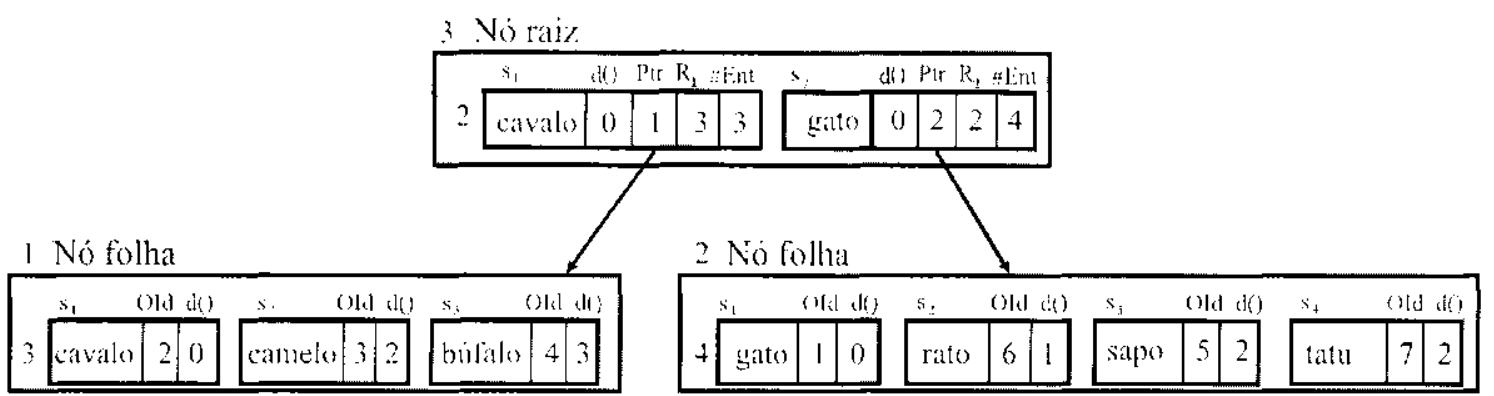

Figura 3.2: Exemplo de indexacão de sete palavras a funç̃ŏo do distância LEd

\subsubsection{Construção de uma Slim-tree}

$N_{a}$ inserção de um novo objeto en uma Slim-bree começando pela rais. o algoritmo tenta encontrar um nó em que o raio de cobertura cubra o novo objeto. So nonhum nó for qualificado, escolhe-se o nó que temha o objeto representativo mais próximo do novo objeto, aumentando-

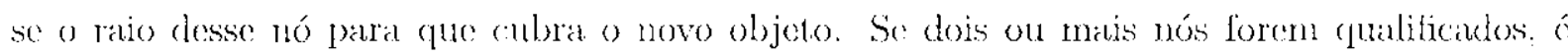
excrutado um algoritmo para escolher qual é o nó oncle será inserido o novo objeto. Fxistem trés opçòes para a escolha do nó onde será inserido o objeto:

Aleatória (Random): o nó é escollido aleatoriamente entre aqucles que foram qualificados para inserção sem o aumento do raio de cobertura:

Mínima Distância MinDist: é escolhido o nó (uja distância entre seu objeto representativo e o novo objeto seja a menor, dentre os nós qualificados.

Minima Ocupação (MinOccup): seleciona-se dentre us nós previamente qualificados aquele que apresenta o menor número de objetos já armazonados.

Fise processo é sucessivamente aplieado para cada nívol da Slim-trec.

Na ocorrência de uma nova inserção, pode ocorrer do nó escolhido ter sua capacidade máxima excedicla. Quando isso ocorre, um novo nó ćalocado no mesmo nível. A Slim-trec possui tress 


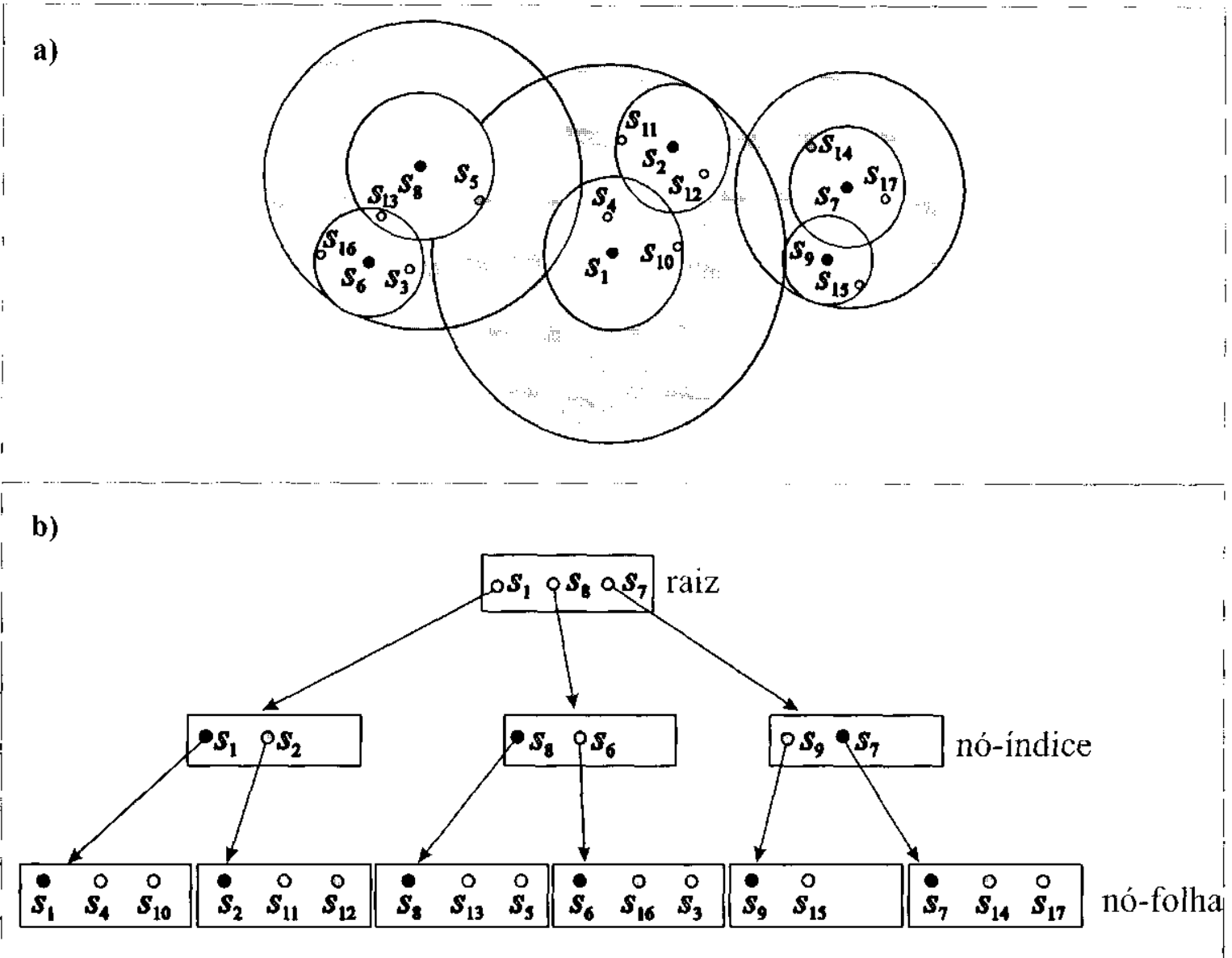

Figura 3.3: Representagão de una Slim-tree em (a) e sua estrutura lógica em (b).

opçoes de algoritmos para a escolha de quais scrão os objetos representativos dos novos nós, (ulando ocorre a quebra de nós (spliting):

Random: são cscolhiclos alcatoriamente dois novos representativos para os rlois mós:

Minmax: todos os possíveis pares de objetos são considerados potenciais representativos. Serão escolhidos cono representativos os dois objetos que minimizarem o raio de cobertura.

MST (Minimal Spanning Tree): é criada uma árvore de menor caminho com os objetos cun dos arcos mais longos ć removido, condo-se então dois agrupamentos.

Depois de escolhidos os representativos, os objetos restantes são distribuidos pelos 2 nós, alocando cada objeto no nó cujo representativo está mais próximo do respectivo objeto. Os objetos escolhidos como representivos dos dois nós depois da divisão deven ser inseridos no nó pai, o que pode gerar a necessidade de nova divisão. O processo de divisão, se neccessário, pode ser repetido nos níveis superiores, aumentando a altura da árvore quando propagado até o nó raiz. As informaşões referentes ao número de objetos nas subárvores c raios de cobertura devem ser atualizados nos nós dos niveis superiores. 


\subsubsection{Consultas por similaridade na Slim-tree}

Na Slim-tree, assim como entre outros MAMs. pode ocorrer a sobreposição da área de cobertura de nós distintos. A Slim-tree utiliza a desigualdade triangular para "podar" cálculos de distáncias.

Como as clistâncias entre todos os objetos armazenados cm um nó a o representativo de tal nó são conhecidas. a proprierlade de desigualdade triangular pode ser usada durante uma. consulta por similaridade para descartar objetos que, não fazem parte do conjunto resposta. A "poda" pode ser leita sem a necessidade de calcular as distancias entre cada objeto armazenado c o objeto de referência para consulta, reduzindo assim o número de cáleulos de clistâncias necessários para a realização da consulta.

Dados o espaço métrico $\mathcal{M}=\langle\mathcal{D}, d()>$, o conjunto de objetos $S \subseteq \mathcal{D}$, o objeto de consulta $s_{q} \in \mathcal{S}$. o raio de consulta $r$ e un objeto representante $s_{\text {rep }} \in S$, um objeto $s_{z} \in S$ poderá ser. descartado pela propriedade de desigualdade triangular se uma das duas condições a seguir forem satisfeitas:

$$
\begin{aligned}
& d\left(s_{r e p}, s_{i}\right)<d\left(s_{\text {rep }}, s_{q}\right)-r \\
& d\left(s_{r p p}, s_{i}\right)>d\left(s_{r e p}, s_{q}\right)+r
\end{aligned}
$$

Um excmplo da utilização da desigualdade triangular para podar cálculos de distância na árvore é mostrado na Figura 3.4 , em que srep é o objeto representativo do nó da árvore, sq é o objeto de referência para busca e $r_{4}$ ć o raio. Os objetos $s_{1}, s_{2}, s_{3}$ o $s_{4}$ pertencem ao conjunto de dados em domínios métricos $S \subset D$. Os clementos s e $s_{3}$ podem ser descartados pela propriedade do desigualdade triangular; o clemento s não pode ser descartado, mas não faz parte do conjunto resposta; e s. não pode ser descartado e faz parte do conjunto resposta.

Na Figura 3.4, a região 1 equivale à condição 3.1 e a região 3 à condiçàn 3.2. Qualquer objcto que estiver na rogiāo 1 ou 3 pode ser descartado através da propriedade de desigualdade triangular, sem calcular sua distância com o objeto da consulta. Já na regiāo 2 , há necessisidade de se calcular a distància entre o objeto de consultic e os objetos pertencentes à região.

Os algoritmos de consult a por abrangêneia r aos k-vizinhos mais proximos siöo basicamente os mesmos em todas as árvores métricas e espaciais 'Roussoponlos et al., 1995:

Algoritmos de consultas por abrangência têm um raio limitante conhecido durante todo o processo de busca. Assim. iniciando pelo nó raiz da árvore, o algoritmo de consulta por abrangêneia percorre a árvore e calcula a distância do objeto $s_{q}$ com os objetos armazenados no conjunto de dados que não podem ser podados pela propriedade de desigualdade triangular, e inchui no conjunto resposta todos aqueles que estão a uma distancia inferior ou igual a $r$.

Já na consulta por vizinhos mais próximos é utilizada uma lista global de páginas válidas, que armazena ponteiros para as páginas (subárvores) que podem conter objetos qualificados para a resposta. mas ainda não percomidas. O raio limilante da resposta da consulta não é conhecido desde o início da busca. Portanto, o raio da consulta é dinânico podendo ser 


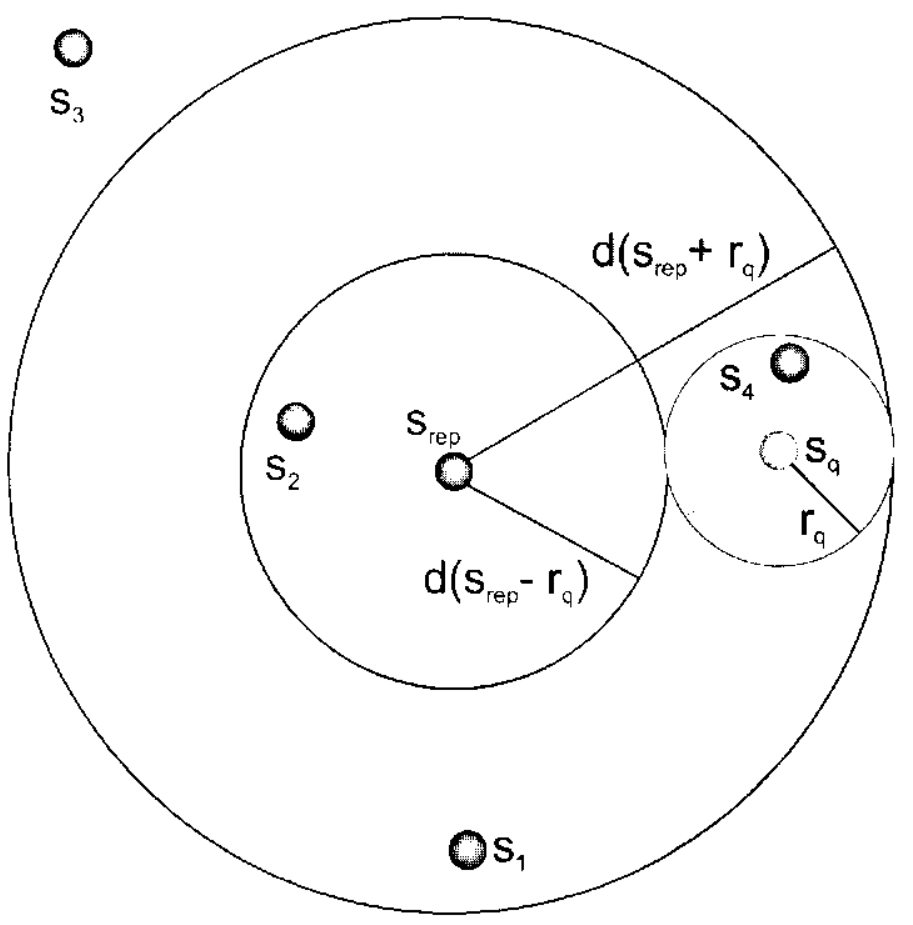

Figura 3.1: Descarte de objetos com o uso da desigualdade triangular

considerado inicialmente como um valor infinito.

A ordem em que são accssados os nós da árvore pode influenciar no desempenho da consulta por vizinhos mais próximos. Visando aumentar a quantidade de subárvores que podem ser podadas, a próxina página a ser percorrida pelo algoritmo é sempre aquela que tem seu objeto representativo mais próxino do objoto do consulta, na lista global de páginas válidats.

Quando são encontrados objetos melhores que aqueles presentes no vetor de respostas, esses objetos são inseridos nesse vetor de maneira a mantê-lo ordenado. O critério utilizado para "podar" subárvores ó dinàmico, sendo baseado na distancia entre o objeto de consulta e o elemento mais distante armazenado no vetor de respostas.

\subsection{Considerações Finais}

Muitas estruturas do indexação foram propostas com o objetivo de agilizar as buscas por similaridade, esperialmente cm domínios métricos. Nos MAMs, normalmente o espaço de busca é particionado de acordo com técnicas específicas de particionamento e são criadas estruturas hierúrquicas para o armazenamento e manipulação dos objotos, geralnente árvores.

As primeiras estruturas propostas cram estáticas, sendo a $M$-Tree [Ciaccia et al., 1997] o primeiro conjunto de MAMs dinâninico proposto na literatura. A Slim-tree, que aperfeiçoou a $M$ Tree com técnicas de reduçáo da sobreposição dos nós, seräo os MAMs utilizado neste trabalho para o desenvolvimento dos algoritunos genéticos para busca aproximada por similaridade em domínios métricos.

Mesmo com a utilizacão dos MAMs, a execução de consultas (exatas) por similaridadte em grancles bases de dados complexos tende a ser proibitiva, pelo sen alto custo computacional 
3.4 Consideraçōes Finais

Para melhorar a eficiencia do tais consultas, podem ser realizadas buscas inexatas, com resultados aproximados. No Capítulo 4 serào apresentadas algumas técnicas de busca incxata. 


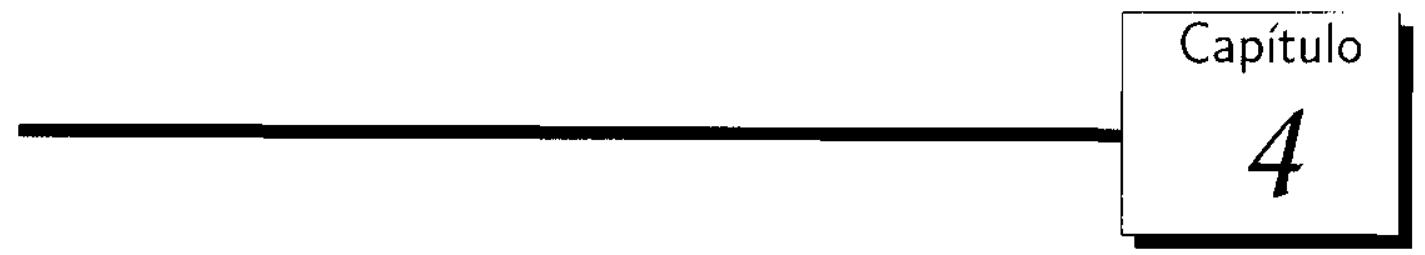

\section{Busca Inexata}

s consultas por similaridade tendem a ter un alto custo computacional om domínion complexos, como domínios mótricos o domínios com alta dimensionalidade. Agilizat as operacóses de busca nesses domínios toma-se muito importante e para isso, algorimos de busca incxata podem ser empregados.

\subsection{Considerações Iniciais}

Fm várias aplicaçoes, principalmente nas de domínios de dados complexos, a rocuperação exata deixa de ser um requisito fundamental, podendo ser trocada por um melhor desempenho.

Além disso, em domínios de dados com alta dimensionalidade, o custo compntacional das consultas tende a ser muito alto. Fase problema é conhecido como "maldiçäo dis dimensionalidade", e ocorre poroue cm altas dimensões as distâncias entre os objetos tendem a se homogenizar, fazendo con gur praticamente toda a estrutura de indexaçäo seja percorrida para a obtencĩo de un conjunto resposta exato. Un comportanento equivalente pork ser observado tanubém ('m espauses métricos [Chávez \& Navarro, 2001].

Na Seção 1.2 são apresentadas algumas técnicas de busca inexata para domínios de dados

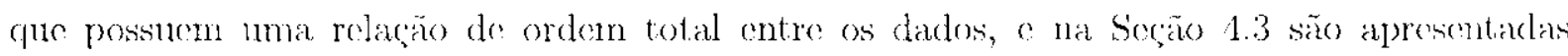
ténicas para domínios de darlos complexos. Na Segano 4.4 , serão feitas as consideracoes finais desse capítulo.

\subsection{Domínios com Relação de Ordem Total}

Dentre as téenicato para busca por dados näo exatos em bases de daclos que mais têm sido

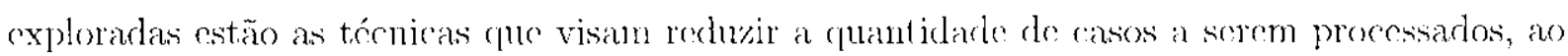
mosmo tempo em que se preservam as propriedades fundamentais dos conjuntos de dados

Várias abordagens tem sido adotadas para reduzir a quantidade de dados envolvikes na

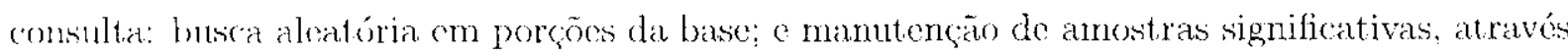
de amostragem, histogramas e wavelets.

No primeiro caso, sempre que una consulta é recebida, as relagöes envolvidas säo parciahnente acessadas, utilizando como critérjo de cscolha a utilizaçäo do cache do gerenciador 
e a distribuição dos dados pelos registros físicos $\mathrm{mm}$ disco [Cortes \& Pregibon, 2001]. Essa abordagem é eficionte na obtengào da resposta c relativanente simples de ser suportada pelos gerenciadores atnais, porém é muito dificil garantir alguma certeza estatística nas respostas obticlas.

Através de regras estatísticas de amostragem, é possivel escolher amostras que podem garantir a certéa cestatística das respostas obticlas; porón à custa de umn impacto significativo

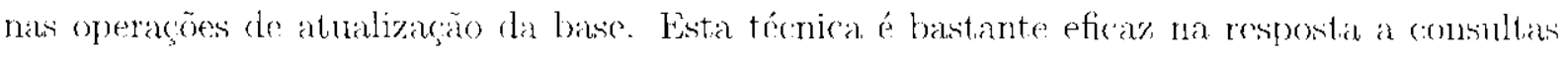
que requerem agregiaça de tuplas.

Sempre que téculcas dr amostragom são utilizadas, as operaçons que podem ser utilizarias tornam-se restritas a um deteminado domínio de aplicaşoes, uma vez cue as propricdades originais dos daclos que são manticlas normalmente são restritas, e cleven serr, portanto, escolhidas as mais adequadas ao tipo de consult a que se pretende acelerar. Dentre os critérios mais estudados para a criação de amostras está a manutenção cle conjuntos que preservam a densidade local dos dados [Palmer \& Faloutsos, 2000] Kollios of al., 2001] [Lee et al., 1998].

A abordagem baseada na manutcnção de amostras utilizada em [Acharya ct al., 2000' cria tabelas resumidas que acompanham as operasöes de atualização de dados da base. Yessa técnica, todas as consultals que solicitam respostas não oxatas são re-cecritab, e a consulta é realizatla de fato nas babelas resumidas [Acharya et al., 1999].

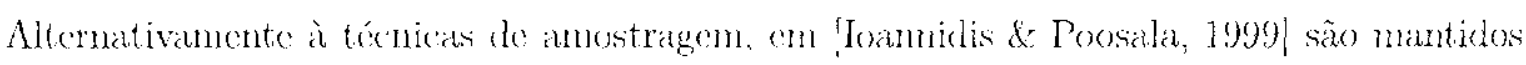
histogranas que representam resumidamente os dados armazenados na base, de forma que as comsultas säo traukizlas o realizadas sobre os histogramas. Já em [Chakrabarti ct al., 2001], săo utilizados wanelets para criaga de tabelas resumidas dos daclos da base, e as consultas (com operadores SQL padrão) são realizadas cliretamente sobre essas tabelas, agilizando as consultas aproximadas.

\subsection{Domínios Complexos}

Operacoes de busca sobre dados mais complexos, como dados em domínios multidimensionais e métricos, são significativamente mais dernoradas do que operaçōs sobre dados om domínios ordenáveis. Portanto, acelerar as oporaçós de busca de darlos nesses

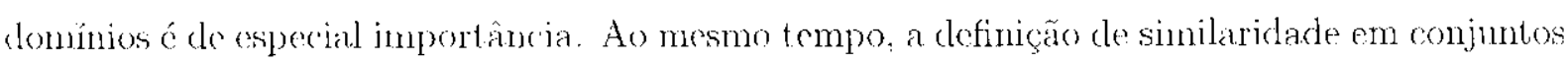
de daulos complexos 6 an geral memos precisa do que en conjuntos de dados mais simples [Tversky \& Gati, 1982] [Rubner \& 'lomasi, 2001; o gue faz com que essas operacōes sejam candidatas naturais para serem tratadas por algoritmos de busca não exata.

() algoritmos para obtençio de respostas não cxatas em domínios multidimensionais apenas recentenente despertaram o interesse dos pesquisadores. Vessa área as principais linhas do pesquisa são: junção espacial em domínios de baixas dimensões, e seleçäo de vizinhos mais próximos em domínios espaciais de altas dimensös.

A primeira área é voltada principalmente para aplicações geográficas, onde o múmero de dimensōes é reduzido (usualmente dois ou três), c o próprio espaço de busca (composto pelas coordenadas geográficas y é a alvo da procura. Em espaços de baixa dimensão, as cxecuçóes de 
operaçós de junção por similaridade são muito mas custosas do que as operaçós de seleção, daí o interesse major que existe nas operaçoes de junção, as quais tem sido o alvo principal das percpuisas Cai ot al., 2001] [Papadias et al. 2000] 1’apadias \& Arkoumanis, 2002]. O interesse

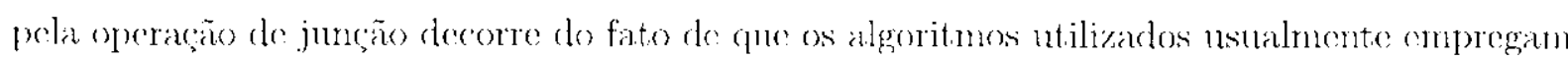
a maior parte dos recursos computacionais tratando o chamado "problema de satisfaräo de restriçös" (Constraint Satisfaction Problem - CSP) [Papadias et al., 1998]. Fsse problema decorre de que consultas em domínios espaciais são expressas como mulata conjuncõos fo algumas disjunçós) de termos de condição (restrição) espacial - por exemplo, objetus que cstão à asquerda do $\mathrm{X}$ e acina de $\mathrm{Y}$ e interseccionam $\mathrm{Z}$ e etc. Essas consultas são

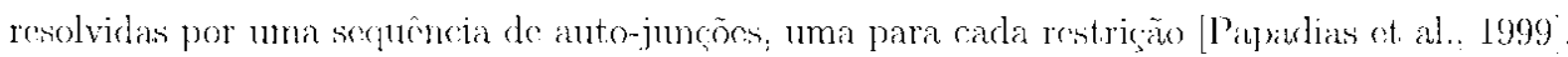
Fm [Papadias \& Arkommanis, 2002] apresenta-se um interessante algoritmo genótico para a resolução aproximada de múltiplas junções por abrangência em espaços de baixas dimensöes.

l'escuisas de busca aproximada can domínios nultidinemsionais também explorann operacóoes

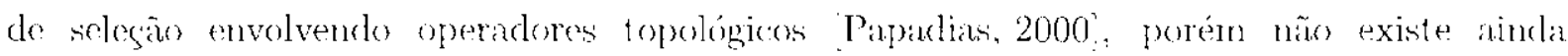
tartamento para operadores de junção por similaridade inexatos nesse tipo de domínio.

Já a área de pesquisa que trata da soleção de vizinhos mais próximos em dománios

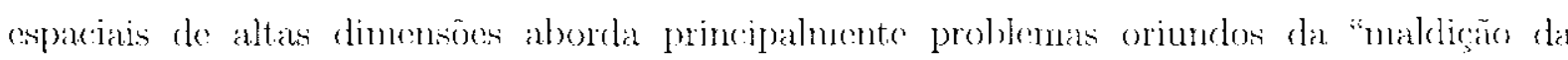
dimensiumaliclade". Esse problema decome do fato de que, em altas dimensões, as distäncias entre os objetos tendem a se homogeneizar - como o grau de liberdade no espaço ó muito grande, o espaço tende a ser muito esparso, assim cada objeto tica muito mais isolado do que nos espraços de bajas dimensós, a a escolha de quais são seus vizinhos mais próximos tende a ficar difusa, e muito mais cara de ser compuladal[Hinneburg of al., 2000); [Korm ed al., 2001].

Em expaços métricos, apesar da inexistência de coordenadas não perrnitir a análise de: complexidade em temos de dimensöes, $1 \mathrm{~m}$ comportannento equivalente pode ser observado Chávez \& Navarro, 20)(01].

Para tratar esses problemas, várias solucooses ten sido tentadas como por exemplo:

- a criaçio de estruturas especificas Sakumi et al. 2000), $\mathrm{m}$ especial a Clinder [Ij et al., 2002] que busca representar os agrupamentos de objetos na própria estrutura, e a Pyramid-tree que particiona um espaço multidimensional em pirâmides bi-dimensionais [Berchtold el al., 1998];

- al criação de estruturas cm hashing como em [Weber \& Böhm, 2000]. [Indyk \& Motwani, 1998] e em [Gionis et al.. 1999];

- através do tratamento algébrico das funções de distância [Sakurai et al., 2001] [Aggarwal, 2001] [Aggarwal et al., 2001] on aceitando taxas de erro controladas nos cáleulos do similaridade [Davis, 1999] Ciaccia \& Patella, 2000;

- determinação de vizinhança bascada em agrupamentos [Palmer \& Faloutsos, 20000] [Kinu et al., 200.1] [Li ct, al., 2002]. 
Fim Böhnn. 2000] é apresentado um modelo de custo para consultas por vizinhanca en espaços de altas dimensós, para estruturas de indexaça espaciais tais como a $R$-lree e a $X$-tree [Berchtokl et al., 1996]: onde os princi])ais fatores que interferem nas consultas (características dos dados, correlacoes entre dimensões e propriedades das estruturas de indexarão) tem sems graus de influencia quantificados.

Existem algumns técnica de consultas aproximalas propostas para aplicaconos espex iffati En Koudas et al., 2004], consultas aproximadas de k-NN săo desenvolvidas para aplicaçoes de "laba-stream", em que os dados chegan continuamente e podem ser acessados somente uma ve\%. Com o algoritmo e-apprommale $k N N$, as respostas aproximadas não cxcedem uma certa distáncia (dada pelo erro absoluto e) do objeto de consulta. Ein Das el al., 2003!, são

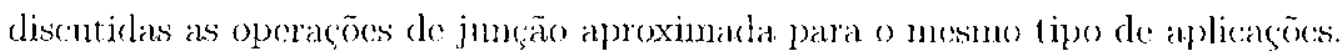

Para consultas aproxinadas em espaços métricos, alguns dos métodos citados podern ser utilizados, como é o caso do PAC-NN (Probably Approximately Correct Nearest Noighbor), proposto em [Ciaccia \& 1'atella, 2000]. O PAC execula 1-NNQs (ou NNQs), sendo que o erro no resultado pode exceder un theshold $E$ com uma probabilidarle limitada $C$, pasaneros definidos pelo usuário.

Em [Zezula et al., 1998], três técnicas de aproximacão foram propostas utilizando a $M$-Tree, todas visundo reduzir o numero de comparaçoes, e diferenciatlas pela heurística ulilizada para abreviar a execução da consulta exata. Na primeira delas é permitido ao usuário definir o falor de crro relativo entre os objetos recuperados e os exatos. Na segunda técnica é exploradal a clistribução das distâncias para controlar a aproximação. Finalmente, a terceira técrnica de aproximagão é haseada na seguinte observação pragmática: a precisão do conjunto resposta anmonta gradalivamente no decomer da consulta. mas de maneira que o erescimento dessa precisão é relativamente grande no início da execução, e cai rapidamente durante a execução da

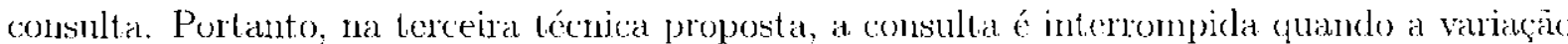
da distuncia ent re os objetos recuperados e o objeto de consulta torna-se relativarnente baixa.

Em Goldstein \& Ramalirishnan, 2000]: os autores propusoram a P-Sphere tree, (Probabilistic sphere tret), estrulura de indexação que realiza consultas de 1-VNQ. As técnicas descuvolvidas baseian-se no requisito de que exemplos aleatórios da distribuição da consulta estejaun clisponíveis na construção da estrutura de indexaçăo.

Em Bustos \& Navarro, 2004! , são apresentados algoritmos de consulta probabilísticos baseados em adaptaçöes do algoritmo de k- $\mathrm{NNQ}$ incremental |Hjaltason \& Samct, 2000], onde o usuário linita o número de cálculos de distâneias permitidos. Os algoritmos desenvolvieles são aplicáveis a MAMs bascados en particionamento comparto do espaço. Já cm [Chíve\% \& Navarro, 200:3]. foi desconvolvido outro algoritmo probabilístico do aplicacano geral. mas aplicado em MA.Ms bascakdos en pivos. Tal algoritmo reduz o raio da consultat; anmentando a poda pela manipulagão da desigualdade triangular.

Outro expediente amplamente estudado e utilizado o o mapeamento do objetos presentes em espaços complexos, em que o cálculo da distância entre os objetos tende a ser mais custesso, cun espaços onde tal cálenlo seja monos complexo. cono espaços Fuclideanos. Exemplos dessas 
técnicas são o FastMap [Faloutsos \& Lin, 1995], o Melric-Map [Wang et al., 2000] o o BoostMap [Athitsos ct al., 2004].

A maioria das técnicas de aproximação citadas tem restriçoes quanto a sla aplicação. Como

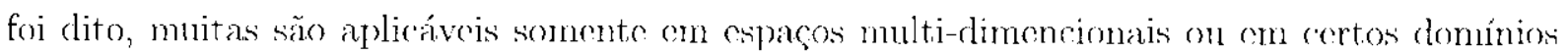
específicos. Algumas, aplicáveis ao caso mais geral de domínios métricos, são restritas às $1-$ NNQs [Ciaccia \& Patella, 2000] [Goldstcin \& Ramakrishnan, 2000].

Algunas das ténicas citadas requerem a definição de parâmetros de erro relativo ou absoluto nas distàncias dos objetos consultados, o que pode ser difícil dependendo da natureza dos dados.

Quanto às técuicas propostas end [Zezula et al., 1998] a [Bustos \& Navarro, 2004], as heuristicas são utilizadas somente para aloreviar a execucão da consulta exata convencional.

A área de aplicagão dos algoritmos desenvolvidos neste trabalho abrange qualquer conjunto de dados onde uma função de distância (mótrica) tenha sido definida. São aplicávejs às consultas por similaridarde k-.NQQ, RQ e várias de suas variaçöes, como por exemplo $k$-farthest neighbor querics $(\mathrm{k}-\mathrm{F} \mathrm{NQ})$ e external range querics (ERQ).

Alón de permitir abreviar a excongo da consulta exata, limitando o tempo de processamento da consulta, os algoritmos desenvolvidos neste trabalho visam acelerar a formação do conjunto resposta através da utilização de algoritmos genéticos para otimização do percurso na árvore.

\subsection{Considerações Finais}

En domínios de dados totahnente ordenávejes os principais meanismos mupregarlos para busca inexata são técuicus de amostragom, que visam reduzir a quantidade de dados a serem processados na opcração do busca.

En domínios complexos existom praticamonte duas áréas de pesquisa:

Junção espacial em domínios de baixa dimensionalidade: voltada principalınente para aplicaçōes geográficas:

Seleçāo de vizinhos mais próximos em domínios espaciais de alta dimensionalidade: visa resolver problemas oriundlos da "maldiçäo da dimensionalidade".

Neste trabalho foram descnvolvidos algoritmos de consultas por similaridade $k-N N Q$, RQ e algumas do suas variaçós, que podex ser aplieados on qualquer conjunto de dados onde uma. função de distância, ou métrica, tenha sido definida. Além de permitir abreviar a exccução da consulta exata, os algoritmos desenvolvidos visam acelerar a fomação do conjunto resposta, utilizando-se algoritmos genéticos 


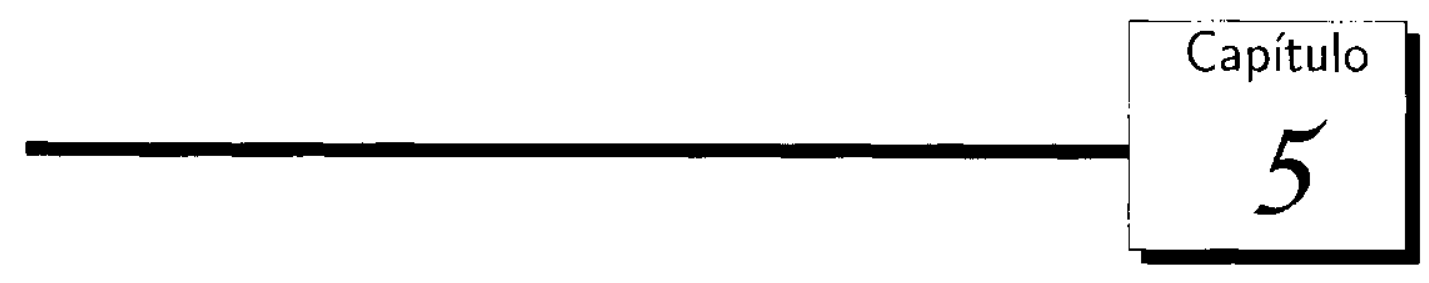

Algoritmos Genéticos

O

s Algoritunos Genóticos, introduzidos por John Holland em 1975 jHolland, 1975 ; tên siclo cada vez mais explorarlos na soluçäo de problemas envolvendo buscas o otimizaçōes, principalnonte pola robustez e simplicidarle que oferecem. Algorimos Genéticos são modelos computacionais inspirados na teoria evolutiva biológica.

\subsection{Considerações Iniciais}

Algoritmes genétices säo modelos de processamento computarional glue visan simular os

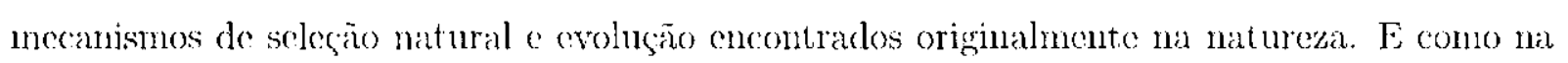
natureza, os indivíduos mais adaptados tên mais chances de sobreviverenn, se reproduziremo transmitirem suas características genéticas para as geraçoes futuras.

No contexto compulacional. cada resposta candidata presente no espaço de busca do problenda é considerada cono nu indivíduo, e representada mivocamente por uma cadcia de símbolos de tamanho finito, chamada de cromossomo. Cada símbolo presento na calcia de símbolos do um cromossomo ć chamado de gene.

Partindo de uma populaç̃ó inicial de indivíduos candidatos à solução do problema, são aplicados ciclicamente os operadores genéticos, dando origem a novas geraçoes de indivíduos A pressáo seletiva, que na natureza é excrcida pelo ambiente ć simulada pola aplicacáo do uma

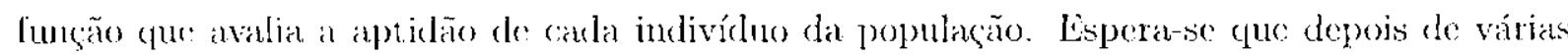
greracoes, a populaço inicial evolua, danclo origem a uma populacão final de indivíduos mais aplios.

Na Secão 5.2 são apresentados alguns conceitos e características dos Algoritmos Genćticos e as ctapas necessárias para implementação. Na Seção j.3.1, 5.3 .2 c 5.3 .3 são descritos respectivamente os operadores genéticos de Seleção, Cruzamento e Mutação. Finalnente, na

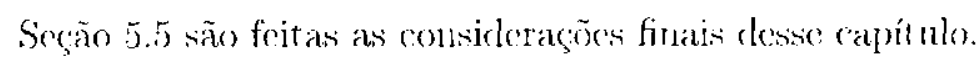

\subsection{Algoritmos Genéticos}

Algoritmos genéticos são hascados no mecanismo de seleção natmal e genética, e o que

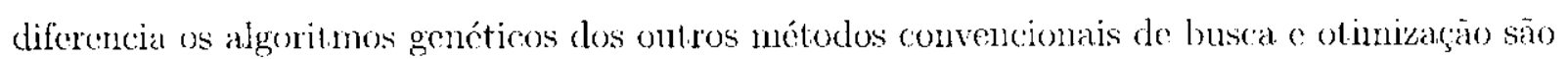


quatro característicals Goldberg: 1989]:

1. Os Algoritmos Genéticos trabalham com codificações das variáveis do problema, e não com as próprias variáveis, utilizando similaridade ontre os códigos:

2. Algoritmos Genéticos realizam a busca a partir de uma população de pontos, e não a partir de um único ponto, o que reduz a probabilidade de o processo de busca cstacionar em máximos locais:

3. Os Algoritmos Genéticos utilizam apenas a função de avaliação, não ntilizando informaçōes adicionais sobre os indivíduos;

1. Algoritmos Genéticos utilizam regras probabilísticas de transição, e nãu regras decerministicas

Apesar de serem algoritmos probaljilísticos, não são algoritmos de busca simplesmento aleatórios. Algoritmos Genéticos ulilizam a escolha aleatória como um artifício para direcionar a buscal para regiós clue pareçan mais promissoras.

Para a implementacão dos algoritmos genéticos a primeira tarefa clue precisa ser realizada é a codificação das soluçōes presentes no espaço de busca em cadeias de símbolos de tamanho finito.

Definida a codificação dos indivíluos, deve ser estabelecido un mecanismo para a obtenção da população inicial, que ć o conjunto de indivíduos que sáo soluçöes iniciais para o problema. A escolha dos indivíduos para compor essa população pode ser feita aleatorianente ou de acordo com alguma informação adicional que esteja disponível solbre o problema .

Fn um Algoritmo Genético simples, são aplicados sobre a população os operadores do seleçâo, cruzamento e mutação, dando origem, em cada ciclo, a uma nova população chamada de nova geração. Fssa nova população será também submetida aos opcradures genéticos: dando origem a outra geração. Esse cielo é executado até que seja interrompido por um critério do parada, que pode ser bascado no númern de geraçöes. na taxa do alteração entre geracöns sucessivas, ou no tempo de execução. A pós várias iterações, espera-se que haja a evolução da populaçäo inicial: dando origem a indivídnos mais adaptados, ou seja, soluçöes melhores.

\subsection{Operadores Genéticos}

Os principais operadores genéticos, que são aplicados cm urn algorituno genético simples, são seleção, cruzanento e mutação. 'Tais operadores são aplicados ciclicamente sobre a população do algoritmo genćtico. A seguir são descritos os principais operadores genćtiens.

\subsubsection{Seleção}

A selegão consiste na escolha dos inclivíduos da população atual para reprodução, de modo que os mais aptos tenham mais chances de se reproduzir. Una função de avaliação (função objetivo) determina a aptidão de cada um dos indivíduos. Os indivíduos mais aptos, on seja. aqueles em que aplicaçoes da função objetivo rosultam valores maiores, terão maiores chances 
de serem escolhidos para se reproduzirem. Esse mecanismo é uma simulação do que ocorre na natureza, onde os indivíduos mais adaptados têm mais chances de sobreviverem, reproduzirem e transmitirem suas características genéticas para as geraçōes futuras.

Existem várias técnicas para a realização da seleção [Blickle \& Thiele, 1995], sendo que a mais comum é a implementação de uma roleta, onde cada indivíduo tem uma área correspondente a sua aptidão em relação aos outros. Com isso, indivíduos com pouca aptidão tendem a se extinguir, enquanto os mais adaptados tendem a se reproduzir e manter suas características.

Um exemplo da aplicação da técnica da roleta é apresentado na Tabela 5.1 e na Figura 5.1, considerando-se uma população com 8 indivíduos.

Tabela 5.1: Exemplo da técnica da roleta em uma população de 6 indivíduos.

\begin{tabular}{|c|l|l|}
\hline Indivíduo & Aptidão & Participação na Roleta \\
\hline 1 & 4 & $5 \%$ \\
\hline 2 & 20 & $25 \%$ \\
\hline 3 & 16 & $20 \%$ \\
\hline 4 & 24 & $30 \%$ \\
\hline 5 & 8 & $10 \%$ \\
\hline 6 & 8 & $10 \%$ \\
\hline
\end{tabular}

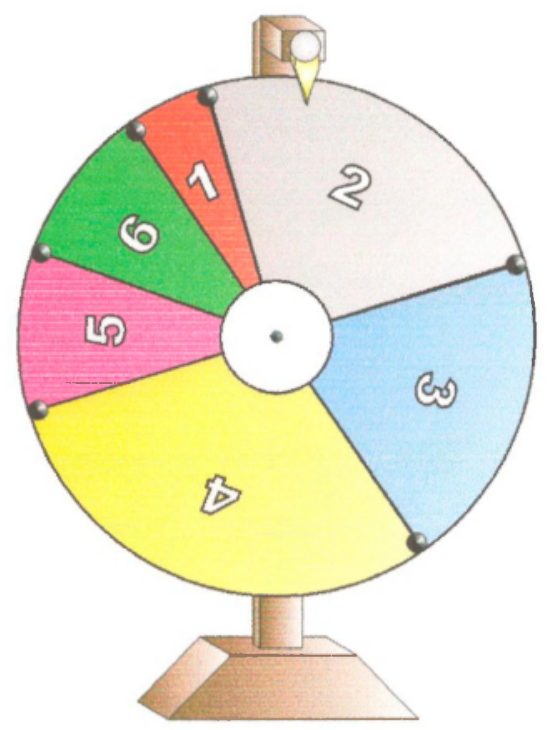

Figura 5.1: Representação gráfica da roleta relativa a Tabela 5.1.

Nesse exemplo, a roleta será girada 6 vezes. para selecionar os 6 indivíduos.Cada indivíduo da população selecionado é copiado na nova população temporária, para a aplicação dos outros operadores genéticos.

\subsubsection{Cruzamento}

Após terem sido selecionados os indivíduos, os cruzamentos (crossover) entre eles podem ser realizados. 
O operador genético de cruzamento possibilita a criação de novos indivíduos, os filhos, pela combinação dos cromossomos dos indivíduos pais. Com isso, indivíduos diferentes são gerados mantendo as características genéticas dos indivíduos pais.

Existem várias formas de se realizar o cruzamento. O método mais comum é o cruzamento de 1 ponto. Os indivíduos são pareados aleatoriamente. Para cada par de indivíduos é definido um ponto de cruzamento, que divide o cromossomo dos pais em duas partes: parte $A$, composta pelos genes em posições anteriores ao ponto de cruzamento definido; e parte $B$, com o restante dos genes. Então, as partes $B$ são trocadas entre os indivíduos, dando origem a dois novos indivíduos, como pode scr visto na Figura 5.2.
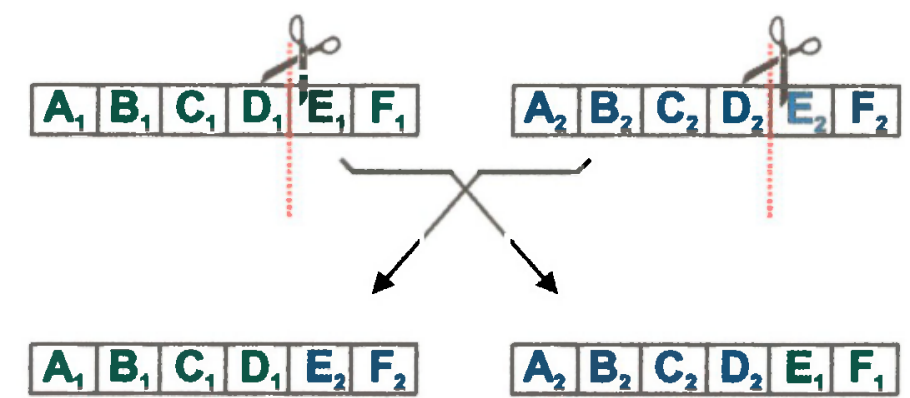

Figura 5.2: Cruzamento de 1 ponto.

É definida uma probabilidade para que scja realizado o cruzamento. Por isso, nem scmpre ocorre o cruzamento. Quando não ocorre, os pais são apenas "copiados", dando origem a seus filhos.

\subsubsection{Mutação}

A operação de mutação altera o código genético de um indivíduo, e é aplicada de acordo com uma probabilidade definida, geralmente baixa. Uma mutação consiste na alteração aleatória do valor de um gene do cromossomo.

Com a mutação, torna-se possível a exploração de áreas do espaço de busca que não poderiam ser alcançadas somente com a aplicação do operador genético de cruzamento. Com a aplicação da mutação, não existem áreas inalcançáveis do espaço de busca.É uma movimentação aleatória pelo espaço de busca, necessária para a diversidade genética da população.

Resultados empíricos mostram que a taxa de mutação adequada para a obtenção de bons resultados é muito pequena, assim como ocorre em populações naturais, levando a conclusão de que o operador de mutação pode ser considerado um mecanismo secundário [Goldberg, 1989].

\subsubsection{Elitismo}

Durante a evolução de um algoritmo genético, pode acontecer de o indivíduo mais apto de uma geração não estar presente na geração seguinte, devido principalmente à característica não-determinística dos algoritmos genéticos. 
A "Estratógia Elitista": on Elitismo, sugere um tratamento especial aos elementos mais aptos da população, garantindo que o melhor ou melhores indivíduos gerados nào serão perdidos entre geraçoes consecutivas como consedüência da aplicagão dos operadores genéticos [De Jong. 1975?. () clitismo visa acclerar a busca pela solucẽon ótima com o aumento da pressão soletiva.

\subsection{Convergência dos Algoritmos Genéticos}

A escolha dé téenica de selecăo e a definição dos paràmetros do algoritmo genótico sào responsáveis pela sua eficácia em convergir pará a soluçăo ótima.

O favorecimento dos indivíduos mais aptos ó chamado de pressão soletiva, o o aplicada pelo operador de seleção. () aumento da pressão seletiva detemina a redução da diversidaule dos indivíchus presentes na população, agilizando a convergencia do algoritmo genético.

A pressão selctiva alta pode levar o algoritmo a convergir prematuramente para máximos locais. Por outro lado, quaudo nào há favorccimento aos indivíduos mais aptos c portanto ten-se una pressio soletiva muito baixa, apesar de a diversidade dos indivíduos da populaça ter tendencia a se manter alta a eficácia do algoritmo genćtico é reduzicla, podendo,no caso de pressão scletiva muito baixa, se considerar um passeio randomico pclo espaço do busca.

\subsection{Considerações Finais}

Algoritmos Genéticos simulam os mecanismos de seleçäo natural e genética em sistemas computacionais, sendo aplicadns com exito na solucão de problemas de busca c otimizacãa do diversas áreas.

Utilizando o conceito da sobrevivência dos indivíduos mais aptos, uma população inicial de soluções evolui pela aplicação cícljca de operadores genéticos, gerando novas gerações com respostas que tendem a ser melbores.

Os principais operadores genciticos são:

Seleçāo: operador responsável pela escolha probabilística de quais indivíduos da população atulat sc reproduzirão;

Cruzamento: gera novos indivílues a partir da troca do informaroues genéticas dos indivíduos pais;

Mutação: alteração aleatrória slo código gonótico de um individuo que possibilita a exploração de regiões do espaço de busca que scriam inalcançáveis somente com a operação de cruzamento

Algoritmos Genéticos apresentan robustez, eficiência e simplicidade, c serão utilizados no descnvolvinento de algoritmos para busca por similaridade. 


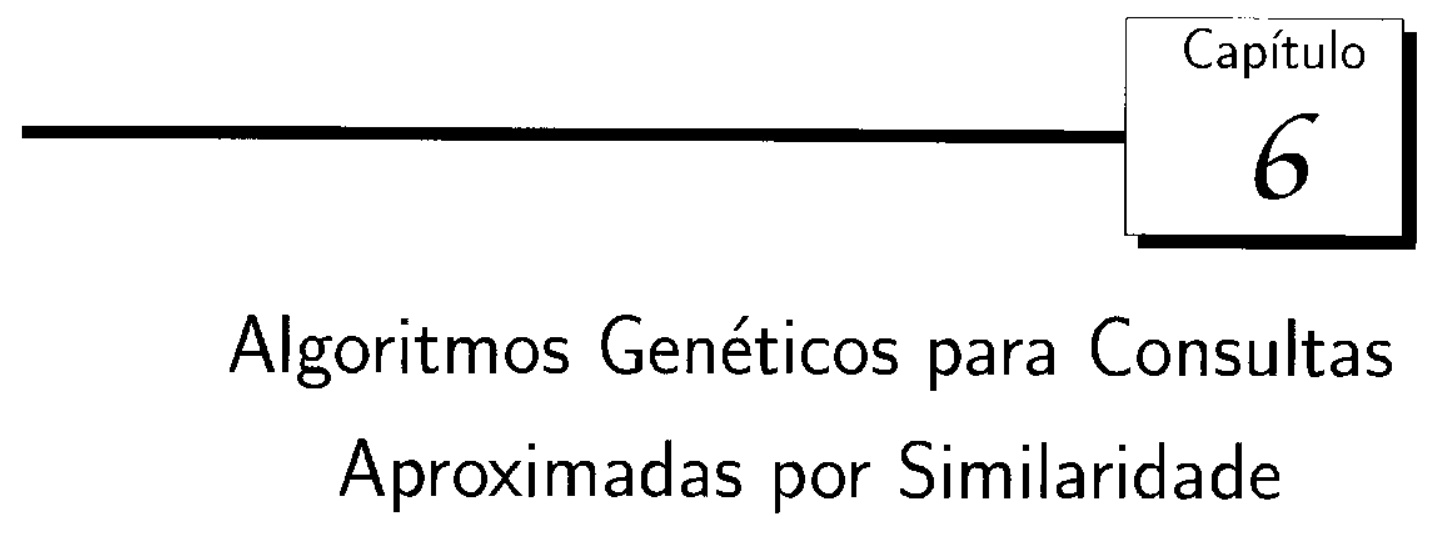

$\mathcal{M}$ esino com al utilização dos MAMs, a execução de consultas (exatas) por similaridade em grandes bases de dados complexos tende a ser proibitiva, pelo scu alto custo comput acional. Para melhorar a eficiencia de tais consultas, podem ser realizadas buscas inexatas, com resultados aproximados, utilizando uma quantidade de tempo reduzida.

Este capitulo apresenta os algoritmos para consultas por similaridade aproximadas bascados em algoritmos genéticos, que constitucm a principal contribuição deste projeto de mestrado ao estado da arte.

\subsection{Considerações Iniciais}

Neste traballo foram desenvolvidos algoritmos para recuperaf̧ão aproximada do conjunto resposta de consultas por similajidade utilizando algoritmos genciticos. Tais algoritmos operam $\mathrm{cm}$ dados indexados pela Slim-tree. Os algoritmos de RQ, $k$-NNQ e algumas de suas variacóes são parecidos. Assimn, as versões baseadas em algoritmos genćticos descnvolvidas também são semelhantes. P’or isso, será usado como exemplo a partir daqui o algoritmo de consulta aproximada de $\mathrm{k}-\mathrm{NNQ}$

Note-se que, embora o ganho mais expressivo obtido com as técnicas de algoritmos gencéticos ocorram nas consultas k-NN, mesmo em RQs com respostas aproximadas, a orden em que serão accssados os nós da árvore pode influenciar na precisão das respostas, pois provavelnente não scrăo acressados todos os nós possíveis.

Os algoritmos desenvolvidos foram integrados aos MAMs Slim-tree como opçōes de consulta alternativas e poden ser utilizados por qualquer usuário do MAM, com a necessidade apenas da definição adicional do critério de parada, alés daquelas requeriulas para a utilização convencional da Slim-lree, que são as definições dos objetos e da função de distância (métrica) entre eles. Definiçôes do algoritmo genético, como taxas de aplicação dos operadores e pesos também podem ser definidus. Com issos a área de aplicaçăo dos algoritmos descnvolvidos 
abrange qualquer conjunto de dados onde uma função de distáncià métrica tonha sido dofinida

\subsection{O Algoritmo Genético}

O objetivo inicial deste trabalho foi desenvolver algoritmos de busca que permitissem explorar a navegagão das subárvores scm ficar restrito a nma sequencia fixal alravés do algoritmos genéticos

O algorimo genético procura pelos melhores caminhos na árvore, com o intuato de melhorar e agilizar a formaçäo do conjuntos resposta.

Para a implementação do algoritmo genético, é necessária a representação cromossômica do espaso de busca, ou seja, cada possível soluçâo do algoritmo genético deve sex representada univocamente por um cromossomo. Portanto, cada caminho na arvore, que comece na rais e pode chegar a um nó-folha, é considerado como um indivíduo do algoritmo genótico, é representado por un cromossomo com $h-1$ posiçöes onde $h$ é a altura da árvore. A codificação dos indivíduos en cromossomos é feita a partir do caminho percorrido na estrutura. desde a raiz até o objeto. O valor inttciro presente em cada posição do cromossomo indica a posição na página do respectivo nívol na árvore, como pode ser visto na Figura 6.1
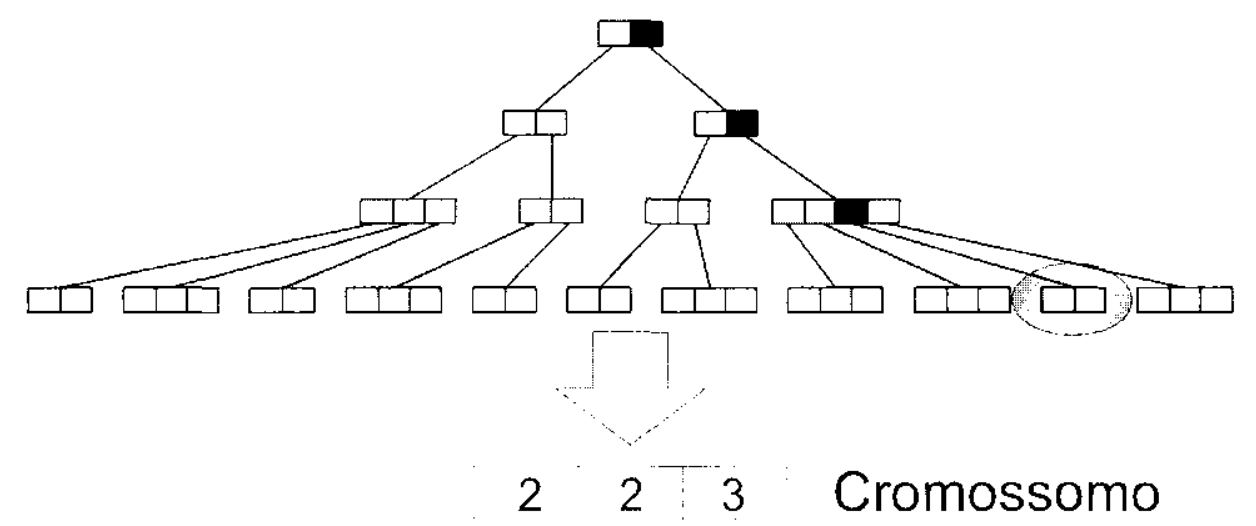

Figrua 6.1: Representação Cromossomica.

Com isso, dado um indivíduo que tenha um cromossomo factivel, o caminho representado por esse cromossomo levará até un nó-folha, onde serão avaliados os objctos para possível inclusão no conjunto resposta.

A popmlação iniciul ó gerada aleatoriamente, carla indivídno da população é avaliado o recebe urı valor de aptidão, seu fitness. Tal avaliação é feita com una incursâo na árvore, percorrendo o caminho representado pelo cromossomo do indivíduo e calculando sua aptidão com a função objetivo.

A aptidão de cada caminho é calculada baseando-se: em sua seletividado e na "qualidade" de seus objetos, estimada pela proximidade dos nós do caminho com o objeto de referéncia para consulta, cono pode ser visto na Segão 6.4 .

Depois de avaliados, é aplicado o operador genético de seleção sobre os inclivíduos. A seleção consiste na escolla dos indivíduos da população atual para reprodução, de modo que os mais aptos tenham mais chances de se reproduzir. Foi utilizada a técnica da rolela [Goldberg, 1989], 
discuticla no capítullo anterior. Indivíduos com pouca aptidão tendem a se exlinguir, enculanto os majs adaptados tendem a se reptuduzir o manter suas caracteristicas nas geraçoes seguintes. Carda indivíluo da populaçào selecionado é copiado na nova população, para a aplicação dos operadores genóticos de cru\%anento o mutarario.

() operador genético de cruzamento possibilita a criacão de novos indivíduos, os filhos: pela combinaryão dos romossomos dos indivíduos pais. Foi utilizado o cruzamento de 1 ponto, em que os individuos sän parcados aleatoriamente e para cada par de indivíduos é definiclo um ponto de cruzamento. Os cromossomos dos pais säo divididos em duas partes que são trocadas entre des, dando origem a dois nowos cromossomos filhos.

A operaçäo de mutaüuo altera o código gonético de um indivíduo, cé aplicada de acordo com

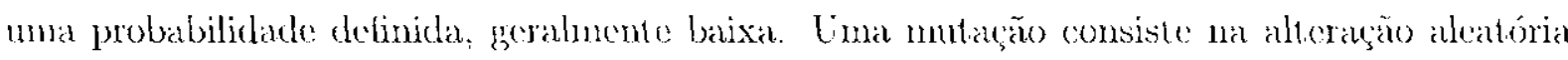
do valor de um gene do cromossomo.

Depois da aplicação dos operadores genéticos é formada uma nova população. e inicia-se um novo ciclo, como pode ser visto na Figura 6.2.

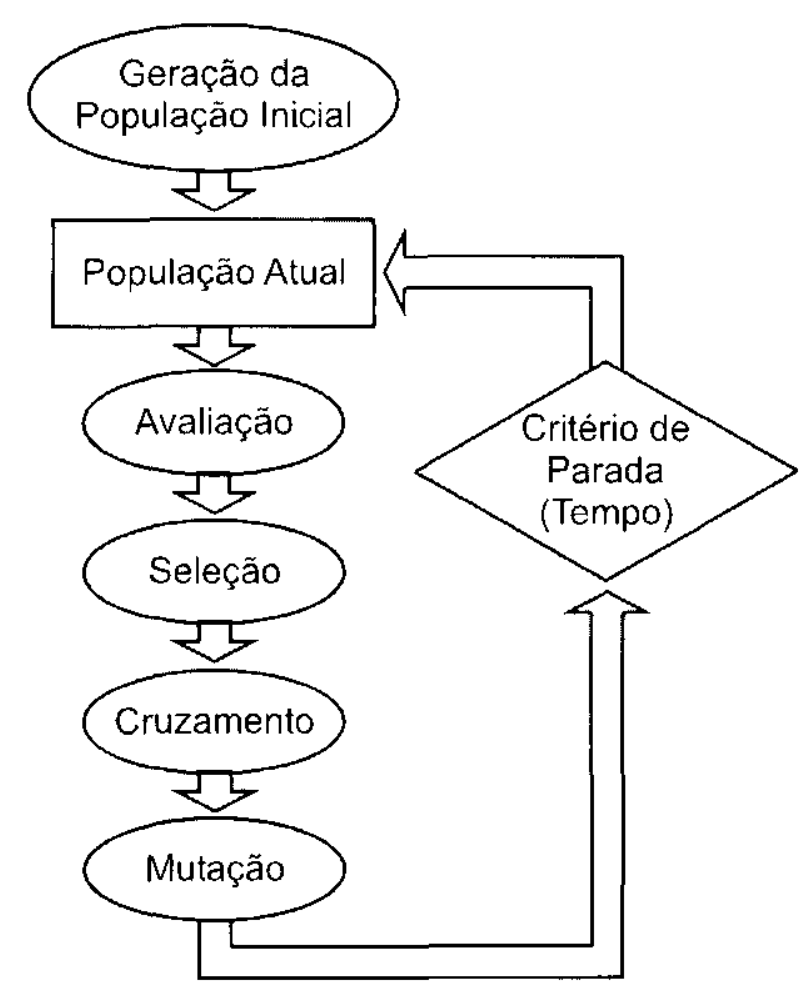

Figura 6.2: Algoritmo genético para Consultas por similaridade.

() critério de parada do algoritmo genctico desenvolvido ó o tempo de processamento. definido pelo usuário. Como versôes alternativas, tambóm podem serr ulilizados como critérios de parada o número de cálculos de distancia realizados, o númoro de acessos a disco on o número de geraçoes do algoritmo genético. 
É importante ressaltar que, quando é passado como parâmetro tempo suficiente, o algoritıno realiza a consulta obtendo o mesmo conjunto resposta do algoritmo de consulta exata.

\subsection{Estrutura de controle}

Nos algoritmos de consulta por similaridade exatos, os nós da árvore métrica são percorridos numa ordem determinada. Com isso, cada nó-folha ć acessado somente uma vez. Nos algoritmos genéticos de consulta por similaridade aproximados, pode ocorrer que um indivíduo da população atual seja idêntico a um indivíluo de uma população anterior, representando o mesno canninho na árvore e chegando ao mesmo nó-folha, já analisado anteriormente. Também porle ocorrer de um indivíduo tor un cromossomo que leva nãu necessariancute até o mesno nó-folha, mas à uma área da árvore métrica que já foi percorrida e analisada.

Para tratar desses problemas, foi criada uma estrutura de controle auxiliar, que armazena as distâncias já calculadas entre o objeto de referência e os representativos dos nós já percorridos da árvore, as quais ainda podem ser necessárias para o algoritmo de consulta.

\subsection{Função Objetivo}

No caso do algoritmo k-NNQ, como são procurados os objetos mais próximos ao objoto do referencia para consultad, procura-se mininizar a distancia cutre os objetos indexados e o objeto de referência na construção do conjunto de resposta do algoritmo genético.

Como foi dito anteriormente, a aptidão de um caminho é calculada bascando-se na "qualidade" do objetos alcançados e pela quantidade de objetos qualificados para compor" conjunto respostic.

Quando um cromossomo representa um caminho factível, ou seja, um caminho que leva até un nó-folha, o algoritmo genético para consultas por similaridade analisa o nó-follaa, qualificaudo esse nó utilizindo sua distinncia ató o objete de referencia para consulta.

Para calcular a distância entre o objeto de referência para ronsulta e um determinado nó da árvore, foram consideradas três alternativas distintas, que diferem quanto aos objetos que são considerados no cálculo da distancia:

- Menor distância: são avaliados os objetos do nó e considera-se como a distancia para esse nó a menor distancia calculada entre un objeto desse nó e o objeto de referencia para consulta:

- Média das distâncias: da mesma Corma que a opção anterior, são avaliados os objetos nó, més considera-se cono a distância para esse nó a média das distâncias calculadas:

- Distância para o representativo: considera-se como a distância para o nó avaliado o valor da distância entre o objeto de referência para consulta e o objeto representativo do nó:

Os experimentos realizados indicaram a terceira alternativa como sendo a melhor, ou scja, deve-se considerar a distância entre o representativo do nó-follá e o objeto cle referência, como 
pode ser visto na Seção 7.2.1. Dessa forma, na implementação final dos algoritmos é considerada a. "distância para o representativo" para calcular a distância entre o objeto de refercincia para consulta e um determillado nó dá árvore

O caso cm que um caminho náa é faxtível, não (hegando a um nó-folha, scrá discutido na Seção 6.5

Como trata-se de $1 \mathrm{~m}$ problema de minimização, é necessário mapear a função de distanncia para a função objotivo [Goldlucrg, 1989]:

$$
f()=D_{\text {Max }}-d()
$$

oncle $D_{\text {Max }}$ é o maior valor da função de distância calculado na geração atual, $d($ ) ó a função de distância métrica calculada e $f($ ) é a função objetivo do algorit mo genético.

Alóm da distância entre o ob jeto de consulta e os objetos do nó-folha, outro fator importante na avaliação de $u m$ caminho é a seletividade do nó-folha, indicada pela quantidade de objetos com que o nó-folha contribuiu para a formação do conjunto resposta.

O peso da seletividade no cálculo da função objetivo é defindo dinamicanente, com pequena contribuição nas primeiras geracōons do algoritmo gencitico e anmento gradativo durante a cvolução.

A seguir temos a definição da função objetivo com análise da seletividade:

$$
f^{\prime}()=f()+f() \times W s \times S e l
$$

onde $f^{\prime}()$ é a nova função objetivo com a inchusão da seletividide, $f()$ é a função objetivo calculada scm a influencia da schtividade (Equação 6.1), Sel representa a seletividado do caminho e Ws o peso dado para a seletividade, definido nas Equaçós 6.3 e 6.4.

A definição do Ws depende de qual o critério de parada vai scr utilizarlo na consulta. Abaixo temos a clefinição de Ws quando utiliza-se o número de geraçoes do algoritmo genético como critério de parada:

$$
W s=\frac{g}{y_{M a x}}
$$

sendo Ws o peso dado à selctividade no cálculo da função objetivo, g é a quantidarle do

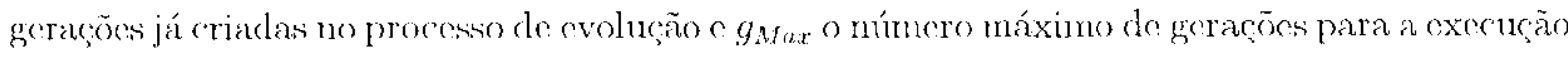
attual.

Com essa definição, a seletividade não influencia no inicio la execução do algoritmo, tendo crescimento lincar durante a evolução. De acordo com os outros critérios de parada, Ws é definido de forma sinilar, cono por exemplo, considerando-se o criterio de parada como tempo de exernção:

$$
W s=\frac{t}{t_{M a x}-}
$$

sendo $W s$ o peso da scletividade, l o tempo decorrido no processo de evolução até a geração 
atual e $t_{M a x}$ o tempo máximo para a execução da consulta.

\subsection{Tratamento de indivíduos infactíveis}

Após a aplicação dos operadores genéticos de cruzamento e mutação, ou inicialmente, depois da formação da população inicial, os indivíduos gerados pelo algoritmo genético podem ter cromossomos que levem a caminhos infactíveis na árvore.

Os caminhos podem ser infactíveis por dois motivos:

- os caminhos representados pelo cromossomo passam por nós inexistentes;

- os caminhos representados pelo cromossomo passam por nós que podem ser podados utilizando-se a propriedade de desigualdade triangular.

Quando nós incxistentes na árvore cstão represcntados pelo cromossomo de um indivíduo, como na Figura 6.3a, a técnica utilizada foi a substituição do gene que representa este nó inválido pelo gene mais próximo do original e que represente um nó válido na árvore. como pode ser visto na Figura $6.3 \mathrm{~b}$

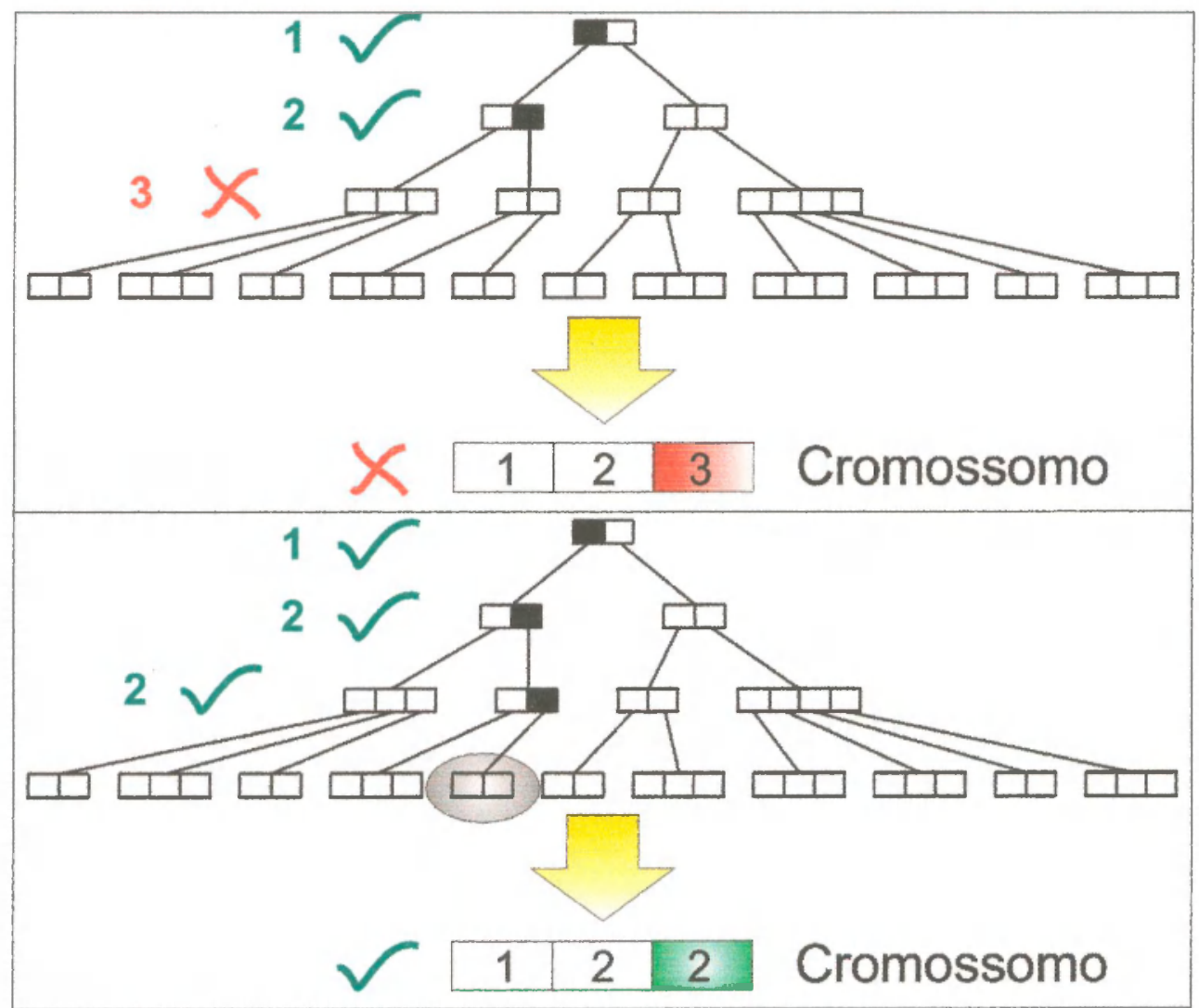

Figura 6.3: a)Cromossomo infactível; b)cromossomo corrigido

Já no segundo caso, quando o indivíduo tem um cromossomo que representa um caminho que leva a uma subárvore que pode ser podada utilizando-se a propriedade de desigualdade triangular, foram desenvolvidas duas técnicas: correção dos caminhos que podem ser podados e função objetivo com aplicação de penalidades. 


\subsubsection{Correção dos caminhos que podem ser podados}

Com esta técnica, no final da fase de avaliacão dos caminhos (Figura 6.2), todos os cromossomos representam caminhos que levam a nós-folla da árvore, a não scr no caso de todos os cauninhos lactíveis já terem sido percorriclos, tendo sido realizada, nesse caso, una consilta com obtenção do conjunto-resposta exato.

Quando, durante a fase de avaliação, um caminho passa por um nó que pode ser podado pela aplicaçăo da propriedade de desigualdade triangular. ou então leva a um nó raiz de uma subrirvore onde já esgot ou-so as possibilidades de exploraçáa, csse nó é substituído por un out to que seja factível, ou scja, não porle ser postarlo e leva a uma subárvore válicla.

Esse nó válido é procurado entre os nós "irmãos" do nó inválido. No caso de não haver mais nenhum nó irmão factível. sobe-se um nível na árvore. repetindo o mesino mecanismo no nível superior. Com isso, a subárvore onde foran esgotadas as possibilidades de busca ć marcada como inválicla na cstrulura de controle. impedindo uma futura tentativa de cepplorá-la.

Portanto, nesses casos, o cromossomo original é modificado, passando a representar um caminho factível que leve até um nó-folha.

Pode-se considerar a busca por um caminho factível no caso do cromossomo representar um caminho infactível, como um aprendizado [Concilio, 2000]. A modificação do código genético (cromossomo) bascada nesse aprendizado, como aconteco na implementação do algoritmo genétice para consultas aproximadas, pode ser considerada uma forma de evoluçáo Lamarkista (bascada na teoria de Jean-Baptiste Lamarck, em que a influencia do anbiente produz nudanças nos individuos, gue podem transmiti-las para seuts descendentes). Também existen a possibilidade da não modificaçăo do código genélico. utilizando-se o aprendizado apenas para calcular a função objetivo do individuo sem modificar seu cromossomo, continuando nesse caso a evolução sendo Daruiniana (baseada no mescanismo de seleção natural de Charles Darwin). Vários fenòmenos associados com a combinação de aprendizado e evolução são coletivamente conhecidos como Efcito Baldwin[Whitlcy ct al.. 1991]. Nos algoritmos implementados foi utilizada a técnica de modifiengão do código genético.

\subsubsection{Função objetivo com aplicação de penalidades}

Essa técnica busca penalizar os indivíduos con cromossomos que representam caminhos infactíveis, que não atinjam um nó-folha válido.

Como foi apresentado na Seção 6.4, a função objetivo é calculada a partir da distância do objeto representativo de um nó-folha ao objeto de consulta, e da seletividade desse nó. No caso en questão, o caminho infactível não leva a utn nó-folha, portanto a soletividade do caminho é nula, não contribuindo para o cálculo da função objetivo, que baseia-se somente na distância entre o objeto de consulta o o nó-índice de maior profundidade ná árvore alcançado pelo canninho indactível.

Mesmo com a utilização desse cxpediente, é dada una chance de aprendizado ao indivíduo em questão. Se um nó é inválido, são analisados os irmãos desse nó, e se algum dclos for válido, este substitui o nó inválido e o cromossomo ć alterado. É nuito comum que um individuo muito 
bem adaptado numa geração seja inváliclo na geração scguinte, pois já foi percorrido e esgotado scu caminho. Desta forma. pode ter-se a falsa impressão de que a área não seja promissora.

Essa estratégia também é indicada devido ao modo como os nós săo lidos do disco, comentados em 6.7, sendo que os immãos do nó inváliclo já tên suas distancias calculadas de cualquer forma, osuas avaliaçoes nöo implica em urn custo computacional adiecional significativo.

Por exemplo: um caminho infactível pode alcançar o quinto nível de una árvore que tenha altutra oito: pois o nó-ínclice do sexto nível representado pelo cromossomo e ainda todos sens "irmãos" são inváliclos. Nesse caso, utilizal-se para o cálenlo da funcäano objetivo a distància entre o objeto de consul ta e o último nó-índice váliclo oncontrado no caminho, nesse caso o do quinto nível da árvore.

$A$ penalidale a ser aplicada é relativa ao nivel que o caminho consceguiu alcancar em sua incursão na árvore, senclo que quanto majs próximo do nó-folha esteja o nó-índice alcançado pelo caminho, menor a penalidade. A aplicação das penalidades é feita da seguinte maneira:

$$
f^{\prime}()=f() \times P()
$$

onde $f^{\prime}()$ é a nova função objetivo com a aplica(̧ão cla penalidade, $f()$ é a funçãa objetivo

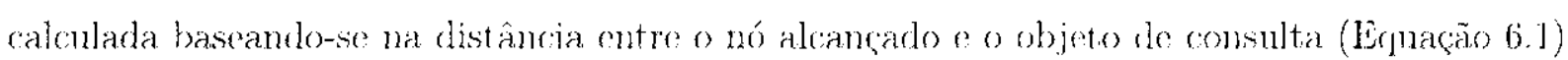
c $P($ ) representa a penaliclade, sendo:

$$
P()--\frac{1}{(h \cdots l) \times W p}
$$

sendo ha altura da árvore, lo nível atingido pela incursão do caminho inlactível nárvore e $W$ o peso dado à penalidade.

Inicialmente $W p$ ć definido com o valor 1, mas pole ter seu valor aumentado ou dinimúclo. gerando penaliclarles mais ou menos severas.

\subsection{Algoritmos desenvolvidos}

() Algoritmo 6.6.1 apresenta o funcionamento básico dos algoritmos para comsultas por similaridacle aproxinndas que foram desenvolvidos.

A populacana inicial é gerada aloatoriamente (linla 1), e os indivíduos gerados são, em seguida, avaliados. A avaliação é feita com a incursão na árvore segnindo o caminbo representado pelo cromossomo de cada indivíduo. (O procedimento Avalia(Pop) posle ser realizado de duas manciras, diferinde quanto ao tratamento dos indivíduos invádidos, e apresentadas nos Algoritmos 6.6 .2 e 6.6 .3 , detalhados a seguir

Após a avaliação dos indivíduos da população, são solecionados pares de inclivíduos para reprodução (linha 5 e 6 ), que seräo submetidos aos operadores genéticos de cruzannento o mutação. A seleção. como foi dito antes, utiliza a técnica da roleta.

Por fim, os indivíduos gerados, armazenados nd população anxiliar Aux Pop, são copiados para população corrente Pop, o em seguida são avaliados para o recomeço do ciclo do algoritmo genético. 
Esses procedimentos são repctidos ciclicamente gerando várias gerações de indivíduos ató que a condição de parada scja verdadeira, ou seja. o tempo de exernçáa disponível termine

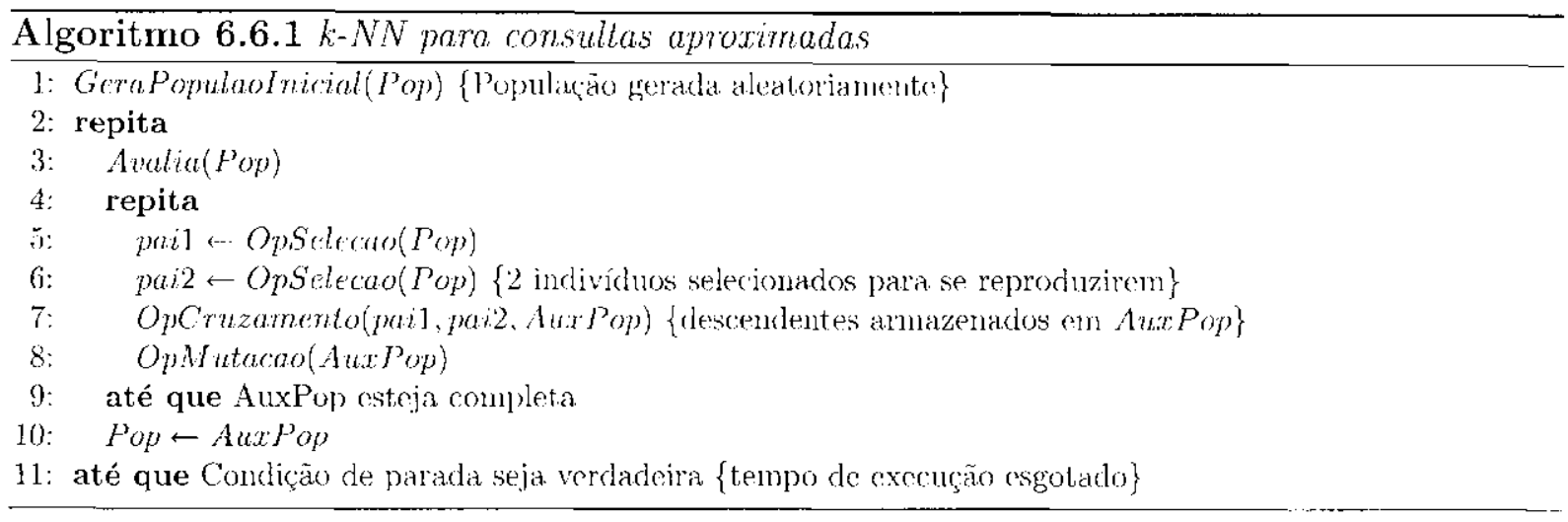

No Algoritmo 6.6.2 é apresentado o procedimento Avalia (Pop) utilizando Algoritmo de reparação, discutide na Secão $6 . \overline{5}$.

$D_{M u}$ armazena o maior valor da função de distância calculado na geracão atual, no ó um ponteiro para subárvores, e aponta inicialmente para a raiz da árvore. Considera-se no algoritmo como *no sendo o conteúdo da subárvore apontada por no. Portanto *nó(0) aponta para a subárvore apontada na primeira entrada do nó.

Para cada um dos indivíduos da população, é tealizada urna incursão na árvore, com o objetivo de atingir um nó folhı. Os indivíduos ind tềm os atributos de distância, seletiviclade c. aptidào (fitress).

A incursão ć realizada de acordo com o caminho representado no cromossomo de cada individuo.

Se un gene do cromossomo indica uma subárvore que não scja válida. procura-se por uma subárvore válida no mesmo nó (linha 9). Se é econtrada. o geno (antes inválido) do cromossomo original é modificado (linha 11), passando a representar o caminho que leva a subárvore válida selecionada, e a incursão continua no nivel seguinte. Se não é encontrada nenhuma subárvore válida no mesmo nó, é necessário que se suba um nível na árvore (linha 17) e repita-se? a busca por uma outra subárvore que scja válida, agora no nível superior. A subárvore com possibilidades de busca esgotadas é marcada como inválida (linha18).

So a raiz da árvore tem suris possibilidades de busca osgotedlas, o algoritmo de consulta cnecrado, o a resposta obtida polo algoritmo ć cxata (linha 15).

Ao chegar na linha 19, no aponta para um um nó-folha, que será examinado para a composição do conjunto resposta e cálculo da adaptação (fitness) do indivíduo. Na linha 27 é realizado o cálculo do fitness de cada indivíduo, segundo a. Equação 6.2

Ao final do procedincrito Avalia(Pop) do Algoritmo 6.6.2, a não ser que a consulta tenha sido cncerrada por ter pesquisado todos os nós válidos (linha 15), todos os indivíduos tên suas aptidõess calculadas e estão prontos para serem submetirlos ao processo de seleção.

No Algoritmo 6.6 .3 ć aprescntado o procedimento Avalia $\left(P^{P} o p\right)$ utilizancio a aplicação de penalidades no cálculo da função objetivo do algoritmo genético, técnica também apresentada nà Seçäo 6.5 . 


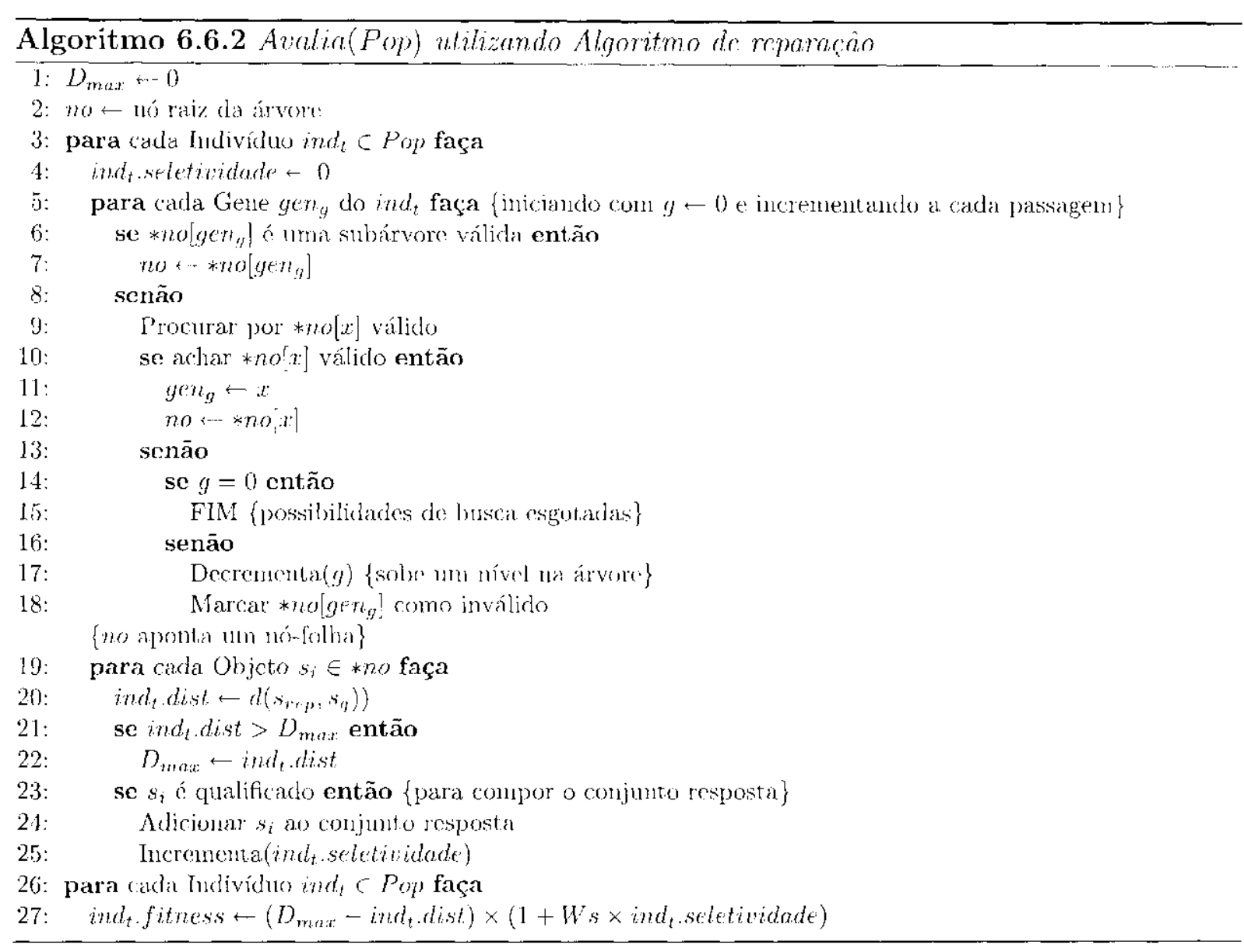

() algoritmo tem mecanismo semelhante ao anterior, diferindo no seguinte ponto: quando um gene indica una subárvore que não seja válida, e näo é encontradia nemhuma subárvoro válida no mesmo nó, o algoritmo interrompe sua incursão na árvore, marcando a subárvoro como inválida e calculanulo a distância até o nó-indice alcançado ná incursão (contro linhas 21 e 28). É também armazenado pelo indivíduo o nível alcançado na incursão, pois esse valor será utilizado na aplicação da penalidade no cálculo da função objetivo (linha 40), segundo as Equacoes 6.5 e 6.5

\subsection{Modificações para redução de acessos a disco}

Os resultados dos experimentos realizados inicialmente mostravam que os algoritmos desenvolvidos apresentavam uma boa aproximação do conjunto resposta exato com um número reduzido de cáletulos do distância.

Por ontro lado, a redução do nimero de cálculos de distância não é proporcionalmente

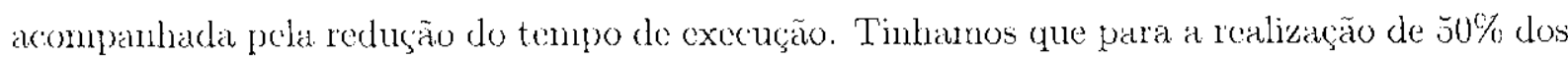
áleulos de distâneia da busca exata cram necessários, em média. mais de $75 \%$ do tompo do execução da buscia exata.

Com a análise do algoritmo e de outros experimentos realizados foi constatado que apesar da menor quantidade de cálculos de distancia em relação à consulta exata, os algoritmos inicidmente desenvolvidos apresentavan un número consideravehmente maior de accssos a 


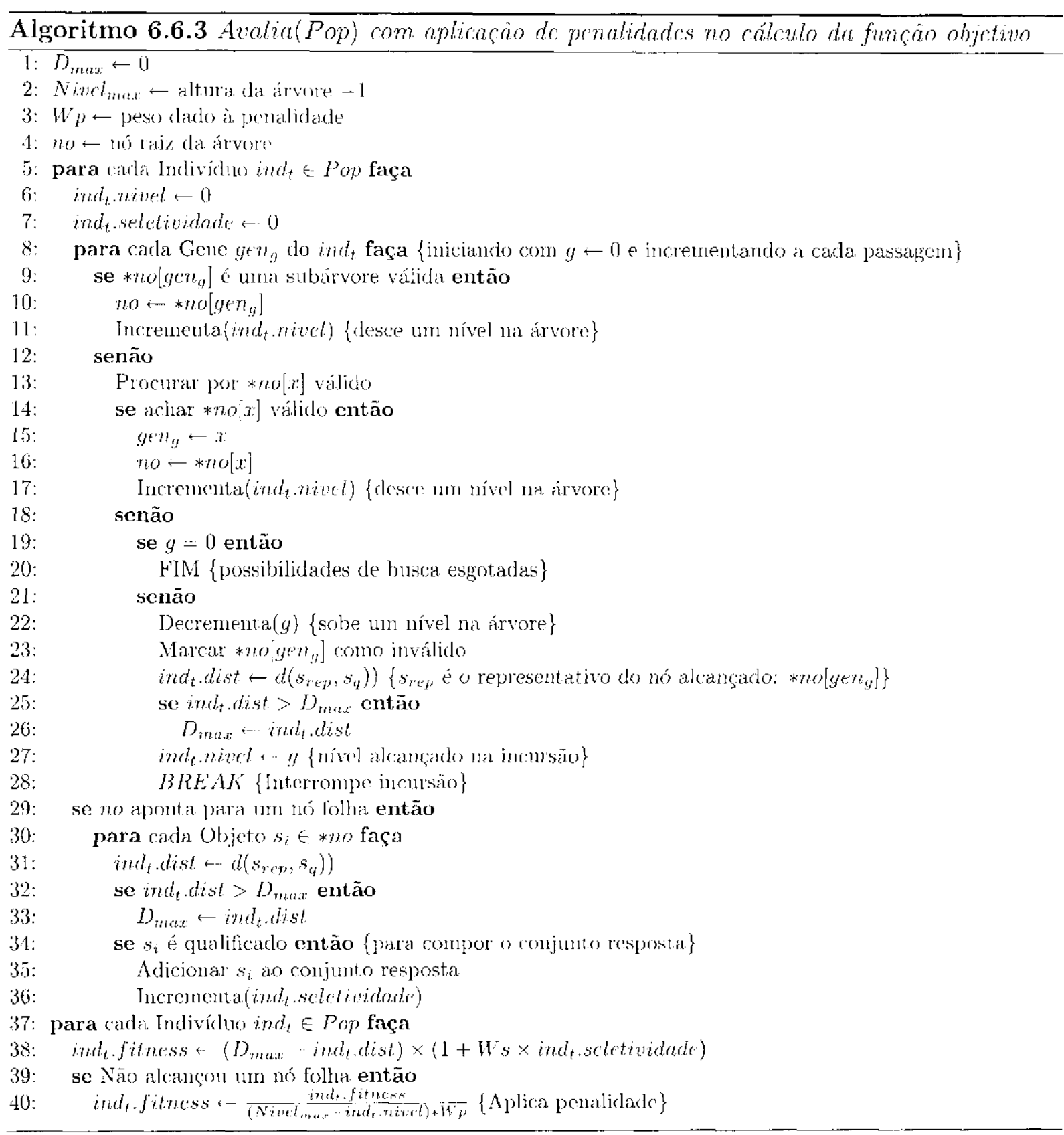

clisco. Isso se deve a não existencia de uma ordem definida para o percorrimento da árvore de indexação, fazendo com que as páginas fossem relidas do disco.

Para diminuir a quantidade de acessos a disco e consequentemente o tempo de execuçào dos algoritmos, foram feitas algurnas modificaçóes nos algoritınos.

Os algoritmos desenvolvidos inicialmente calculavam as distâncias apenas para as páginas da árvore de indexação que estavam representadas por um cromossomo, ou seja, quando uma. bágina cra liela do disco, calculava-se apenas a distância entre o objeto de referência e a página filha indicada pelo cromossono atual. que seria percorrida pela incursão ao próximo nível da árvore. Esse experliente difere daquele utilizado no algoritmo tradicional de k-N.NQ cm que, quando uma página é lida do disco são calculadas as distâncias para todas as "págináa fillas" que nào podem ser podadas, de modo que a página lida näo precise ser recuperada novamente 
do disco.

Com as modificaçós foram criados três novos métodos que tratam do acesso a disco.

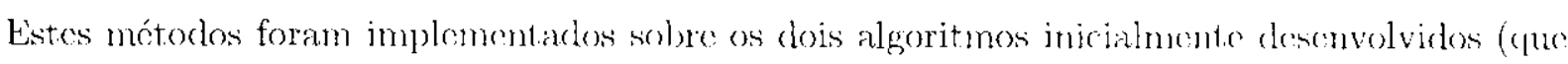
variavam quanto ao tratamento do indivíduos infactíveis), clando origem a seis novos algoritmos.

Os dois primeiros métodos mantên o expediente dos algoritmos iniciais, calculando a distância apenas para a página que será acessada na incursão atual, com a inchusão de medidas

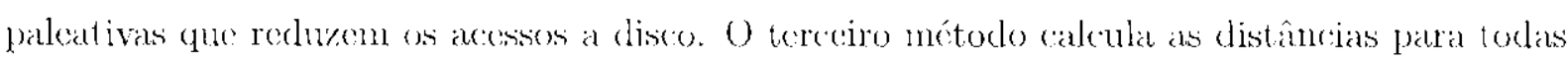
as págiuas filhas, cenotando a página atual. Os trôs métodos desenvolvidos são apresentados a seguir.

\subsubsection{Método 1: Organização da População}

As páginas lidas em todos os níveis da incursão atual são mantidas em memória mesmo depois do término da incursão e avaliação do nó-folha, de forma que só seräo subtituíclas casoso näo sejann utilizarlas durante a próxima incursão. Dessa forma, (itso o cromossono respomsável pela próxina incurtão seja pareciclo com o cromossomo atual, páginas utilizarlas podern ser reutilizadas, sem a nocessidade de releitura.

Portanto, a população atual é organizada de forma que cromossomos semelhantes sejam avaliados consecutivamonte pelo algoritmo genético. Com isso, o núnero de aresses a clisco é reduzido, principalnnente e'm estágios mais avançados da evoluçăo, onde diminui a diversidade popularional o os cromossomos temelem a ser mais parecidos, com a dinimuçäo da variabiliclacto genétic:a.

\subsubsection{Método 2: Caches por nivel}

Seguinclo idéia parecida com a clo primeiro método, esse método mantém caches de memória para caula nível da árvore de inclexação. () tamanho desse cache foi definido a partir de resultados empíricos, ondo o melhor valor encontrado lica cntre 1.5 e 2 vezes o tamanho da populaçào utilizaclo no algoritmo genético.

Quendo uma página é requisitadia, cla ó buscada inicialmente no cache relativo ao nível que deve ser alcançado. So não for encontrada, é efetuada a leitura do clisco o a página é armazenàda no cache do seu nivel na árvore de indexação.

P'ara a manutenção dos caches foi utilizada a política de substituiģäo de páginass "Menos Recentemente Usadas" (Lrast Recently Used - LRC), que substitui a página que está sem acestio há mais tempo.

\subsubsection{Método 3: Esgotamento da página lida}

Esse método utiliza mecanismo semelhante a utilizado no algoritmo k-NNQ tradicional para consultas exatas. Quando uma página é lida do disco são calculadas as distâncias para todas as "páginas filhas" que näo podem ser podadas pela propriedade de clesiglialdade triungular.

As distâncias calculadas e ontras informaçoces sobre as páginas filhas são armazenadas em memória, garantinclo portanto que uma página lida não será requisitada novamente.

Foram realizados vários experimentos, apresentados na Seção 7.2.1. que mostraram que 
os algoritmos implementados com o método 3 ("Esgotamento da página lida") aprescntam os melhores resultados. Portanto. o método de "Esgotanento da página lida" foi o escollido para a implementação final dos algoritmos.

\subsection{Estratégia Elitista}

Depois de implementados c testados os algoritmos genéticos para consultas aproximadas, foi desenvolvida versões dos algoritmos que aplicavam a estratégia elitista, ou seja, que garantem o inclivíduo mais apto de mua geração na geração seguinte.

O elitismo foi implementado de maneira que o melhor jndivídno da geração atual seja transferido automaticamente para a geração seguinte como um indivíduo adicional, não descartando assim nenhum inclivíduo gerado pela aplicação dos operadores genéticos.

Por excmplo, para uma execusão do algoritmo genético com tamanho do populacão definido como 10, o melhor indivíduo de cada geração é copiado para a geração seguinte como sendo o $11^{\circ}$ indivíduo da população.

Com a aplicação da estratégia elitista, o esquema do algoritmo genético para consultas aproximadas por similaridade apresentado na Figura 6.2 ó modificado, como poede ser visto na Figura 6.4

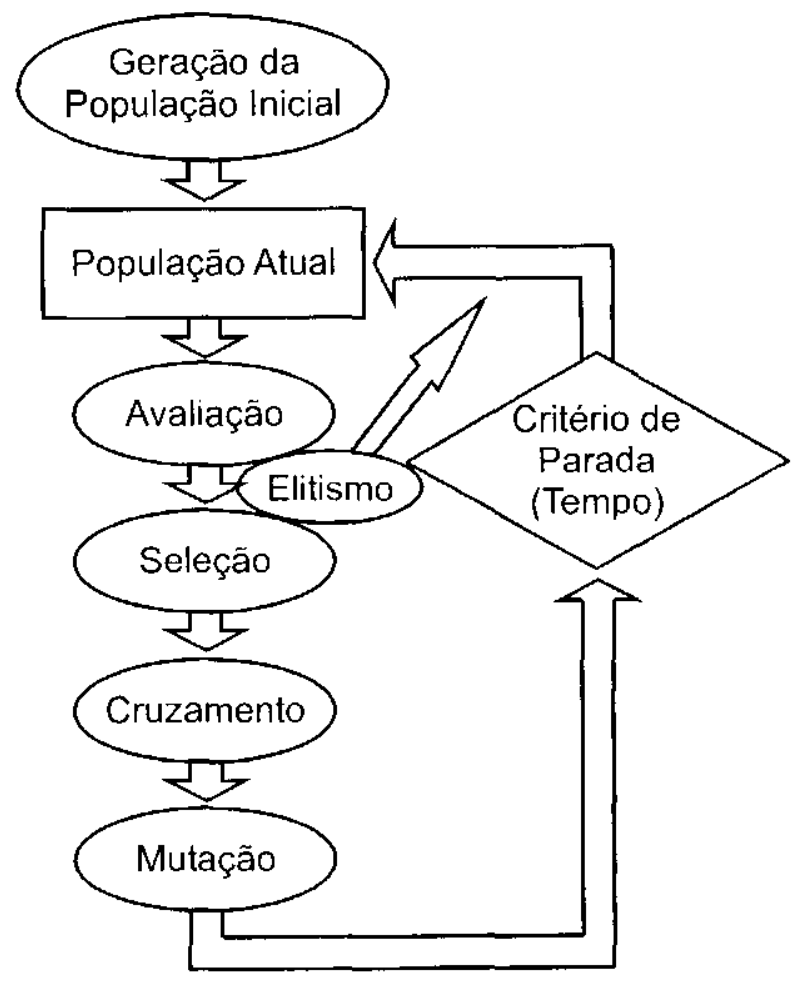

Figura 6.4: Algoritmo genético para Consultas por similaridade com aplicação da estratégia elitista. 


\subsection{Considerações Finais}

Consultas exatas por similaridade en grandes bases de dados complexos tencle a wer proibitiva, pelo seu alto custo computacional. Para tratar desse problema, neste trabalho foram desenvolvidos algoritnos para recuperação aproximada do conjunto resposta de consultas por similaridade utilizando algoritmos genéticos.

() algoritmo genético desenvolvido procura pelos melhores caminhos na árvore, agilizando a formação do conjunto resposta.

Para implementaçào definitiva nos MAMs Slim-lree foram desenvolvidos 2 algoritmos, que diferem quanto ao tratamento de inclivíduos infactíveis. No primeiro, é utilizado um algoritmo de reparação para os caminhos infactiveis, tomando-os válidos. No segundo algonitmo, são aplicadas penalidades aos indivíduos infactiveis.

Foram ainda utilizados alguns artifícios para agilizar a execução dos algoritmos desenvolvidos, como a utilização de métodos para redução do acesso a discos e a aplicação da cotratégia elitista nos algoritmos genéticos. 


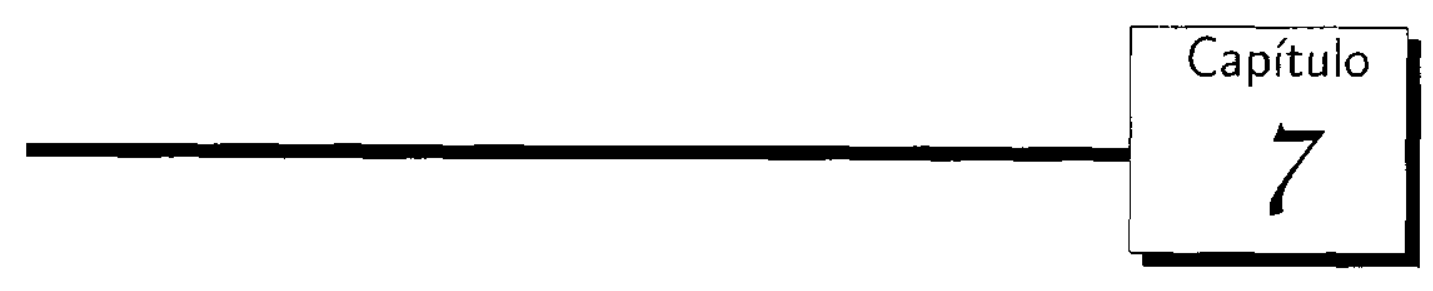

\section{Experimentos Realizados}

O

s métodos de indexação para dados complexos tendem a apresentar nós com sobreposiçäo, dificultando a modolagen de sua complexidade durante as consultas. Comparar analiticamente métodos de acciso voltados para consultas por similaridarle 6 quase inviável, sendo poucos os trabalhos que apresentam equacões do estimativa de custo. Esta deficiência se deve à dificuldade em modelar a distribuição dos dados e à complexidade da estrutura interma clos métodos [Santos, 20033].

A abordagem encontrada na literatura comsiste em comparar os novos métodos de acesso aos existentes, através de experimentação.

Com isso, os algoritmos desenvolvidos foram avaliados e comparados através de experimentação, seguindes a aloordagem encontrada na hiteratura para comparação de novos métodos de acesso aos existentes. O processo de experiment ação envolve a colcta c comparação de medidas de desempenho obtidas a partir de testes práticos com os algoritmos desonvolvidus.

\subsection{Materiais e métodos}

Os algoritmos desenvolvidos paja consultas aproximadas por similaridade foram testarlos para validação e avaliação de desempenho com uma grande variedade de conjuntos do dados. tanto reais quanto sintiéticos, que diferem quanto ao número de dimensões, o tamanho dos objetos e do conjunto de daulos, distribuição dos dados no espaço e função de distâne ia utilizada.

Os conjuntos de dados utilizados são descritos na Tabela 7.1 .

() conjunto de dados "MRTHistogramas" é composto de imagens de várias partes do corpo

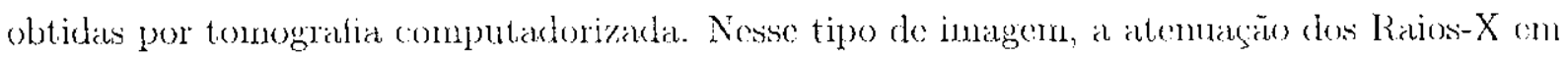
diferentes tecidos do corpo é medirla usando a excalia de IJounefficls, onde os valores varian entre -1000 e +1000 . Portanto, são considerados histogramas com 2000 dimensões.

Os conjuntos "Random50", "Randonn128" e "Cluster128" foram desenvolvidos pela feramenta DBGen [Buejo et, al., 2004], desenvolvida uo GBDI-ICAC-USP.

Para mostrar a distribuigáa dos objetos dos conjuntos de dados utilizados nos experimentos, foi gerada a visnalização do cada conjunto utilizando-se o algoritmo FastMap [Faloutsos \& Lin, 1995], mapeando os objetos do espaço métrico para um espaço enclidiano 
Tabela 7.1: Descrição dos conjuntos de dados utilizados nos experimentos.

\begin{tabular}{|c|c|c|c|c|}
\hline Nome & Nro. Objis & Dimensão & Mŕtrica & Descrição \\
\hline Randomino & 5000 & 50 & $L_{2}$ & $\begin{array}{l}\text { Dakros sintéticos aleatorianente } \\
\text { distribuídos }\end{array}$ \\
\hline Random 128 & 10000 & 128 & $L_{2}$ & $\begin{array}{l}\text { Dadios sintéticos alenioriamonte } \\
\text { distribuídos }\end{array}$ \\
\hline Cluster128 & 20000 & 128 & $L_{2}$ & $\begin{array}{l}\text { Dados sintéticos com } 8 \text { nuvens } \\
\text { de agrupamentos }\end{array}$ \\
\hline Palavras om Inglês & $\overline{2} 514 \overline{3}$ & Actimentional & $\overline{L_{\text {Edit }}}$ & $\begin{array}{l}\text { Conjunto de palavras extraidas } \\
\text { do dicionários dla língua inglesa. }\end{array}$ \\
\hline Histogramas 256 & 3080 & 256 & $I_{2}$ & $\begin{array}{l}\text { Histogrramas de imagens de } \\
\text { Mamografias }\end{array}$ \\
\hline MRTHistogranias & 39740 & 2000 & $L_{2}$ & $\begin{array}{l}\text { Histogramas de imagens de várias } \\
\text { partes do colpo obtiklas por tomografia. }\end{array}$ \\
\hline
\end{tabular}

de 2 dimensões. Tal mapeamento é feito visando preservar as distâncias entre os objetos no espaço métrico original. Dado um conjunto de clados e uma funçào distância, o fastmap mapeia cacla um dos objetos do conjunto on um ponto no espace u-dimensional, geralnente espaços euclidianos de 2 ou 3 dimensões, facilitando a visualizaçăo.

Na Figura 7.1 são apresentadas as visualizações dos conjuntos de dados utilizados nos experimentos.

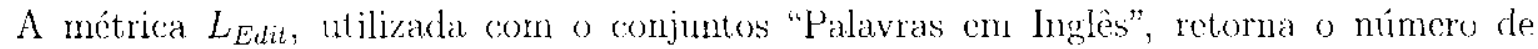

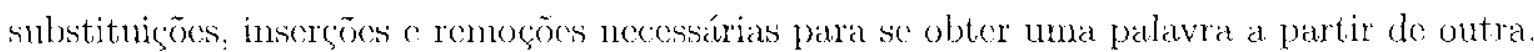

Os resultados foram gerados pelos algoritmos implementados em $\mathrm{C}_{+}+$(Borland $\mathrm{CH}+$ Builder), cxecutados em um computador AMD Athlon XP 2.6GHz, com $512 \mathrm{Mb}$ de $R A M$ (: $40 G b$ de disco rígido, com o sistema operaxional Windous 2000 Professional.

As respostas obtidas pela execucão do algoritmo convencional de consulta exata são consideradas como corretas. A precisão das respostas dos algoritmos de consultas aproximadas f́ dada pela proporção dos objetos recuperados que são considerados corretos.

Em todos os resultados apresentados, os experimentos foram realizados com o tamanho de população do algoritmo genético sendo 10 , a taxa de probabilidade de cruzamento igual a $75 \%$ c a taxa de mutação de $0,5 \%$, valores que mostraram-se adequados para obtenção dos molhores resultados.

Para realização dos testes, os objetos de cada conjunto de dados foram aleatorianente "embaralhados", simulando inserções aleatórias, comuns em atividades reais em bancos de dados. De cada um dos conjuntos de dados da Tabela 7.1 foram selecionados aleatoriamente 500 objotos para compor o conjunto cle objetos centrais para consultas. Dos objetos selecionados, 250 foram removidos do conjunto de dados originais. Portanto, metade dos objetos do conjunto de busca pertencem ao conjunto indexado c metade não pertence.

Os gráficos de desempenho apresentados neste capítulo foram gerados con o programa GmuPlot

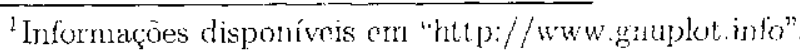




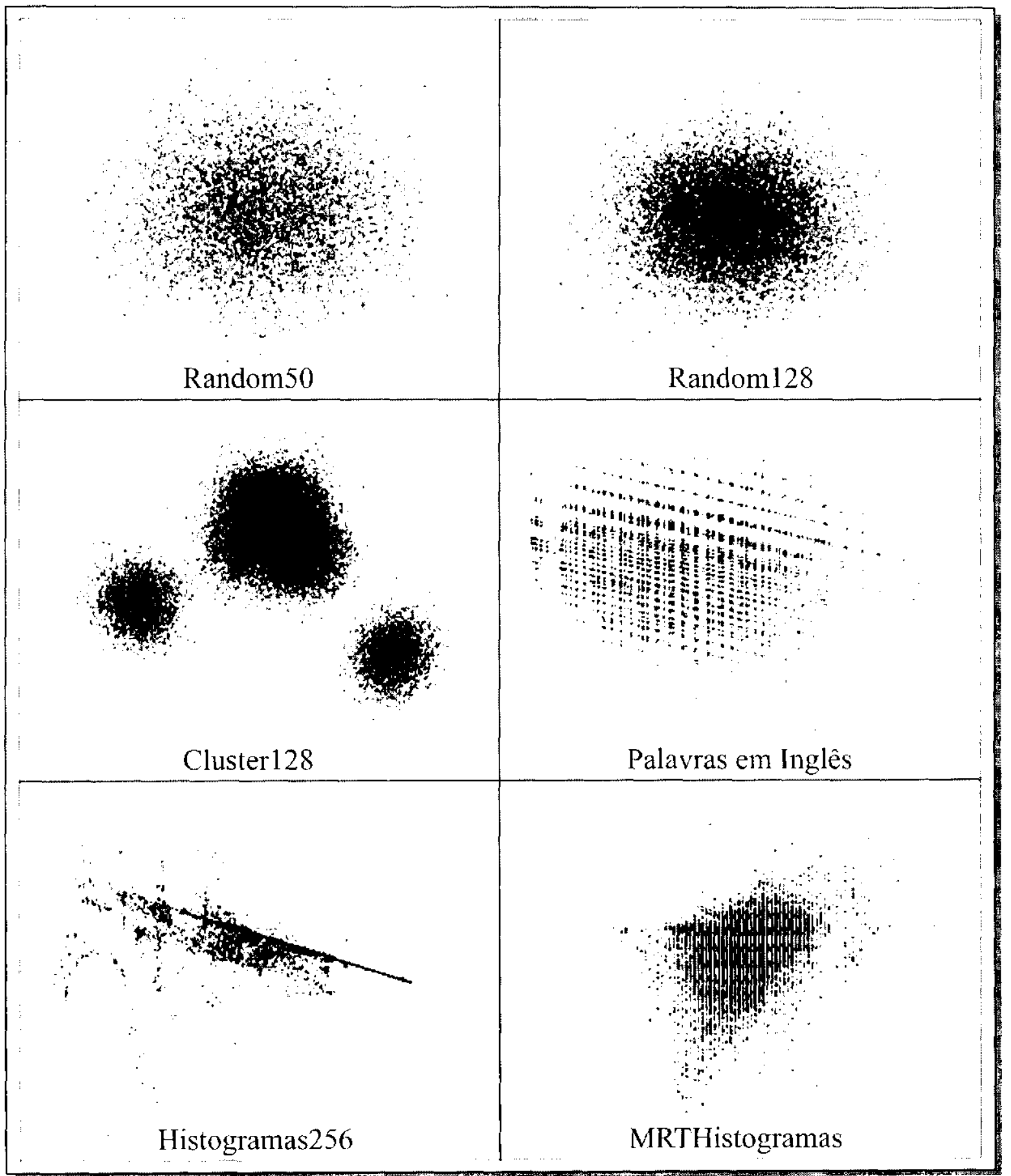

Figura 7.1: Visualização da distribuição dos conjuntos de dados utilizados nos experimentos

\subsection{Resultados e discussão}

Inicialmente serão mostrados os resultados de alguns experimentos realizarlos no docorrer do desenvolvimento do projeto. para escolhas entre implementações distintas. Em seguida, na Seção 7.2 .2 são apresentados resultados de experimentos realizados com os algoritmos delinitivos implementiados. 


\subsubsection{Avaliação dos Algoritmos Iniciais}

No decorrer do desenvolvimento dos algoritmos, em vários momentos apresentaram-se diversas opções para resolver um mesmo problema, com mais de uma possível implementação. Nesta seção apresentamos algumas dessas opções. e as respectivas opções de implementação escolhidas.

Cálculo da distância para nós da árvore

Inicialmente foram consideradas três alternativas para o cálculo da distância entre o objeto de referência para consulta e um nó da árvore, sendo que o valor dessa distância compõe a função objetivo para qualificação do nó:

- menor das distâncias entre objetos do nó e o objeto de referência;

- e média das distâncias de todos os objetos do nó e o objeto de referência;

- distância entre o representativo do nó e o objeto de referência;

$\mathrm{Na}$ Figura 7.2 são apresentados gráficos comparativos entre as três alternativas apresentadas, comparando a precisão das respostas obtidas pelos algoritmos para consultas aproximadas.

No experimento que deu origem aos gráficos da Figura 7.2 foram realizados consultas aos 10 vizinhos mais próximos, variando-se a quantidade de gerações para evolução do algoritmo genético. Cada ponto dos gráficos é resultado da média de 500 consultas com diferentes objetos centrais de consulta, apresentando as precisões alcançadas pelas respostas em relação do tempo de execução. No primeiro gráfico com o conjunto "Histogramas256", foi utilizado o algoritmo que utiliza a função objetivo com aplicação de penalidades, e no gráfico relativo ao conjunto "Random128" foi utilizado o algoritmo que repara os caminhos infactíveis.
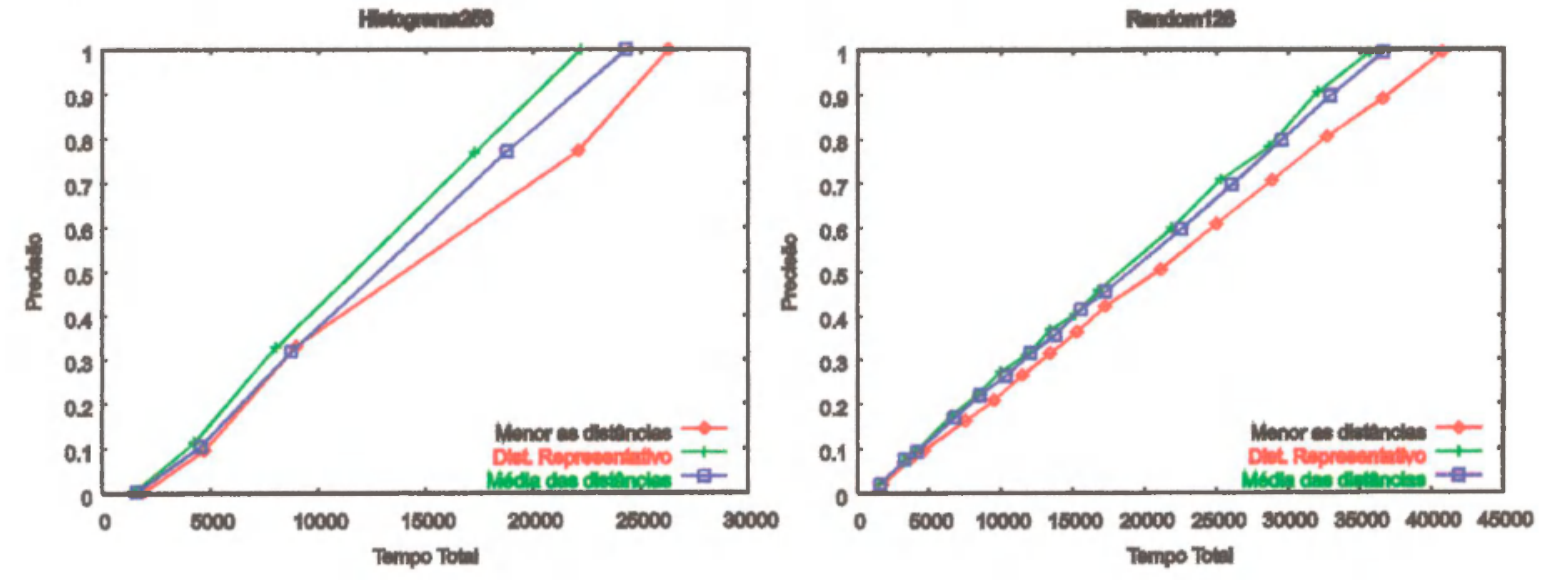

Figura 7.2: Conjunto Histograma256 e conjunto Random128: Alternativas para qualificação de um nó da árvore.

Como pode ser visto, nos dois algoritmos a opção que considera a distância para o objeto representativo alcança a maior precisão em relação às outras duas opções para um mesmo tempo de execução. 
Foram realizados vários experimentos que, em gcral, como aconteceu nos experimentos da Figura 7.2, indicaram a terccira altemativa como sendo a molhor, ou seja, considerando a distância entre o representativo do nó e o objeto de referència. Dessa formal, eswa foi a altermativa cocolhirla para a implomentaran final dos algoritmos.

Modificações para redução de acessos a disco

Como foi dito na Scção 6.7, apesar de os algoritmos implementados inicialmento apresentarem boas aproximaçóes com um númoro reduzido de ráleulos de distância, tais algoritmos deixavam a desejar quanto ao número de acessos a disco

Para melhorar a performanec dos algoritmos, foram desenvolvides trós métodos para reducaúo dos acessos a disco na execução dos algoritmos aproximados:

- Método 1 - Organização da população: organizando a população com o agrupamento de cromossomos parecidos:

- Método 2 - Caches por nível: mantendo caches em momória dos diversos níveis da ¿irvore;

- Método 3 - Esgotamento da página lida: calculando as distâncias para todas as subárvores que não podem ser podadas, garantindo que a página não será lida novramente do disco.

Foram realizados diversos testes com os algoritmos genćticos para consulta aproximada modificados. De acordo com o método utilizado para redução de acessos a disco e o tipo de tratannento dado aus indivíduos infactíveis, os algoritmos podem ser identificados nas legendas dos grálicos dessa segão segundo a Tabela 7.2

Tabela 7.2: Identificação dos algoritmos segundo o método utilizado para redução de acessos a disco e o tipo de tratamento dado aos individuos infartiveis.

\begin{tabular}{|c|c|c|}
\hline Método para redução de acessos a disco & Tratamento dos indivíduos infactíveis & Identificação \\
\hline \multirow{2}{*}{ Algoritmo Inicialmente implementado } & Algoritmo de Correça & Aprox 1 \\
\hline & Funçăo Objetivo com penalidardes & Aprox2 \\
\hline \multirow{2}{*}{ Mélodo 1} & Algoritino de Correção & Aprox3 \\
\hline & Furção objetivo com penalidades & Aprox4 \\
\hline \multirow[t]{2}{*}{ Método 2} & $\Lambda$ lgoritmo de Correção & $\Lambda_{\mathrm{prox}}$ \\
\hline & Fungino Objetivo com peralidades & $\Lambda$ prox6 \\
\hline \multirow[t]{2}{*}{ Mélodo 3} & Algoritmo de Corregâo & Aprox7 \\
\hline & Função Objetivo com penalidarles & Aprox8 \\
\hline
\end{tabular}

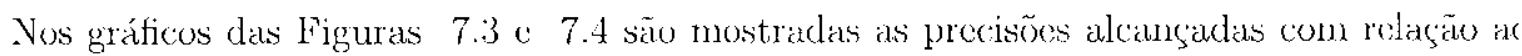
número de cálculos de distancia, quantidade de acessos a disco e tempo de processamento. Em todos os gráficos citados são mostrados também os valores médios obtidos pelo algoritmo de k-NNQ para consultas exatas, com a legenda de Exato. Todos os resultados referem-se a consultas aos 20 vizinlıos mais próximos. 

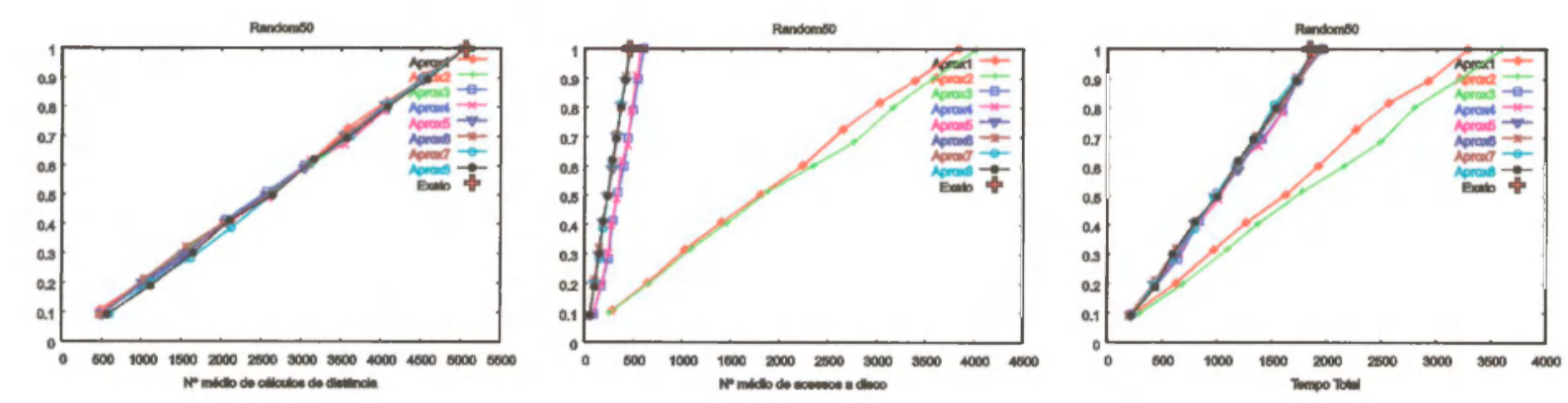

Figura 7.3: Precisão vs. Cálculos de distâncis, Precisão vs. Acessos a disco e Precisão vs. Tempo de execução, conjunto Random50.

Nos experimentos que deram origem a tais gráficos, cada um dos pontos dos gráficos é resultado da média de 50 consultas para o conjunto de Palavras e 100 consultas para o conjunto Random50, com diferentes objetos centrais de referência para consulta.
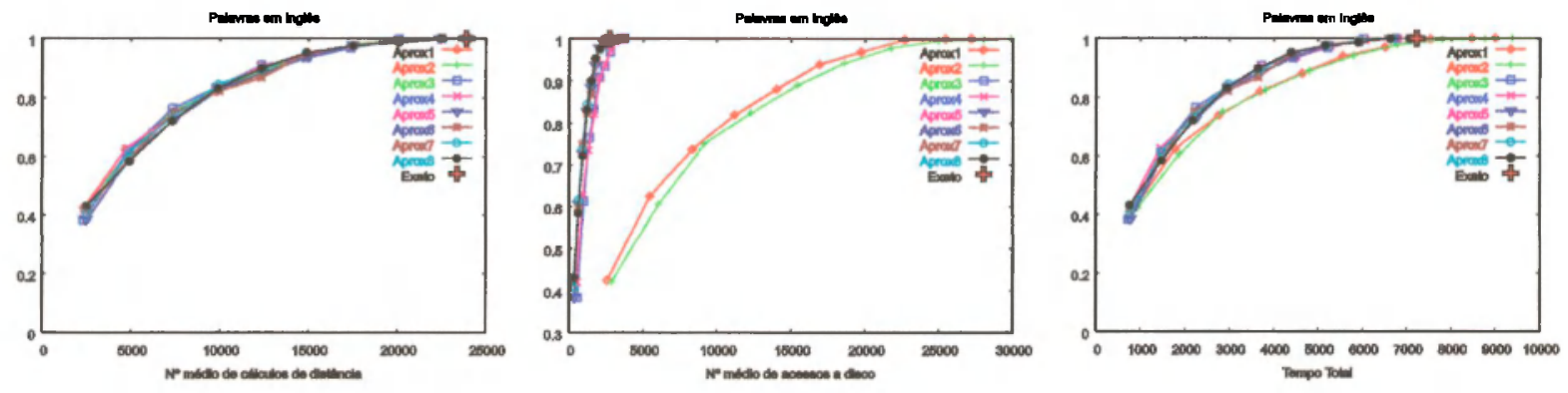

Figura 7.4: Precisão vs. Cálculos de distâncis, Precisão vs. Acessos a disco e Precisão vs. Tempo de execução, conjunto Palavras em Inglês.

Os algoritmos implementados com o método 3 ("Esgotamento da página lida") apresentam os melhores resultados quanto ao número de acessos a disco, alcançando melhores precisões com menos acessos. Quanto ao tempo de execução, os resultados obtidos pelos métodos 2 e 3 são praticamentes os mesmos, com leve vantagem para o método 3 . Portanto, pela superioridade dos algoritmos implementados com o método 3 , este foi o escolhido para a implementação definitiva dos algoritmos de consultas aproximadas.

\section{Aplicação da estratégia elitista}

Nos experimentos dos gráficos da Figura 7.5 foram realizadas consultas aos 10 vizinhos mais próximos, variando-se a quantidade de gerações para evolução do algoritmo genético. Cada ponto dos gráficos é resultado da média de 500 consultas para com diferentes objetos centrais de consulta, apresentando as precisões alcançadas pelas respostas em relação do tempo de execução.

Os gráficos da Figura 7.5 mostram que a aplicação da estratégia elitista aumenta a precisão das respostas obtidas no mesmo tempo de execução. As melhoras são verificadas tanto no algoritmo que utiliza função objetivo com penalidades como no que utiliza algoritmo de reparação para os indivíduos infactíveis. O mesmo comportamento foi verificado com outros conjuntos de dados. 

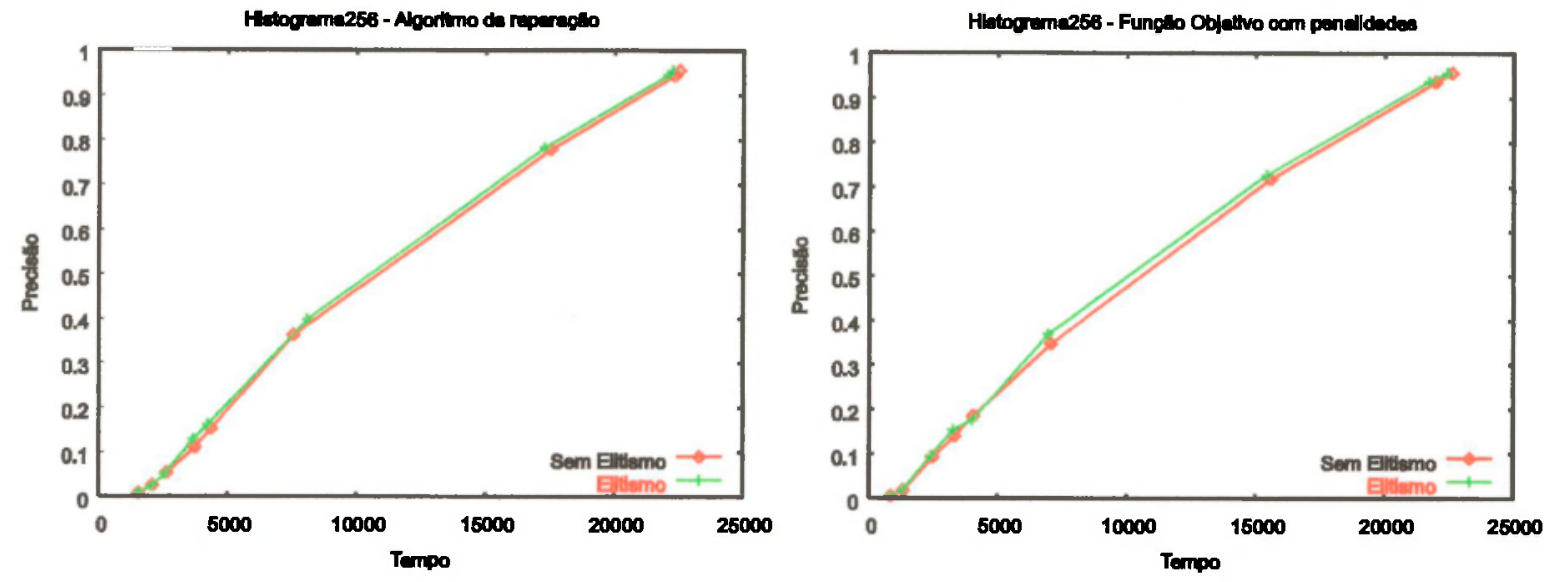

Figura 7.5: Conjunto Histograma256, aplicação da estratégia elitista. a)Algoritmos de reparação; b) Função com penalidades

Portanto, a estratégia elitista foi aplicada na implementação definitiva dos algoritmos desenvolvidos.

\subsubsection{Avaliação dos Algoritmos definitivos}

De acordo com as escolhas de implementação feitas no decorrer do projeto, citadas na seção anterior, foram desenvolvidos 2 algoritmos para implementação definitiva nos MAMs Slim-tree. Os dois algoritmos diferem somente na maneira como são tratados os indivíduos infactíveis: utilizando um algoritmo de reparação ou funções objetivo com aplicação de penalidades (detalhes na Seção 6.5).

Os algoritmos desenvolvidos foram comparados entre si, e também com o algoritmo de consulta exata dos MAMs Slim-tree. A motivação foi analisar o desempenho dos algoritmos desenvolvidos de acordo com o tempo de execução disponível, contrastando com o algoritmo para consultas exatas.

No experimento que deu origem ao gráfico da Figura 7.6 foram realizadas consultas aos 10 vizinhos mais próximos, variando-se a quantidade de gerações para evolução do algoritmo genético, representando a média de 500 consultas com diferentes objetos centrais de consulta, apresentando as precisões alcançadas pelas respostas em relação do tempo de execução registrado.

Como pode ser visto, para alcançar a formação do conjunto resposta exato, os algoritmos para consultas aproximadas utilizam aproximadamente o mesmo tempo do algoritmo de consulta exata. No caso deste experimento, o algoritmo utilizando a função objetivo com aplicação de penalidades alcançou a resposta exata em menos tempo do que o algoritmo de consulta exata.

Para uma melhor avaliação dos algoritmos para consultas aproximadas, os gráficos a seguir apresentam as precisões obtidas limitando a execução dos algoritmos à frações do tempo exigido para execução do algoritmo de consulta exata. O algoritmo de consulta exata é executado repetidas vezes com diferentes objetos de referência para consulta, para a obtencão do tempo 


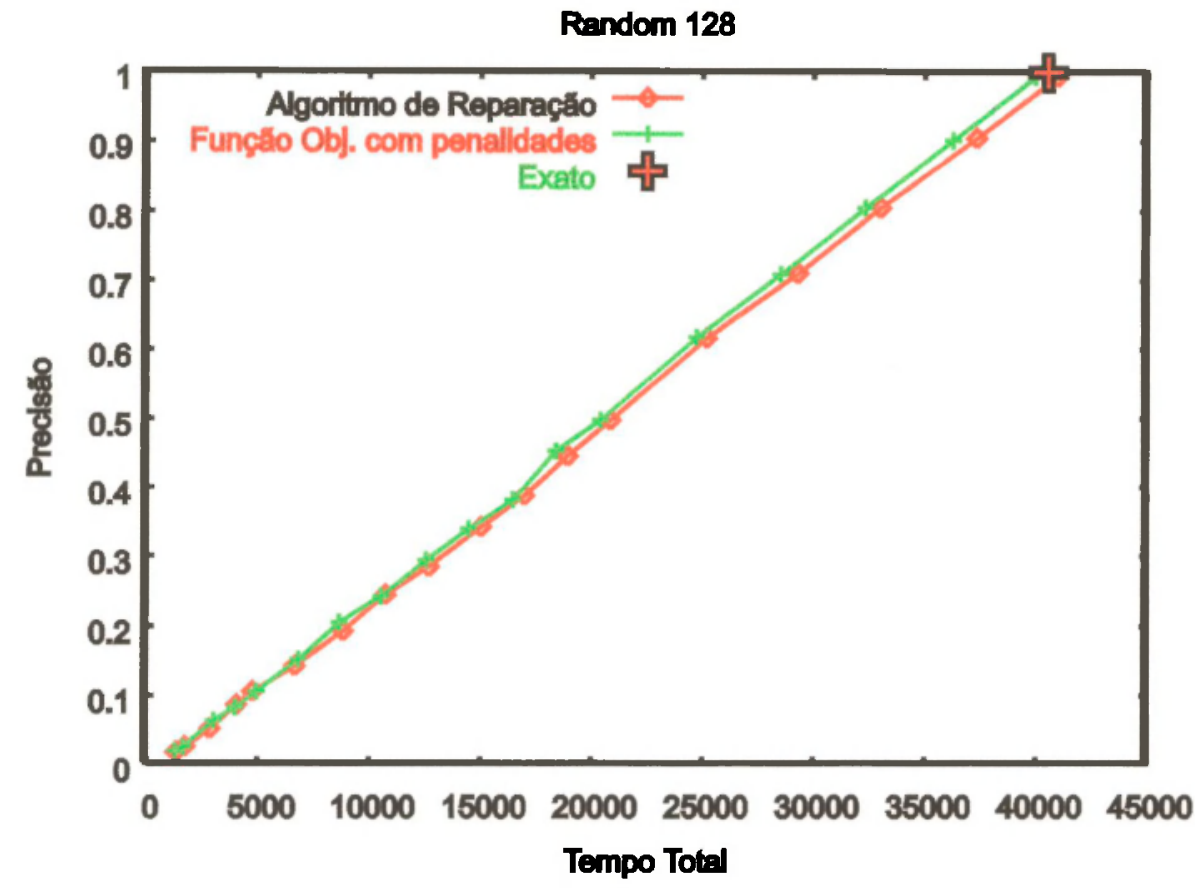

Figura 7.6: Precisão vs. Tempo de Execução, conjunto Random128, comparando as precisões das respostas obtidas pelos algoritmos, variando o número de gerações do algoritmo genético.

médio de execução. Depois, com os mesmos objetos de consulta, os algoritmos aproximados são executados várias vezes, limitados por diferentes frações do tempo médio da consulta exata.

Para a geração dos gráficos da Figura 7.7 foram realizados consultas aos 50 vizinhos mais próximos com o conjunto de dados de "Palavras em Inglês", com o cálculo da média de 500 consultas com diferentes objetos centrais de consulta.

Analizando o gráfico Precisão vs. Porcentagem do tempo de execução da consulta exata, pode-se ver que com $20 \%$ do tempo requerido para uma consulta exata obtém-se aproximadamente uma precisão de $65 \%$ na formação do conjunto resposta, e com $50 \%$ do tempo da consulta exata alcança-se aproximadamente $90 \%$ de precisão para ambos os algoritmos.
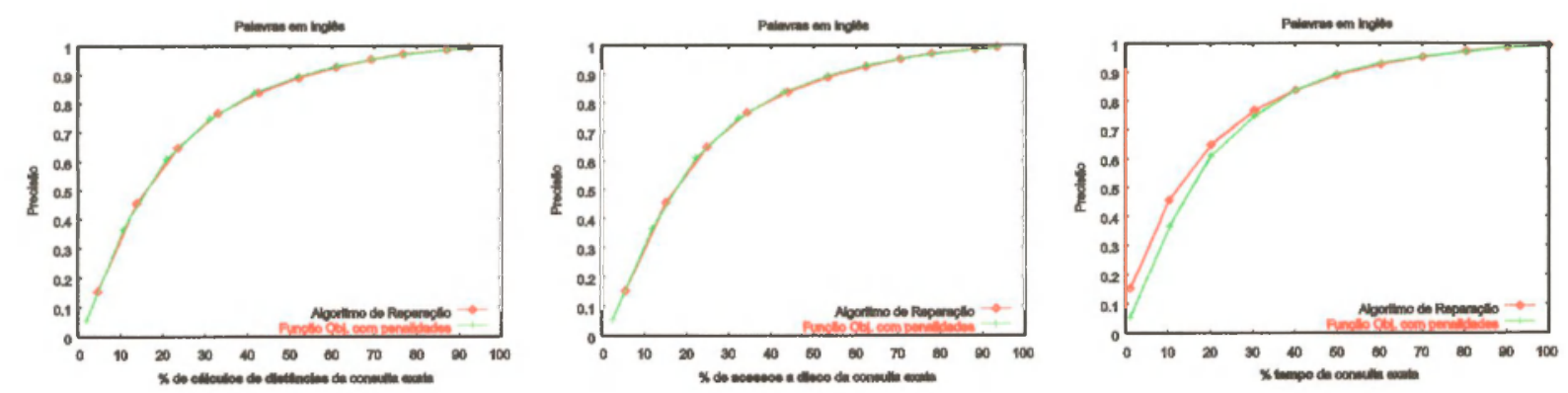

Figura 7.7: Precisão vs. Porcentagem de cálculos de distâncias da consulta exata, Precisão vs. Porcentagem de acessos a disco da consulta exata e Precisão vs. Porcentagem do tempo de execução da consulta exata, conjunto Palavras em Inglês.

Na Figura 7.7, além da apresentação das precisões obtidas com relação ao tempo de 
consulta disponível, são apresentados também as precisões com relação ao número de cálculos de distâncias e número de acessos a disco, ambos obtidos pela média nas 500 consultas. Como pode ser visto, os gráficos apresentam comportamento muito parecidos, de maneira que a análise do gráfico de Precisão vs. Porcentagem do tempo de execução da consulta exata é suficiente para a avaliação dos algoritmos.

Na Figura 7.8 é apresentado um gráfico de Precisão vs. Porcentagem do tempo de execução da consulta exata para o conjunto "Clusters128". Para a contrução do gráfico também foram executadas consultas aos 50 vizinhos mais próximos, com o cálculo da média de 500 consultas com diferentes objetos centrais de consulta.

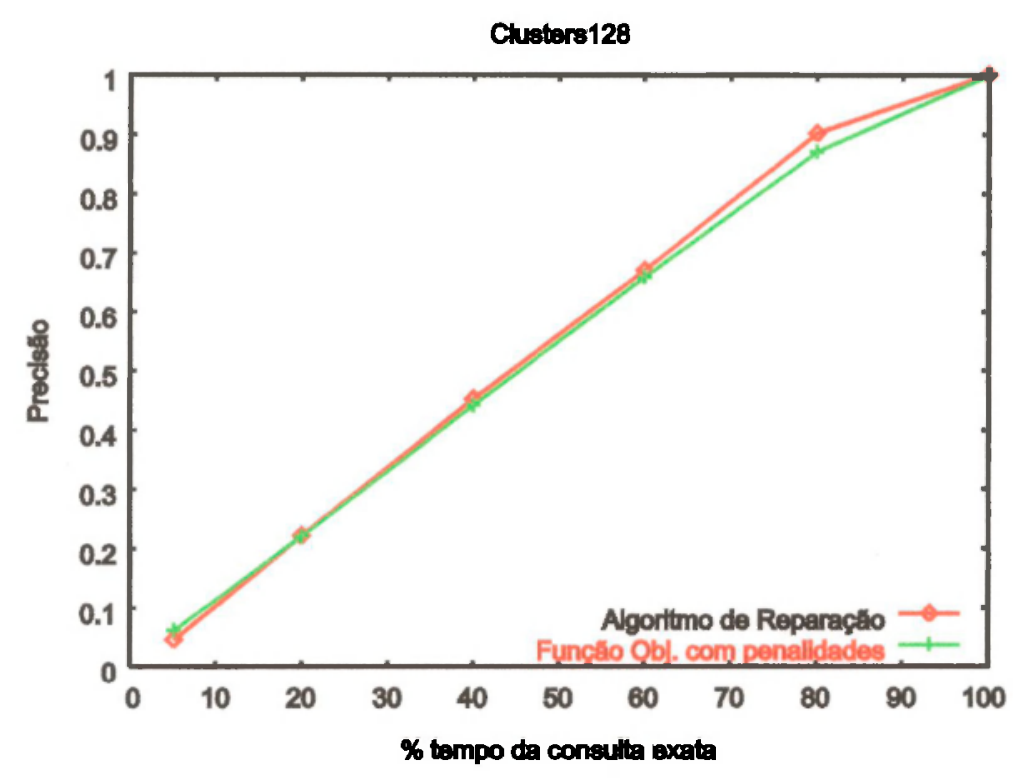

Figura 7.8: Precisão vs. Porcentagem do tempo de execução da consulta exata, conjunto Cluster 128.

Apesar dos resultados alcançados neste esperimento não terem sido tão bons como os da Figura 7.7, pode-se observar que a média de tempo necessário para a obtenção da resposta exata pelos algoritmos de consultas aproximadas não ultrapassa a média de tempo da consulta exata. Verifica-se que com $40 \%$ do tempo requerido para uma consulta exata, obtém-se a precisão de $45 \%$ com os algoritmos para consultas aproximadas, e com $80 \%$ do tempo da consulta exata, alcança-se aproximadamente $90 \%$ de precisão.

Para a construção do gráfico da Figura 7.9 foram executadas consultas aos 50 vizinhos mais próximos, calculando a média de 50 consultas com diferentes objetos centrais de consulta.

Analizando o gráfico de Precisão vs. Porcentagem do tempo de execução da consulta exata, verifica-se que com $20 \%$ do tempo médio de uma consulta exata obtém-se uma resposta aproximada com precisão de $55 \%$ utilizando-se a estratégia de função objetivo com aplicação de penalidades (e aproximadamente $52 \%$ utilizando o algoritmo de reparação), e com $60 \%$ do tempo da consulta exata alcança-se aproximadamente $90 \%$ de precisão.

Nesse experimento com o conjunto "MRTHistogramas", pode-se observar que, na média, a resposta exata não é alcançada com tempo do algoritmo exato pelo algoritmo de consultas 


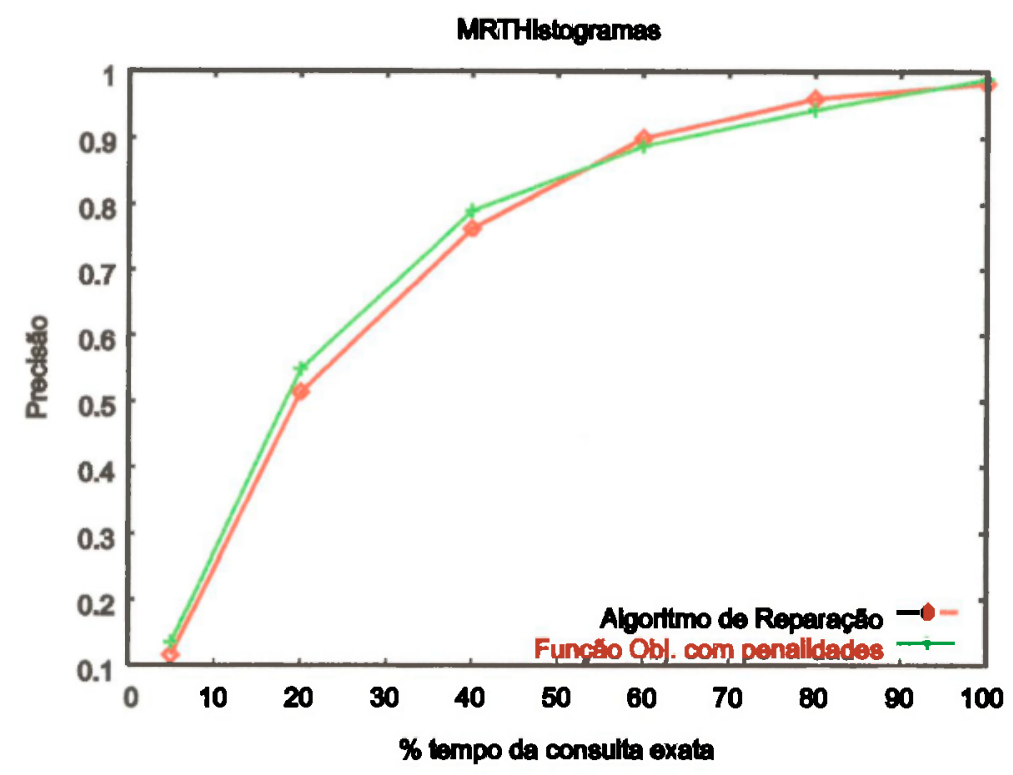

Figura 7.9: Precisão vs. Porcentagem do tempo de execução da consulta exata, conjunto MRTHistogramas.

aproximadas. Apesar disso, a precisão das respostas dos algoritmos de consultas aproximadas quando é utilizado o mesmo tempo do algoritmo exato fica entre $98 \%$ e $99 \%$. Como a precisão mostrada no gráfico é resultado da média de 50 consultas, pode-se considerar que na maioria das vezes a resposta exata é encontrada.

Quanto à comparação entre os dois algoritmos desenvolvidos, ambos tem desempenho muito parecido. Os dois algoritmos se alternam em melhor desempenho dependendo do conjunto de dados utilizado e do raio da consulta, mas não foi possível reconhecer um padrão para a adequação de cada algoritmo a cada situação.

Por fim, existe a possibilidade de obter-se a resposta exata com os algoritmos de consulta aproximada, não limitando-se o tempo de execução dos mesmos.

Nas Figuras 7.10 e 7.11 são mostrados gráficos comparativos de desempenho entre o algoritmo de consulta exata convencional e os algoritmos desenvolvidos sem limitação de tempo de execução. Nestes experimentos, variou-se o número de vizinhos requeridos pela consulta (k). Para a construção dos gráficos foi considerada a porcentagem dos objetos do conjunto de dados recuperada pelas consultas.

Na Figura 7.10, o experimento foi realizado com o conjunto "Palavras em Inglês" e as medidas consideram a média dos cálculos de distância de 500 consultas, realizadas com objetos centrais de consulta diferentes. São apresentados gráficos que avaliam o custo das consultas considerando o tempo e o número de cálculos de distâncias.

Como pode ser visto, apesar de não ser o principal objetivo dos algoritmos desenvolvidos, neste experimento eles foram capazes de obter a resposta exata com custos inferiores aos algoritmos convencionais de consulta exata, seja considerando-se o tempo de execução ou o número de cálculos de distância. O algoritmo convencional precisou de aproximadamente $15 \%$ 

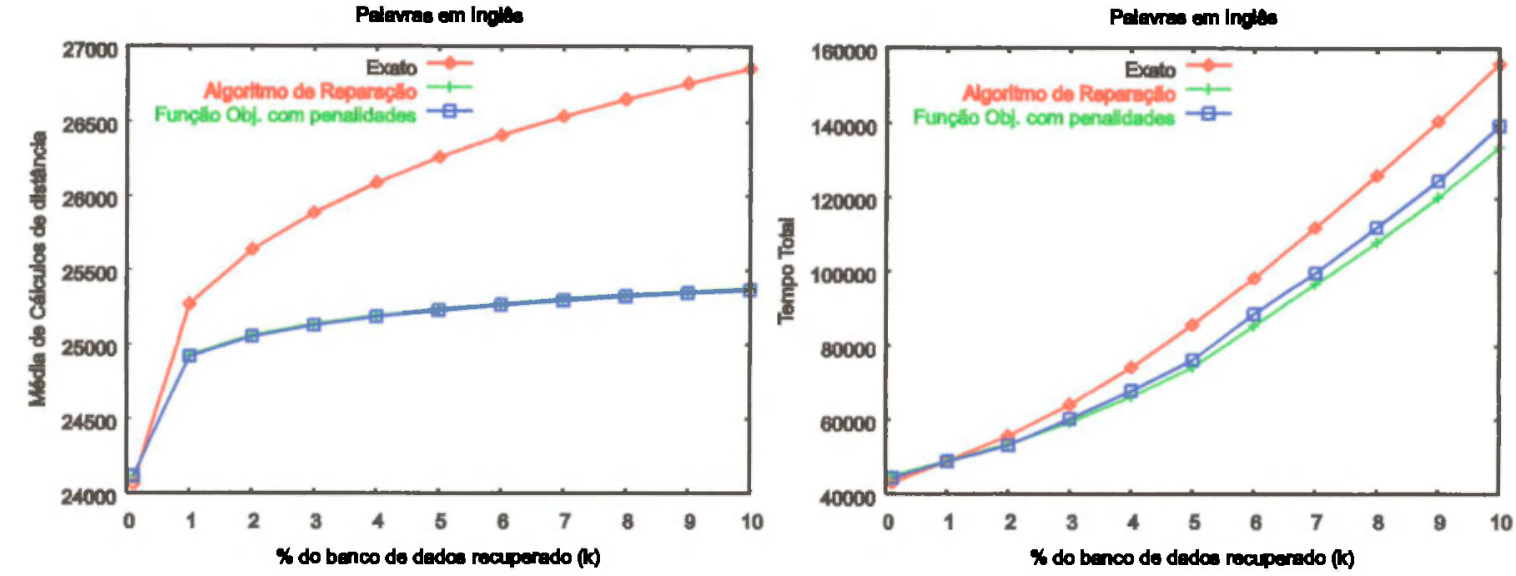

Figura 7.10: Média de cálculos de distância vs. \% de dados recuperados pela consulta $k$-NN e Tempo de execução vs. \% de dados recuperados pela consulta $k-N N$, conjunto Palavras em Inglês, comparando o algoritmo de k-NNQ exato com os algoritmos para consultas aproximadas sem limite de tempo para execução

a mais de tempo do que o algoritmo de consultas aproximadas para obter a mesma resposta, com a consulta recuperando $5 \%$ do conjunto de dados.

Experimento similar foi realizado com o conjunto "Random128", dando origem ao gráfico da Figura 7.11. As medidas também consideram a média dos cálculos de distância de 500 consultas, realizadas com objetos centrais de consulta diferentes. O gráfico apresenta o custo das consultas considerando o número de cálculos de distâncias.

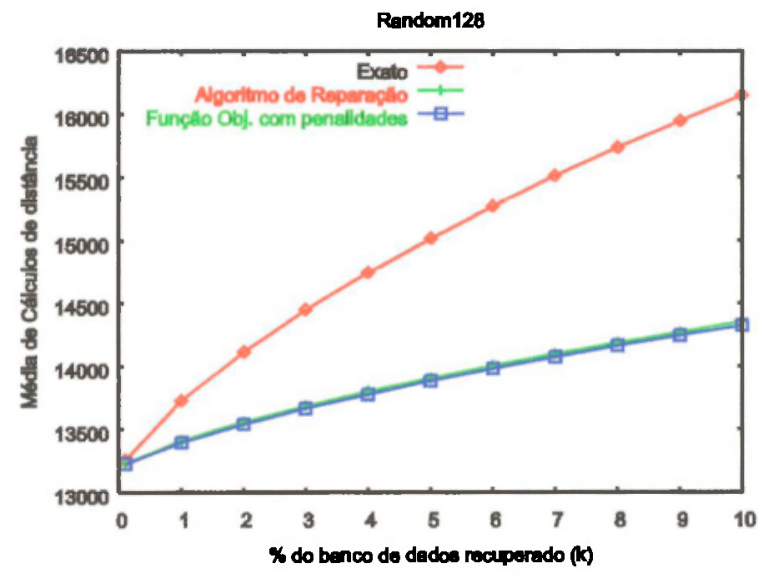

Figura 7.11: Média de cálculos de distância vs. \% de dados recuperados pela consulta $k$ $N N$, conjunto Random128, comparando o algoritmo de k-NNQ exato com os algoritmos para consultas aproximadas sem limitar o tempo de execução

Neste experimento, o algoritmo convencional de consulta exata realizou $8 \%$ a mais de cálculos de distância do que o algoritmo de consultas aproximadas para consultas recuperando $5 \%$ do conjunto de dados, e $12 \%$ a mais com consultas recuperando $10 \%$ do conjunto de dados. 


\subsection{Considerações Finais}

Os algoritmos desenvolvidos form avaliados com uma grande variedade de experimentos. Neste capítulo foram aprescntados alguns dos experimentos realizados, feitos com dados sintéticos e reais, com dimensionalidades, distribuicooes e tamanhos variados. Os experimentos visaram, durante o desemvolvimento do projeto. comparar estratégias distintas de implementaçóes possivivis.

As estratégias utilizadas para a redução de accssos a disco c a aplicação da estratégia elitista na execução do algoritmo genético surtiram os efeitos descjados, melhorando a perfornance dos algoritmos desenvolvidos.

Postcriormente, os algoritmos desenvolvidos para consultas aproximadas foram comparados com o algoritmo convencional para consulta exata.

Como pode ser visto, os algoritmos desenvolvidos são capazes de obter respostas aproximadas com boa precisão utilizando apenas uma fração do tempo exigido pela consulta exata. Com o conjunto de "Palavras cm Inglês", por exemplo, foram obtidas respostas com precisão superior a $90 \%$ utilizando apenas metade do tempo da consulta exala. Já com o conjunto "MRTIIistogranads", respostas com precisão de aproximadamente $55 \%$ foram obtidas com a utilização de apenas $20 \%$ do tempo da consulta exata com o algoritmo convencional.

Além disso, apesar de não ser o principal objetivo dos algoritmos desenvolvidos, eles mostraranr-se capazes de obter a resposta exata com custos inferiores aos algoritmos convencionais de consulta exata. considerando-se o tempo de exccução ou o número de cálculos de distância.

Em resumo, os resultados dos experimentos demonstraram que os algoritmos desenvolvidos sào eficientes para a realização de consultas aproximadas e até mesmo para consultas exatas. 


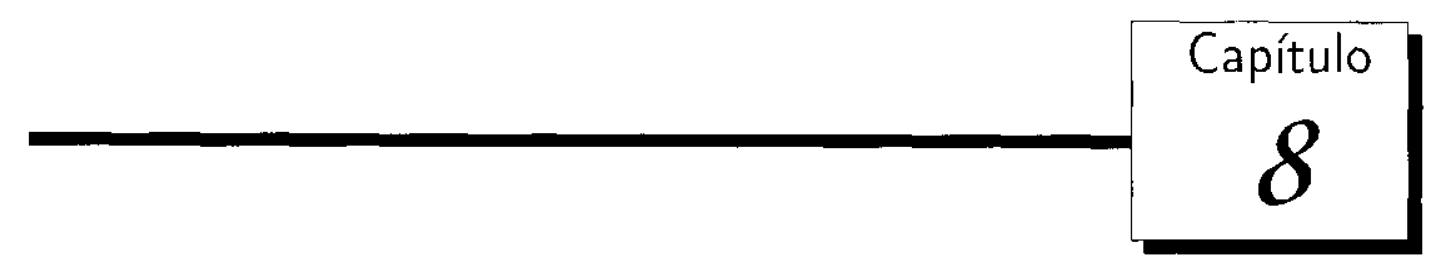

\section{Conclusões}

$O$

s SGBDs foran desenvolvidos inicialmente com o objetjvo de armazenar e recuperar grancles arquivos de dados, compostos de atributos numéricos e textnais. $\Lambda$ recuperação cxata ć um requisito das aplicaçoes que os SGBDs originalmente deverian suportar.

Atualmente, outras aplicaçoes foram inchúdas no rol daquclas que os gerenciadores devem suportar, culminando atualmente no esforgo para ammanenar e recuperar adequadanente dados muito mais complexos, tais como dados multimídia estruturas genéticas, ete. Para dados desse tipo nāo existe a relaçào de ordem total entre os clementos: a a similaridade entre pares de elementos é a relação utilizada na realização de consultias.

Em domínios de dados complexos, são quase sempre extraídas características dos elementos,que são utilizadas para realizar comparaçóes com outros elenentos, ao invés de utilizar os próprios denentos de darlos. Portanto, consultas exatas realizadas solore diados nesse: tipo do domínio obtêm respostas exatic segundo as características utilizadas nas comparacöes, mas frequentemente isso não implica que as respostas obtidas sejam as melhores, on então exalias, segundo a percepção do ustário. Dessa forma, os resultados obtidos por algoritmos para consultas aproximadas podem ser tão bons quanto aqueles obtidos pelos algoritmos de consultas exatas, muito mais custosos.

Neste trabalho foram desenvolvidos algoritmos para consultas por similaridade aproximadas em donúnios métricos, empregando algoritmos genéticos para acelerar a obtencuão do respostas aproximarlas.

Os algoritmos desenvolvidos têm sua execução limitada a lun tempo pré-determinado, fornecido pelo usuário da consulta. Se o tempo for suficiente, a resposta exala é obtida.

Durante a execução dos algoritmos, é explorada a navegação das subárvores buscando melhores caminhos de incursão na árvore, visando refinar o conjunto resposta. Uma boa aproximação do conjunto-respessta exato pode ser obtidá com um subconjunto do subárvores percorridas bem menor do que o conjunto de todas as subárvores válidas.

Os resultados dos experimentos realizados mostram que os algoritmos descnvolvidos são capazes de obter respostas aproximadas con boa precisão utilizando apenas uma fração do tempo exigido pela consulta exata. Respostas con precisäo superior a $90 \%$ foram obtidas 
limitando o tempo de execução dos algoritmos a apenas metade do tempo da consulta exata com o algoritmo convencional, e respostas com até $65 \%$ de precisão foram obtidas com $20 \%$ do tempo da consulta cxata.

Alóm disso, as cstratégias dre busca bascadas cm algoritmos genóticos também podem ser utilizadas para a obtenção das mesmas respostas exatas que os algoritmos tradicionais. Em muitos casos, a resposta exata é obtida com um custo menor do que com os algoritmos tradicionais.

Por fim, vale ressaltar que os experimentos apresentados neste trabalho comparam as respostas obtidas pelos algoritmos desenvolvidos com aquelas dos algoritmos tradicionais de consultas exatas. Mas como já foi discutido antes neste trabalho, respostas que não são consideradas exatas considerando comparações sobre as caracteristicas extráclas podem ser consideradas corretas por urn usuário humano. Assim, considerando a percepção humana, os algoritmos desenvolvidos podem recuperar respostas tão boas quanto aquelas obtidas pelo algoritmo para consultas exatas.

\subsection{Trabalhos futuros}

O trabalho realizado durante este mestrado proporciona a continulação da pesquisa referente a consultas por similaridale em domínios métricos, ntilizando algoritmos genéticos. Algumas possibilidades para trabalhos futuros são:

- Aclaptação dos algoritmos desenvolvidos para algoritrnos genéticos paralelos, aproveitando o paralelismo implícito dos algoritmos genćticos;

- Implementação dos algorit unos desenvolvidos utilizando outros métodos de acesso mótricos disponíveis na literatura, c realização de experimentos comparativos:

- Inclusão de novos operadores genéticos ainda não explorados. Explorar a formação de nichos e subpopulaçōes;

- Inclusão de novas heurísticas de busca e otimização, gerando algoritmos genéticos híbridos Incorporação de busca local mais efetiva: algoritmos menuéticos;

- Desenvolvimento de versões dos algoritmos genéticos desenvolvidos com critério de parada relativo an erro das respostas.

- Realização de experimentos comparativos com a inplementação de ontros operadores de consulta por simiralidade. 


\section{Referências Bibliográficas}

[Acharya et al., 1999] Acharya, S., Gibbons, P. B., e Poosala, V. (1999). Aqua: A fast decision support systems using approximate query answers. In Atkinson, M. P., Orlowska, M. E., Valduriez, P., Zdonik, S. B., c Brodie, M. L., editors, Intl. Conf. on Very Large Databases (VLDB), pp. 754-757, Edinburgh, Scotland. Morgan Kaufmann.

[Acharya et al., 2000] Acharya, S., Gibbons, P. B., c Poosala:, V. (2000). Congressional samples for approximate answering of group-by queries. In Chen, W. Naughton, J. F., e Bernstein, P. A., editors, ACM Int'l Conference on Data Management (SIGMOD), pp. 487-498, Dallas, TX. ACM Press.

[Aggarwal, 2001] Aggarwal, C. C. (2001). Re-designing distance functions and clistance-based applications for high dimensional data. SIGMOD Record, 30(1):13-18.

[Aggarwal et al., 2001] Aggarwal, C. C., Hinnoburg, A., e Keim, D. A. (2001). On the surprising behavior of distance metrics in high dimensional spaces. In Bussche, J. V. d. e Vianu, V., editors, ICDT 2001, pp. 420 434, London, UK. Springer Verlag.

[Albuz et al., 2001] Albuz, E., Kocalar, E., e Khokhar, A. A. (2001). Scalable color image indexing and retrieval using vector wavelets. IEFE Transactions on Knowledge and Data Engineering, 13(5):851 861.

[Athitsos et al., 2004] Athitsos, V., Alon, J., Sclaroff, S., e Kollios: G. (2004). Boostmap: A method for efficient approximate similarity rankings. In IEEE Conference on Computer Vision and Pattern Recognition (CVPR), pp. 268-275.

[Beckmann et al., 1990] Beckmann, N., Kriegel, II.-P., Schneider, R., e Seeger, B. (1990). The $\mathrm{R}^{*}$-tree: An efficient and robust access method for points and rectangles. In $A C M$ Int't Conference on. Data Management (SIGMOD), pp. 322-331.

[Berchtold et al., 1998] Berchtold, S., Böhm, C., e Kriegel, H.-P. (1998). The Pyramid-trec: Breaking the curse of dimensionality. In ACM Int'l Conference on Data Management (SIGMOD), pp. 142 -153, Seattle, WA.

[Berchtold et al., 1996] Berchtold, S., Keim, D. A., e Kricgel, H.-P. (1996). 'The X-tree: An index structure for high-dimensional data. In Intl. Conf. on Very Large Databases (VLDB), pp. 28 39, Bombay, India.

Böhm, 2000] Böhm, C. (2000). A cost model for query processing in high dimensional data spaces. ACM Transactions on Database Systems (TODS), 25(2):129 178.

Böhm et al., 2001] Böhnn, C., Berchtold, S., e Keim, D. A. (2001). Searching in highdimensional spaces - index structures for improving the performance of multimedia databases. ACM Compuling Survey.s, 33(3):322 - 373. 
[Böhm \& Kriegel, 2001] Böhm, C. e Kriegel. H.-P. (2001). A cost model and index archit.ccture for the similarity join. In Intl. Conf. on Dala Engineering (ICDE), pp. 411 420, Heidelberg, Germany. IEEE Computer Society.

[Blickle \& Thiele, 1995] Blickle, T. e Thiele, L. (1995). A comparison of selection schemes used in genetic algorithms. TIK-Report 11, TIK Institut fur Technische Informatik und Kommunikationsnetze, Computer Engineering and Networks Laboratory, F:TH, Swiss lederal Institute of Technology.

[Braunmüller et al., 2000] Braunmüller, B., Ester, M., Kriegel, H.-P., e Sander, J. (2000). Efficiontly supporting multiple sinularity queries for mining in metric databases. In 16th International Conference on Data Engineering - ICDE, pp. 256-267, San Diego, CA. IEEE Computer Society.

[Brin, 1995] Brin, S. (1995). Near neighbor search in large metric spaces. In Dayal, U., Gray, P. M. D., e Nishio. S., editors, Intl. Conf. on Very Large Dalabases (VLDB), pp. 574-584, Zurich, Switzerland. Morgan Kaufmann.

[Bueno et al., 2004] Bueno, R.. Traina, Ferreira, M. R. P., e Traina, Caetano, J. (2004). Dbgen, mannal da ferramenta. Relatório técnicos 246. ICMC/USP, Cniversidade do São Paulo

[Burkhard \& Keller, 1973] Burkhard, W. A. e Keller, R. M. (1973). Sone approaches to bestmatch file searching. Communications of the ACM, 16(4):230-236.

[Bustos \& Navarro, 2004] Bustos, B. o Navarro, G. (2004). Probabilistic proximity search algorithms based on compact partitions. Journal of Discrete Algorithms, 2(1):115-134.

[Cai et, al., 2001] Cai, J.-y., Chakaravarthy, V. T., Kaushik, R., e Naughton, J. F. (2001), On the complexity of join prodicates. In Symposium on Principles of Database Systems (PODS2001), pp. 207 214, New York, NY, USA. ACM Press.

[Chakrabarti et al., 2001] Chakrabarti, K., Garofalakis, M., Rastogi, R. e Shim, K. (2001). Approximate query answering using wavelets. VLDB Journal, 10 (Special Issue, Best Papers of VLDB 2000)(3):199-223.

[Cháver \& Navarro, 2003] Chávez. E. e Navarro. G. (2003). Probabilistic proximity search: Fighting the curse of dimensionality in metric spaces. Information Processing Lellers, 85:39 46 .

[Chávez \& Navarro, 2001] Chávez, E. c Navarro, G. (2001). Towards measuring the searching complexity of metric spaces. In Proc. Mexican Compuling Meeling, v. II, pp. 969-978, Aguascalientes, México. Sociedad Mexicana de Ciencias de la Computación.

[Chávez ct al., 2001] Chávez, E., Navarro, G.. Baeza-Yates. R. A., e Marroquín, J. I. (2001) Searching in metric spaces. ACM Compuling Surveys: 33(3):273-321.

[Ciaccia \& Patclla, 2000] Ciaccia, P. e Patella, M. (2000). PAC nearest neighbor qucries: Approximate and controlled search in high-dimensional and metric spaces. In 16th International Conforence on Duta Engineering - ICDE, pp. 244-255, San Diego, CA. IEEE Computer Society

[Ciaccia et al., 1997] Ciaccia. P., Patella, M., e Zezula, P. (1997). M-tree: An efficient access method for similarity search in metric spaces. In Jarke, M., editor, Intl. Conf. on Very Large Databases (VLDB), pp. 426 435, Athens, Greece. 
[Concilio, 2000] Concilio, R. (2000). Contribuiçöes ì Solução de Problemas de Escalonamento pcla Aplicaçio Conjunta de Computuçio Evolutiva o Otimizaçâo com Restriçocs. Dissertação de mestrado: Universidade Estadual de Campinas, FEEC. Orientaclor: Prof. Dr. Fernando José Von Zuben

[Cortes \& Pregibon, 2001] Cortes, C. e Pregibon, D. (2001). Signature-based methods for data streams. Data Mining and Knowledge Discovery, 5(3):167 182.

[Das et al., 2003] Das, A., Gehrke, J., e Riedewald, M. (2003). Approximatc join processing over data streams. In SIGMOD '03: Proceedings of the 2003 ACM SIGMOD international conference on Manayement of dala, pp. 40 51. ACM Press.

[Davis, 1999] Davis, E. (1999). Order of magnitude comparisons of distance. Journal of Artificial Intelligence Research, 10:1-38.

[De Jong; 1975] De Jong, K. A. (1975). An Analysis of the Behavior of a Class of Genetic Adaptive Systems. Tese de doutorado, University of Michigan, Dept. of Computer and Communication Sciences.

[Faloutsos, 1996] Faloutsos, C. (1996). Searching Multimedia Databases by Conlent. Kluwer Acadenic Publishers, Norwell, MA, USA.

[Faloutsos, 1997] Faloutsos, C. (1997). Indexing of multimedia data. In Multimedia Dalabases in Perspcctive, pp. 219-215. Springer Verlag.

[Faloutsos \& Lin, 1995] labloutsos, C. e Lin, K.-I. D. (1995). FastMap: A fast algorjthm for indexing, data-mining and visualization of traditional and multimedia clatasets. In Casey M. J. e Schneider, D. A., editors, ACM SIGMOD International Conference on Management of Data, pp. 163 174, San Jose, CA. ACM Press.

[Gidede \& Günther, 1998] Gaede, V. e Günther, O. (1998). Multidimensional access methods. ACM Computing Surveys, 30(2):170-231.

[Gionis et al.: 1999] Gionis, A., Indyk, P., e Motwani, R. (1999). Similarity scarch in high climensions via hashing. In Atkinson, M. P.. Orlowska, M. E., Valduriez, P., Zclonik, S. B., e Brodic. M. L., cditors, International Conference on Very Large Databases (VIDB), v. 1, pp. 518-529. Fdinburgh, Scotland, UK. Morgan Kanfinann.

[Goldberg, 1989] Goldberg. D. E. (1989). Genetic algorithms in search, optimization, and machine learning. Addison-Wesley, 1 edition.

[Goldstein \& Ramakrishnan, 2000] Goldstein, J. e Ramakrishnan, R. (2000). Contrast pluts and P-sphere trees: space vs. time in nearest neighbour searches. In 26 th VLDB, pp. 429110.

[Guiting, 1994] Güting, R. H. (1994). An introduction to spatial database systems. VLDB Journal, 3(4):357-399.

[Guttman, 1984] Guttman, A. (1984). R-tree: A dynamic index s1.ructure for spatial searching. In ACM Inl'l Conference on Data Management (SIGMOD), pp. 47 57, Boston, MA. ACM PRess.

[Hinneburg et al., 2000] Hinneburg, A., Aggarwal, C. C., e Keim, D. A. (2000). What is the nearest neighbor in high dinensional spaces? In Fl Abbadi, A., Brodie, M. L., Chakravarthy, S., Dayal, U., Kamel, N., Schlageter. G., e Whang, K.-Y. editors, Intl. Conf, on Very Large Databases ( $V L D B$ ), pp. 506 515, Cairo - Lgypt. Morgan Kaufmann. 
[Hjaltason \& Samet, 2000] Ijaltason, G. R. e Samet., H. (2000). Incrementa] similarity search in multimedia databases. Computer Science Department TR-4199, University of Maryland, College Park, MD

¡Hjaltason \& Samet, 2003] Hjaltason, G. R. e Samet. H. (2003). Index-driven similarity search in metric spaces. ACM Trans. Database Syst., 28(4):517-580.

[Holland, 1975] Holland, J. H. (1975). Adaptation in natural and arlificial systems. University of Michigan Press, Ann Arbor.

[Indyk \& Motwani, 1998] Indyk, P. e Motwani, R. (1998). Approximate nearest neighbors: Towards removing the curse of dimensionality. In Proceedings of the 30th Annual ACM Symposium on the Theory of Computing, pp. 604-613, Dallas.

[Ioannidis \& Poosala, 1999] Ioannidis, Y. E. e Poosala, V. (1999). Histogram-based approximation of set-valued query-answers. In $V L D B$ '99: Procedings of the 25th International Conference on Very Large Data Bases, pp. 174-185. Morgan Kaufmann Publishers Inc

[.Johnson \& Shasha, 1993] Johnson, T. e Shasha, D. (1993). The performance of current, B-tree algorithms. ACM Transactions on Database Systems (TODS), 18(1):51-101.

[Kim et al., 2001] Kin. S.-W., Aggarwal, C. C., e Yu, P. S. (2001). Effective nearest neighbor indexing with the cuclidean metric. In Tenth International Conference on Conference on Information and Knowledge Management (CIKM), pp. 9-16, Atlanta, GA. ACM Press.

[Kollios et al., 2001] Kollios, G., Gunopulos, D., Koudas. N., c Berchtold, S. (2001). An efticient approximation scheme for data mining tasks. In Intl. Conf. on Data Engineering (ICDE) pp. 453-462, Heidelberg, Germany. IEFE Computer Society.

[Korn et al., 2001] Korn, F., Page], B.-U., e Faloutsos, C. (2001). On the 'dimensionality curse' and the 'self-sinilarity blessing'. IEEE Transactions on Knowledge and Data Engineering, $13(1): 96111$.

[Korn et al., 1996] Korn, F., Sidiropoulos, N., Faloutsos, C., Siegel, E. L., e Protopapas, Z (1996). Fast nearest noighbor search in medical image databases. In Intl. Conf. on Very Large Databases (VLDB), pp. 215-226, Bombay, India. Morgan Kaufmann.

[Koudas et al., 2004] Koudas, N., Ooi, B. C., Tan, K.-L., e Zhang, R. (2004). Approximate nn queries on streams with guaranted error/performance bounds. In VLDB, pp. 804-815.

[Koudas \& Sevcik, 2000] Koudas, N. e Sevcik, K. C. (2000). High dimensional similarity joins: Algorithms and performance evaluation. IEEE Thans. on Knowledge and Data Engineering, $12(1): 318$

[Lee et al., 1998] Lee, S., Cheung; D. W., e Kao, B. (1998). Is sampling useful in data mining? a case in the maintenance of discovered association rules. Data Mining and Knowledge Disconery: $2(3): 233-262$

[Li et al., 2002] Li, C., Chang: E., García-Molina, H., e Wiederhold, G. (2002). Clustering for approximate similarity search in high-dimensional spaces. IEEE Transactions on Knowledgo and Data Engineering, 14(4):792 808 
[Marques et al., 2000] Marques, P. M. d. A., Santos, R. R. d., Traina, A. J. M., Traina, Cactano, J., e Bueno, J. M. (2000). Image retrieval based on texture content. In World Congress on Medical Physics and Biomedical Engineering (WC2000) 726., p., Chicago.

[Palmer \& Faloutsos, 2000] Palner, C. R. e Faloutsos, C. (2000). Density biased sampling: An improved method for data mining and clustering. In $A C M$ Int'l Conference on Data Management (SICMOD), pp. 82 92, San Diego, CA. ACM Press.

[Papadias, 2000] Papadias, D. (2000). Hill climbing algorithms for content-based retrieval of similar configurations. In Belkin, N. J., Ingwersen, P.. c Leong, M.-K., editors, 23rd Annual International ACM SIGIR Conference on Research and Development in Information Retrieval, pp. 240 247, Athens, Greece. ACM Press.

[Papadias \& Arkoumanis, 2002] Papadias, D. e Arkoumanis, D. (2002). Approximate processing of multiway spatial joins in very large databases. In Jensen, C. S., Jeffery, K. G., Pokorný, J., Saltenis, S., Bertino, E., Böhm. K., e Jarke, M., cditors, 8th Intl. Conf. on Extending Database Technology (EDBT), v. 2287 of Lecture Notes in Computer Scicnce, pp. 179-196, Prague, Czech Republic. Springer Verlag. ISBN 3-540-13324-4.

[Papadias et al., 2000] Papadias, D., Manoulis, N., e Delis, V. (2000). Approximate spatiotemporal rotrieval. ACM Transactions on Information Systems (TOIS): 19(1):53-96.

[Papadias et al., 1998] Papadias, D., Mamoulis, N., e Meretakis, D. (1998). Image similarity retrieval by spatial constraints. In Gardarin. G., French, J. C., Pissinou, N., Makki, K., Bouganim, L., editors, International Conference on Information and Knowledge Management (CIKM). pp. 289-296, Bethesda, MD. ACN Press.

[Papadias et al., 1999] Papadias, D., Mamoulis, N., e Theodoridis, Y. (1999). Processing and optimization of multiway spatial joins using R-trees. In ACM Symp. on Principles of Database Systems (PODS), pp. 14-55, Philadelphia, PA. ACM Press.

Papadias et al., 1995] Papadias, D., Theodoridis, Y.. Sellis, T. K., e Egenhofer, M. J. (1995) Topological relations in the world of minimum bounding rectangles: A study with R-trees. In Carey, M. J. c Schncider, D. A., editors, ACM Int'l Conference on Data Manayement (SIGMOD), pp. 92 103. San Jose, CA. ACM Press.

[Petrakis \& Faloutsos, 1997] Petrakis, E. G. e Faloutsos, C. (1997). Similarity soarching in Inedical image databases. IEEE Transactions on Knowledge and Data Engineering, 9(3):435417.

[Petrakis et al., 2002] Petrakis, E. G., Faloutsos, C., c. Lin, K.-I. D. (2002). ImageMap: An image indexing method based on spatial similarity. IEEE Transactions on Knowledge and Dala Engineering, 14(5):979-987.

[l'odgorelec et al., 1999] Podgorelec, V., Kokol, P., e Zavrsnik, J. (1999). Medical diagnosis prediction using genetic programming. In 19th IEEE Symposium on Computer-Based Medicul Syslems (CBMS'00), pp. 202 207, Stamford, C(). IEEE Computer Society.

[Roussopoulos et al., 1995] Roussopoulos, N., Kelley, S., c Vincent, F. (1995). Nearest neighbor queries. In Carey, M. J. e Schneider, D. A., editors, ACM SIGMOD International Conference on Management of Data, pp. 80 91, San Jose, CA. ACM Press.

Rubner \& Tomasi, 2001] Rubner: Y. e Tomasi, C. (2001). Percetual Metrics for Image Database Navigation. The Kluwer International Series in Engineering and Computer Science. Kluwer Acadennic Publishers. 
[Sakurai et al., 2001] Sakurai, Y., Yoshikawa, M., Kataoka, R., e Uemura, S. (2001). Similarity search for adaptive cllipsoid queries using spatial transformation. In Apers, P. M. G., Atzeni, P., Ceri, S., Paraboschi, S., Ramamohanarao, K., o Snodgrass, R. T., editors, 27th International Conference on Very Large Data Bases, pp. 231--240, Roma, Italy. Morgan Kaufmann

[Sakurai et al., 2000] Sakurai, Y., Yoshikawa, M., Uemura, S., c Kojima, H. (2000). The A-tree An index structure for high-dimensional spaces using relative approximation. In El Abbadi, A., Brodie, M. L., Chakravarthy, S., Dayal, U., Kamel, N., Schlageter, G., e Whang: K.-Y., editors, Intl. Conf. on Very Large Databases (VLDB), pp. 516-526, Cairo - Fgypt. Morgan Kaufmann.

[Santos, 2003] Santos, Roberto Figncira, F. (2003). Métodos de Acesso Métricos para suporte a consultas por similaridade: Apresentaçăo da Técnica OMNI. Tese de doutorado Universidade de São Paulo, Instituto de Ciências Matemáticas c de Computação, São Carlos, Brasil. Orientadora: Profa. Dra. Agma Juci Machado Traina.

Santos et al., 2001 Santos, Roberto Figucira, F., Traina, A. J. M., Traina, Caetano, J., e Faloutsos, C. (2001). Similarity search without tears: The OMNI family of all-purpose access methods. In Intl. Conf. on Data Engineering (ICDE), pp. 623 630, Heidelberg, Germany IEEE Computer Society

[Sellis et al., 1987] Sellis, T. K., Roussopoulos, N., e Faloutsos, C. (1987). The R+-1,ree: A dynamic index for multi-dimensional objects. In Intl. Conf. on Very Large Databases (VLDB), pp. 507-518, Brighton, England. Morgan Kaufmam.

[Shim et al., 2002] Shim, K., Srikant, R. e Agrawal, R. (2002). High-dimensional similarity joins. IEEE Transactions on Knowledge and Data Engineering: 14(1):156-171.

[Smeulders et al., 2000] Smeulders, A. W. M., Worring, M., Sartlini, S., Gupta, A., c Jain, R. (2000). Content-based image retrieval at the end of the early years. IEEE Transactions on Patlerns Analysis and Machine Intelligence, 22(12).

[Stehling et al., 2000] Stchling, R. O., Nascimento, M. A., e Falcão, A. X. (2000). On "shapes" of colors for content-based image retrieval. In ACM 2nd Inll. Workshop on Mullimedia Informalion Retricual. pp. 171 174, Los Angeles, CA. ACM Press.

Traina et al., 2002a] Traina, Cactano, J., Traina, A. J. M., Falontsos, C., e Sceger, B. (2002a) Fast indexing and visualization of metric datasets using Slim-trees. IEEE Transactions on Knowlcdge and Dala Engineering, 14(2):244-260.

[Traina et al., 2002b] Traina, Cactano, J., Traina, A. J. M., Santos, Roberto Figueira, F., e Faloutsos, C. (2002b). How to improve the pruning ability of dynamic metric access methods. In Eleventh Intermational Conference on Information and Knowledge Managemenl (CIKM"2002), pp. 219 226, McLean, VA - EUA. ACM Press.

[Traina et al., 2000] Traina, Caetano, J., Traina, A. J. M., Seeger, B., e Faloutsos, C. (2000) Slim-trces: High performance metric trees minimizing overlap between nodes. In Zaniolo, C., Lockemann, P. C., Scholl, M. H., e Grust, T., editors, Intl. Conf. on Extending Database Technology, v. 1777 of Lecture Noles in Computer Science, pp. 51-65, Konstanz, Germany. Springer.

[Tversky, 1977] Tversky, A. (1977). Foatures of similarity. Psychological Revieu, 84(4):327-352. 
[Tversky \& Gati, 1982] Tversky, A. e Gati, I. (1982). Similarity, separability and the triangle inequality. Psychological Review, 89(1):123-154.

[Uhlnann, 1991] Uhlmann, J. K. (1991). Salisfying general proximity/similarity queries with metric trees. Informalion Processing Leller, 10(4):175- 179.

[Vailaya ct al., 2001] Vailaya, A., Figueiredo, M. A. T., Jain, A. K., e Zhang, H.-J. (2001). Image classification for content-lased indexing. IEEE Transactions on Image Processing, $10(1): 117 \cdots 30$

[Vieira et al., 2004] Vieira, M. R., Traina, C., J., Chino, F. J. T., e Traina, A. J. M. (2004) DBM-tree: A dynamic metric access method sensitive to local density data. In XIX Simpósio Brasileiro de Banco de Dados (SBBD). pp. 163 177. Brasilia - DF

[Wang et al., 2000] Wang, X., Wang, J. T,-L., Lin, K.-I., Shasha, D., Shapino, B. A., Zhang, K. (2000). An index structure for data mining and clustering. Knowl. Inf. Syst., 2(2):161-181.

[Weber \& Böhm, 2000] Weber, R. e Böhm, K. (2000). Trading quality for time with nearestneighbor search. In Zaniolo, C., Lockermann, P. C., Scholl, M. H., e Grust, T., editors, 7th Inll. Conf. on Extending Dalabase Technology (EDBT), v. 1777 of Leclure Noles in Computer Science, pp. 21-35, Konstanz, Germany. Springer Verlag. ISBN 3-0̃40-67227-3.

Whitley et al., 1994] Whitley, D. L., Gordon, V. S., o Mathias, K. E. (1994). Lamarckian cvolution, the Baldwin effect and function optimization. In Davidor, Y., Schwefel, H.-P., e Männer, R., editors, Parallel Problem Solving from Nalure - PPSN III, pp. 6-15, Berlin. Springer.

Yang \& Lin, 2001] Yang, C. e Lin, K.-I. (2001). An index structure for efficient reverse nearest neighbor queries. In Inll. Conf. on Data Engineering (ICDE), pp. 485-492, Heidelberg, Germany. IEEE Computer Society.

[Yang \& Lin, 2002] Yang, C. e Lin, K.-I. (2002). An index structure for improving closest pairs and related join queries in spatial databases. In Nascimento, M. A., Ösı, M. T., o Zaiane, O. R., editors, International Database Engincering and Applications Symposium (IDEAS'02), pp. 140^149, Edmonton, Albertia, Canada. IEEE Computer Sociely. Proceedings. IEEE Computer Society 2002.

[Yianilos, 1993] Yianilos, P. N. (1993). Data structures and algorithms for nearest neighbor search in general metric spaces. In Fourth Annual ACM/SIGACT'SIAM Symposium on Discrete Algorithms - SODA, pp. 311-321, Austin, TX.

[7ezula et al., 1998] Zezula, P., Savino, P., Amato, G., c Rabitti, F. (1998). Approximate similarity retrieval with M-trees. VLDB J., 7(4):275-293.

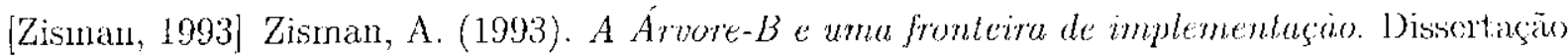
de mestrado, Cruiversidade de São Paulo. Orientador: Prof. Dr. Valdemar W. Setzer.

[7rimec, 2001] Zrinec, Г. (2001). A medical image information system. In Smeulders, A. W. M. c Ghebreab, S., editors, VISIM Workshop: Information Retrieval and Exploration in Largo Collections of Medical Images 5, 1)., Utrecht, Netherland. 